Portland State University

PDXScholar

Fall 1-27-2014

\title{
Abundance and Distribution of Major and Understudied Archaeal Lineages at Globally Distributed Deep-Sea Hydrothermal Vents
}

Alexander Fenner Rutherford Portland State University

Follow this and additional works at: https://pdxscholar.library.pdx.edu/open_access_etds

Part of the Environmental Microbiology and Microbial Ecology Commons Let us know how access to this document benefits you.

Recommended Citation

Rutherford, Alexander Fenner, "Abundance and Distribution of Major and Understudied Archaeal Lineages at Globally Distributed Deep-Sea Hydrothermal Vents" (2014). Dissertations and Theses. Paper 1555. https://doi.org/10.15760/etd.1554

This Thesis is brought to you for free and open access. It has been accepted for inclusion in Dissertations and Theses by an authorized administrator of PDXScholar. Please contact us if we can make this document more accessible: pdxscholar@pdx.edu. 


\title{
Abundance and Distribution of Major and Understudied Archaeal Lineages at Globally Distributed Deep-Sea Hydrothermal Vents
}

\author{
by \\ Alexander Fenner Rutherford \\ A thesis submitted in partial fulfillment of the \\ requirements for the degree of \\ Master of Science \\ in \\ Biology
}

Thesis Committee:

Anna-Louise Reysenbach, Chair

Mircea Podar

Rahul Raghavan

Kenneth Stedman

Portland State University

2013 


\begin{abstract}
Deep-sea hydrothermal vents are some of the most biologically productive ecosystems on Earth, yet receive little to no input of photosynthetically derived organic matter. The trophic system at hydrothermal vents is based primarily on the reductionoxidation (redox) of inorganic chemicals by Bacteria and Archaea. However, the distributional patterns of the microorganisms that colonize deep-sea hydrothermal vent deposits and their link to the geologic setting are still not deeply understood.

The goal of the studies presented in this thesis was to quantify the abundance, and distribution of major and understudied vent colonizing archaeal groups from globally distributed and geochemically distinct hydrothermal vent fields. The archaeal community composition was analyzed using quantitative PCR with lineage specific functional gene primers that target methanogens, and 16S rRNA gene primers designed or optimized from this study for the Thermococcales, Archaeoglobus, Ignicoccus and marine Nanoarchaeota.
\end{abstract}

Overall, a general relationship was demonstrated between the geochemical differences of the hydrothermal vent fields and the archaeal community structure. The archaeal community assemblage varied dramatically from hydrothermal vents with different vent host rocks along the Mid-Atlantic Ridge and Eastern Lau Spreading Center. In contrast, two vent fields in the East Pacific, $9^{\circ} \mathrm{N}$ on the EPR and Guaymas Basin that are basalt and basalt-sediment hosted were found to have similar community composition. These observeddifferences may be driven in part by the metabolically available chemical energy as hydrogen oxidizing lineages of the methanogens and Archaeoglobus were found in higher abundance in the samples from vent field that had a 
high concentration of end-member hydrogen and the heterotrophic Thermococcales constituted a higher proportion of the archaeal community at the less enriched vent fields. Interestingly, the Nanoarchaeota and the genus of its only confirmed symbiont, Ignicoccus, were found to have an inconsistent proportional relationship, with the Nanoarchaeota comprising a larger proportion of the archaeal community at the ultramafic and fast spreading basalt vent fields and Ignicoccus at the ultra-slow spreading basalt and andesite hosted vent fields.

There was also a more localized pattern identified within the hydrothermal vent deposit. The chemosynthetic lineages of the methanogens and Archaeoglobus constituted a higher proportion of the archaeal community in chimney samples compared to Thermococcales that was found in a higher proportion at horizontal flange samples. This archaeal proportional shift could be driven by energetic micro-niches within the vent deposit, as the chemolithotrophic lineages colonize the area closest to the venting source, and the heterotrophic Thermococcales dominate in more mature structures further from the venting source.

Quantitative assessments of the archaeal community composition from this study provided added insight into the dynamic geologic influence on the archaeal lineages that colonize deep-sea hydrothermal vents, on a global and local scale. 


\section{DEDICATION}

I would like to dedicate my thesis to Barack Obama for being an enduring proponent of scientific inquiry. 


\section{ACKNOWLEDGEMENTS}

It is with immense gratitude that I acknowledge the support of my advisor Dr. Anna-Louise Reysenbach for guiding me along the path of scientific discovery. Her commitment, intellectual curiosity, and passion for science pushed me and this project to new limits. It was an honor to work along-side her, and without her guidance this thesis would not be possible.

I would also like to acknowledge my three additional committee members, Dr. Ken Stedman, Dr. Mircea Podar, and Dr. Rahul Raghavan who were committed and eagerly supported me and this project from every angle possible. Through their example they provided me a great example of scientific engagement and inquiry that I will attempt to emulate in the years to come.

I am also indebted to my colleagues from Portland State University, and members of the Reysenbach Lab, both past and present. In particular I would like to thank the Reysenbach graduate students Christine Sislac, Jacob Hyman, and in particular Gilbert Flores. I would also like to thank the CLEE lab manager Annie Lindgren and the post docs that I had the honor to work with, Isaac Wagner and Kristen Brileya. Additional thanks are due to the captain and crew of the Thomas G. Thompson for acquiring the samples used in this study.

Lastly I would like to thank my friends and family for their support, who continually provided me with positive energy throughout this experience.

Financial support was provided by the National Science Foundation (grant no. 1134877). 


\section{TABLE OF CONTENTS}

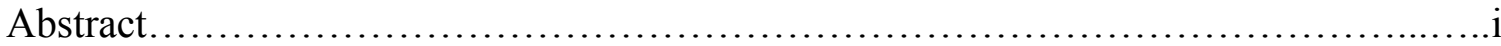

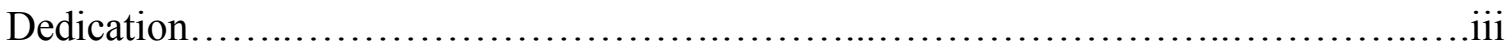

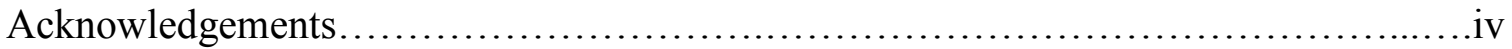

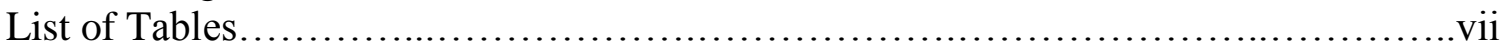

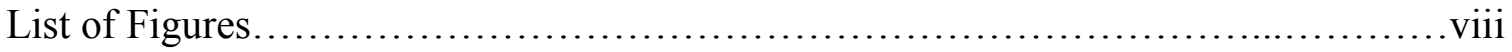

CHAPTER 1: Introduction.....................................................

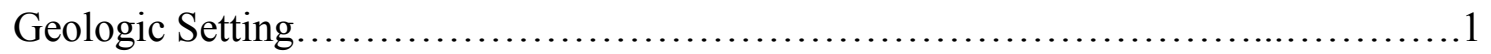

Emerging Patterns in Archaeal Diversity at Deep-Sea Hydrothermal Vents................3

Metabolic Diversity of Major Archaeal Groups......................................... 9

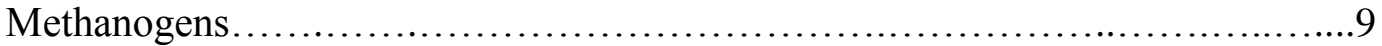

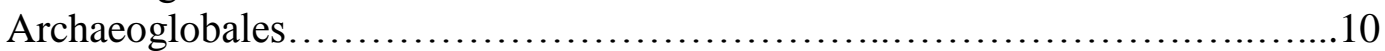

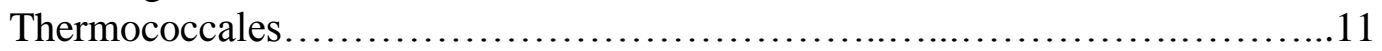

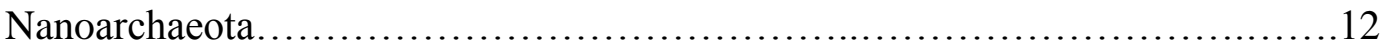

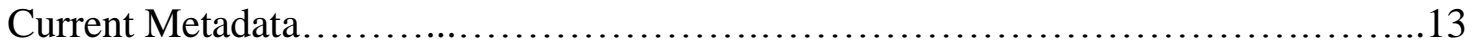

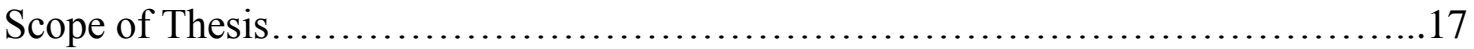

CHAPTER 2: qPCR Primer Design for Hydrothermal Vent Colonizing Archaeal

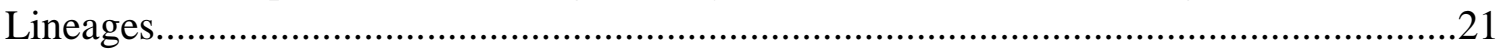

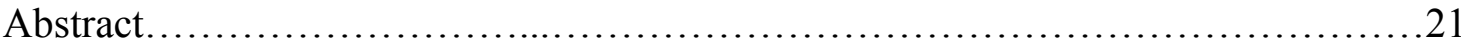

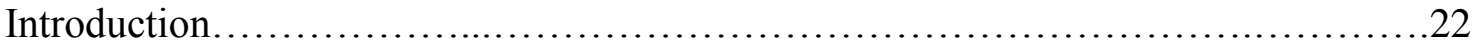

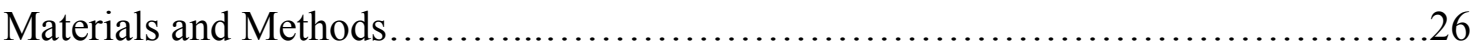

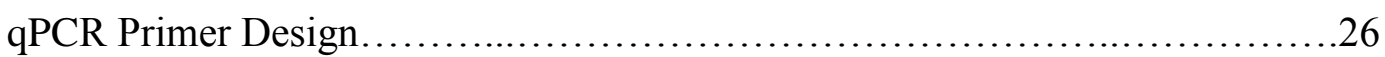

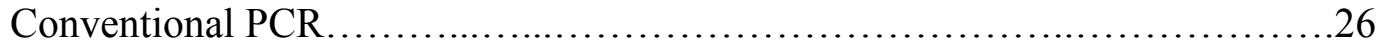

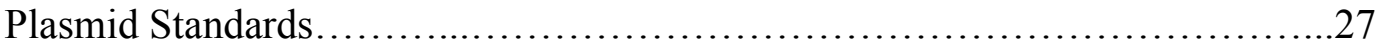

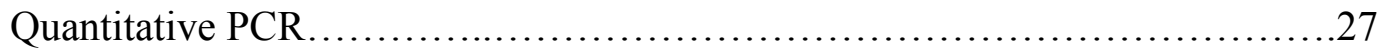

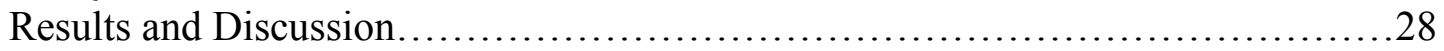

Primer Sequence Alignment Analysis....................................28

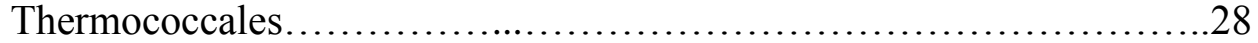

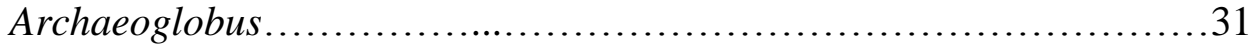

Nanoarchaeota...................................................

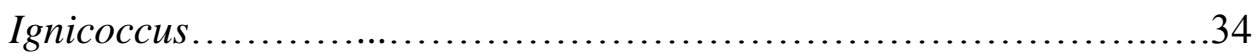

Annealing Temperature Verification........................................

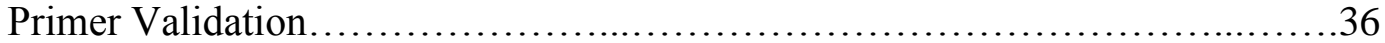

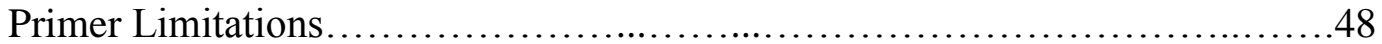

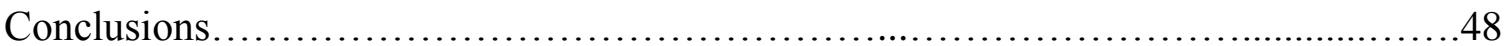

CHAPTER 3: Abundance and Distribution of Major and Understudied Archaeal Lineages at Globally Distributed Deep-Sea Hydrothermal Vents.....................................50

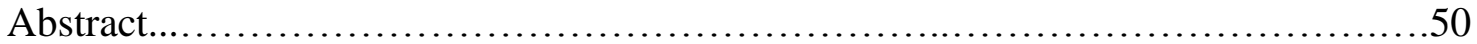

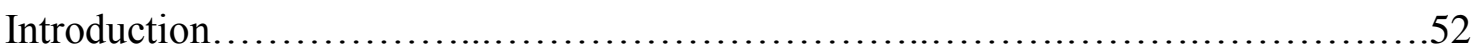

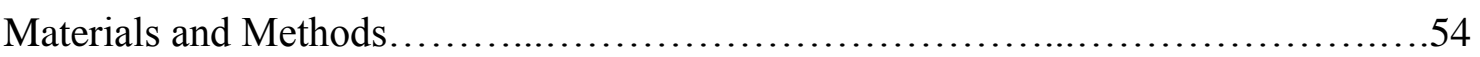

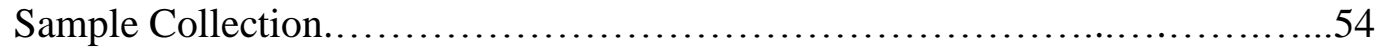

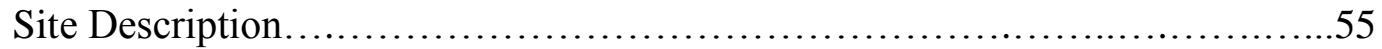


Eastern Lau Spreading Center.......................................55

Mid-Atlantic Ridge.............................................57

Guaymas Basin..................................................58

East Pacific Rise................................................... 58

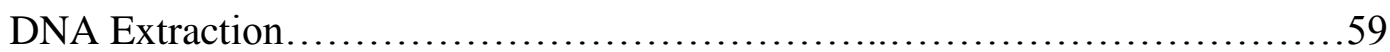

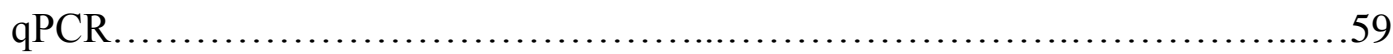

Statistical Analyses...................................................62

Nanoarchaeota- Local Similarity Analysis................................662

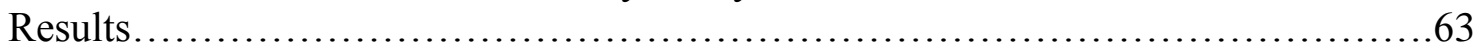

Thermococcales Distribution............................................63

Archaeoglobus Distribution ............................................63

Methanogen Distribution ...............................................63

Nanoarchaeota Distribution ..............................................65

Ignicoccus Distribution .................................................65

Statistical Analyses....................................................65

Overall Community Structure...................................65

Mid-Atlantic Ridge.............................................66

Eastern Lau Spreading Center.......................................66

East Pacific .......................................................66

Nanoarchaeota-Local Similarity Analysis..................................69

Flange versus Chimney...............................................69

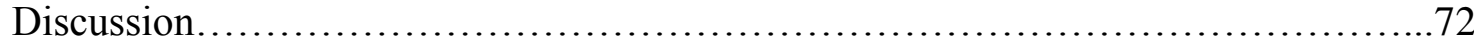

Mid-Atlantic Ridge................................................ 72

Eastern Lau Spreading Center.............................................74

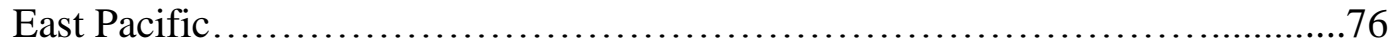

Hydrogen Cycling..................................................... 77

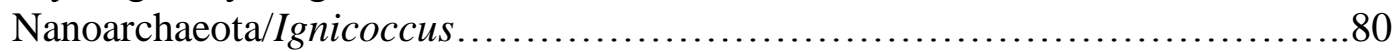

Nanoarchaeota-Local Similarity Analysis.................................. 83

Flange versus Chimney .............................................. 84

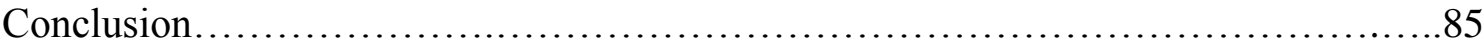

CHAPTER 4: Conclusion........................................................ 87

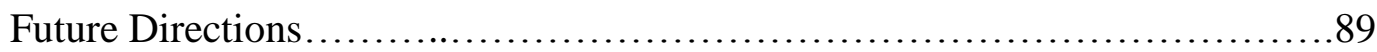

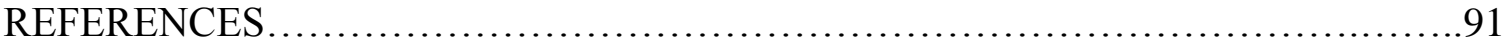




\section{LIST OF TABLES}

Table 1.1 Summary of the barcoded pyrosequencing and clone library percent composition from deep-sea hydrothermal vent deposits for the Archaeoglobales, Thermococcales, methanogens, Nanoarchaeota, and Ignicoccus. AMOR, Arctic Mid-Ocean Ridge; CIR, Central Indian Ridge; JDF, Juan de Fuca Ridge; MAR, Mid-Atlantic Ridge; ND, none detected; ${ }^{1}$ denotes barcoded pyrosequencing studies; ${ }^{2}$ denotes clone library

studies.

Table 2.1. Oligonucleotide qPCR primers and thermal cycling conditions for select archaeal lineages

Table 2.2. Oligonucleotide archaeal qPCR primer conditions and taxonomic coverage....30

Table 2.3 Cultured representatives targeted by the designed or optimized primers...........32

Table 2.4 Sanger sequenced PCR products of designed primer sets.

Table 3.1. End member physiochemical characteristics of sampled hydrothermal vent fields.

Table 3.2. Hydrothermal vent deposit samples used for qPCR. All samples except for EPR were processed by Flores et al. MAR, Mid-Atlantic Ridge; GB, Guaymas Basin. * indicates samples also used in pyrosequencing analyses from Flores et al. (2011, 2012a) and Reysenbach unpublished.

Table 3.3. Results of an ANOSIM pairwise archaeal community comparison from globally distributed hydrothermal vents using Primer v6. The comparative ANOSIM statistical relatedness of each community is represented by $\mathrm{R}$ value $(1<\mathrm{X}<-1)$ and $\mathrm{P}$ values are indicated in parentheses and significant relationships between the vent fields are indicated by bold $(\mathrm{P}<0.05)$. EPR, East Pacific Rise; ELSC B, Eastern Lau Spreading Center Basalt; ELSC A, Eastern Lau Spreading Center Andesite

Table 3.4. Co-occurrence results of the Local similarity analysis of the Nanoarchaeota OTU from 62 sulfide deposit samples. 


\section{LIST OF FIGURES}

Figure 1.1. a) Fraction of barcoded pyrosequencing 16S rRNA gene reads for the Thermococcales, methanogens, and Archaeoglobales at Lucky Strike and Rainbow vent fields along the Mid-Atlantic Ridge. Modified from Flores et al., 2011. Rb, Rainbow; LS, Lucky Strike . b) Map of the location of the hydrothermal vent fields Lucky Strike and Rainbow along the Mid-Atlantic Ridge. Modified from Rouxel , 2004.................................................................14

Figure 1.2. a) Fraction of barcoded pyrosequencing 16S rRNA gene reads for the Nanoarchaeota and Ignicoccus at Lucky Strike and Rainbow vent fields along the Mid-Atlantic Ridge. Modified from Flores et al., 2011. Rb, Rainbow; LS, Lucky Strike . b) Map of the location of the hydrothermal vent fields Lucky Strike and Rainbow along the Mid-Atlantic Ridge. Modified from Rouxel, 2004 .16

Figure 1.3. a) Fraction of barcoded pyrosequencing 16S rRNA gene reads for the Thermococcales, methanogens, and Archaeoglobales at vent fields along the Eastern Lau Spreading Center. Modified from Flores et al., 2012. KM, Kilo Moana; TC, Tow Cam; TaM, Tahi b) Map of the Eastern Lau Spreading Center vent fields. Modified from Flores et al. (2012a) \& Ferrini et al. (2008) using the GeoMapApp (http://www.geomapapp.org/).

Figure 1.4. a) Fraction of barcoded pyrosequencing 16S rRNA gene reads for the Nanoarchaeota and Ignicoccus at vent fields along the Eastern Lau Spreading Center. Modified from Flores et al., (2012a). KM, Kilo Moana; TC, Tow Cam; TaM, Tahi b) Map of the Eastern Lau Spreading Center vent fields. Modified from Flores et al. (2012a) \& Ferrini et al. (2008) using the GeoMapApp (http://www.geomapapp.org/)

Figure 2.1. Primer alignment of partial Ignicoccus spp.16S rRNA gene sequences from barcoded pyrosequencing from Flores et al., 2011, Flores et al., 2012a, and Reysenbach, unpublished. ............................................... 35

Figure 2.2. Conventional PCR annealing thermal gradient with Thermococcales primers. Sample 1) Pyrococcus horikoshii 2) Archaeoglobus luliquidus 3) Methanocaldococcus jannaschii 4) Aciduliprofundum boonei 5) I. hospitalis. 6) no template. Thermal gradient $\left({ }^{\circ} \mathrm{C}\right)$ a) 64 , b) 63.3 , c) 61.8 , d) 59.8, e) 57.4, f) 55.3,

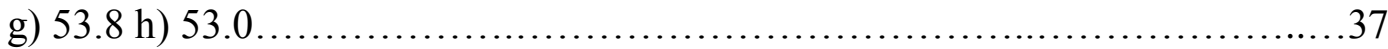

Figure 2.3. Conventional PCR annealing thermal gradient with Archaeoglobus primers. Sample 1) P. horikoshii 2) A. lulqidus 3) M. jannaschii 4) A. boonei 5) I. hospitalis 6) no template... Thermal gradient $\left({ }^{\circ} \mathrm{C}\right)$ a) 64 , b) 63.3 , c) 61.8 , d) 59.8 , e) 57.4 , f)

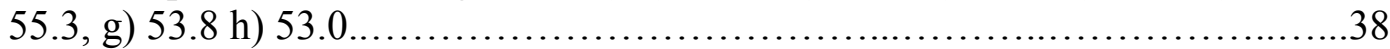


Figure 2.4. Conventional PCR annealing thermal gradient with Ignicoccus primers. Sample 1) I. hospitalis 2) I. hospitalis + N. equitans 3) 2/15/12 "Nano" culture 4) P. horikoshii 5) A. boonei. 6) No template... Thermal gradient $\left({ }^{\circ} \mathrm{C}\right)$ a) 64 , b) 63.3, c) 61.8 , d) 59.8 , e) 57.4 , f) 55.3 , g) 53.8 h) 53.0.

Figure 2.5. Conventional PCR annealing thermal gradient with marine Nanoarchaeota primers. Sample 1) N. equitans 2) $P$. horikoshii 3) M. jannaschii 4) A. boonei 5) P. aerophilium 6) no template. Thermal gradient $\left({ }^{\circ} \mathrm{C}\right)$ a) 64 , b) 63.3 , c) 61.8 , d)

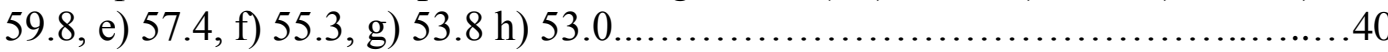

Figure 2.6. Thermococcales primer mock archaeal community analysis. Mock community: P. aerophilium, A. luliquidus, M. jannasii, I. hospitalis. L, Ladder.

Figure 2.7. Archaeoglobus primer mock archaeal community. Mock community: $P$. aerophilium, A. lulqidus, M. jannasii, I. hospitalis, P. horikoshi. L, Ladder.

Figure 2.8. Ignicoccus primer mock archaeal community. Mock community: $P$. aerophilium, A. lulqidus, M. jannasii, A. boonei, P. horikoshi. L, Ladder.

Figure 2.9. Marine Nanoarchaeota primer mock archaeal community analysis of two primer sets 110/458 and 381/458. Mock community: P. aerophilium, A. lulqidus, M. jannasii, I. hospitalis, P. horikoshi. L, Ladder.

Figure 2.10. Melt curve analysis from environmental samples of the four designed primer sets. a) Thermococcales; b) Archaeoglobus; c) Nanoarchaeota; d) Ignicoccus.

Figure 2.11. Standard curves from of the four designed primer sets. a) Thermococcales; $b$ ) Archaeoglobus; c) Nanoarchaeota; d) Ignicoccus

Figure. 3.1. Relative proportion of select archaeal taxa to total archaeal abundance from deposit samples of globally distributed hydrothermal vents. Error bars indicate \pm 1 standard error of the mean (SEM)

Figure 3.2. MDS using Bray-Curtis similarities of square root transformed archaeal community relatedness of the a) Globally distributed hydrothermal vents b) MAR c) ELSC d) EPR and Guaymas Basin. Pairwise relatedness (R value) and significance (P value) are displayed based on ANOSIM analyses in the bottom right. EPR, East Pacific Rise; ELSC B, Basalt hosted vent fields on the ELSC; ELSC A, Andesite hosted vent fields on the ELSC.... 
Figure 3.3 Co-occurrence results of the local similarity analysis of the Nanoarchaeota OTU from 62 sulfide deposit samples visualized using Cytoscape...............71

Figure 3.4. Relative proportion of selected archaeal taxa from chimney and flange hydrothermal vent deposits from globally distributed hydrothermal vents, based on qPCR. Error bars indicate \pm 1 standard error of the mean (SEM) ..............73

Figure 3.5. Relative proportion of Archaeoglobus and methanogen (mcrA) genes based on qPCR. Vent fields are organized in ascending order with the highest hydrogen end member concentrations at the bottom...................................... 78

Figure. 3.6. Relative proportion of the Nanoarchaeota and Ignicoccus from deposit samples of globally distributed hydrothermal vents. Error bars indicate \pm 1 standard error of the mean (SEM)

Figure. 3.7. Relative proportion of the Nanoarchaeota and Ignicoccus sequences, based on qPCR. Vent fields are organized in ascending order with the highest hydrogen end member concentration on the bottom 


\section{CHAPTER 1: Introduction}

Since the discovery of hydrothermal vents in 1977 , more than 150 vent fields have been identified along the $60,000 \mathrm{~km}$ ocean ridge system at back-arc spreading centers, mid-ocean ridges (MORs), active seamounts, and forearcs (Takai, 2011; Hannington et al., 2005). Deep-sea vents are characterized by steep physical and geochemical gradients between the hot, anoxic, and reduced hydrothermal fluid and the cold oxygenated seawater. The chemical disequilibria support diverse microbial populations that gain energy through the reduction and oxidation (redox) of inorganic chemicals. Chemolithoautotrophic bacteria that colonize the chimney provide the trophic base to the most biologically productive and diverse ecosystem on Earth that is nearly devoid of input from photosynthetically derived organic matter (Lutz and Kennish, 1993; Sarrazin and Juniper, 1999).

\section{Geologic Setting}

Hydrothermal vents are formed at seafloor spreading centers as seawater enters the igneous crust through fissures and cracks and saturates the crust. As the seawater descends, it is geothermally heated by shallow pockets of magma and is chemically altered as the host rock interacts with the seawater and is stripped of $\mathrm{SO}_{4}, \mathrm{Mg}$, and $\mathrm{Ca}$ (Bischoff and Seyfried; 1978; Alt, 1995; Tivey et al., 2007). Magmatic volatiles such as $\mathrm{He}, \mathrm{CO}_{2}, \mathrm{H}_{2}$, and $\mathrm{CH}_{4}$ are added to the fluid along with $\mathrm{H}_{2} \mathrm{~S}$. The hot, reduced, and less dense fluid rises quickly through the oceanic crust. When the hydrothermal fluid reaches the seafloor it is expelled and reacts with the cold oxygenated seawater and polymetallic sulfide "chimneys" are formed as the metals precipitate out from the 
hydrothermal fluid (Alt, 1995; Juniper and Tebo, 1995; Tivey et al., 2005). The geochemical composition of the end member hydrothermal fluid is greatly influenced by subsurface interactions between the seawater and the host rock composition (Von Damm, 1995).

There are three main types of hydrothermal vent host rocks that affect the end member fluid composition: mafic, ultramafic, and andesitic (Butterfield and Massoth, 1994; Gamo et al., 1997; Gamo et al., 2001; Charlou et al., 2002; Mottl et al., 2011; Holden et al., 2012). Mafic and ultramafic hosted hydrothermal vent systems are typically found at MORs, while andesitic hosted vents are found at convergent plate boundaries (Tivey et al., 2005). Basalt-hosted mafic hydrothermal vents tend to have significantly higher concentrations of $\mathrm{H}_{2} \mathrm{~S}$ than ultramafic-hosted vents. Ultramafichosted hydrothermal systems have higher concentrations of $\mathrm{H}_{2}, \mathrm{Fe}$, and $\mathrm{CH}_{4}$ than typical MOR systems due to serpentinization, a water-rock interaction that results in the reduction of $\mathrm{H}_{2} \mathrm{O}$ to $\mathrm{H}_{2}$ and the oxidation of $\mathrm{Fe}(\mathrm{II})$ to $\mathrm{Fe}(\mathrm{III})$ (Kelley et al., 2001; Charlou et al., 2002; Schmidt et al., 2007, McCollom, 2007). Andesite, the third type of host rock, tends to be associated with back-arc basins that form parallel to island arcs (Charlou et al., 2002; Tivey et al., 2005). Andesite hosted end-member vent fluid tends to have lower $\mathrm{H}_{2}, \mathrm{CH}_{4}$, and $\mathrm{pH}$ along with increased metal concentrations due to the influence of the subducting plate (Martinez et al., 2007). Due to the non-uniform endmember hydrothermal vent fluid between vent fields, thermodynamically favorable chemical reactions are expected to constrain the diversity and activity of the microbial energetic metabolisms present (McCollom \& Shock, 1997; McCollom, 2007). 


\section{Emerging Patterns in Archaeal Diversity at Deep-Sea Hydrothermal Vents}

The taxonomic distinction of Archaea as a separate domain occurred in the late 1970s due to the work of Carl Woese and colleagues who pioneered prokaryotic phylogeny by utilizing the small subunit rRNA sequencing (Woese and Fox, 1977). The first Archaea isolated and characterized from hydrothermal vents occurred in 1983. It was identified as a methanogen and originally named Methanococcus jannaschii, but later revised to Methanocaldococcus jannaschii (Jones et al., 1983; Whitman, 2001). Since the isolation of the first Archaea from a hydrothermal vent, both culturedependent and culture-independent studies have illuminated the immense metabolic and phylogenetic diversity of Archaea that inhabit these environments (Takai et al., 2006).

The majority of Archaea belong to two main phyla, the Euryarchaeota and Crenarchaeota. The Euryarchaeote-Crenarchaeote evolutionary split was originally proposed based on $16 \mathrm{~S}$ rRNA gene sequences, and is strongly supported by comparative genetics as both phyla have unique replication, transcription, and translation pathways (Woese et al, 1990). Other groups that are less abundant at deep-sea hydrothermal vents are the Nanoarchaeota and Korarchaoeta. The taxonomic distinction between these two phyla, however, is controversial and not well supported (Huber et al., 2002; Brochier et al., 2005; Elkins et al., 2008).

The Euryarchaeota lineages commonly identified at deep-sea hydrothermal vent biotopes are the methanogens, Archaeoglobales, Thermococcales, and the uncultured lineages such as the deep-sea hydrothermal vent group (DHVEG)(Takai et al., 2006a). Based on previous clone library and barcoded pyrosequencing analyses, the Thermococcales, Archaeoglobales, and methanogens, have been identified to often 
constitute greater than $50 \%$ of the archaeal community from hydrothermal vent deposits (Table 1.1).

Methanogens are a diverse group of Archaea characterized by their ability to reduce $\mathrm{CO}_{2}$ or organics to methane as an end product, and are an essential part of the global carbon cycle (Liu \& Whitman, 2008; Wolfe, 1996). The methanogens are composed of the orders Methanococcales, Methanosarcinales, Methanobacteriales, Methanomicrobiales, Methanopyrales, and Methanoplasmatales. The majority of methanogen isolates are mesophilic, neutrophilic, have a wide salinity tolerance, and have been identified in diverse thermal environments (Liu and Whitman, 2008; Martinez et al., 2007; Bonin and Boone 2006; Whitman and Jeanthon, 2006; Kurr et al., 1991; Sakai et al., 2008) (Table 1.1). Of the six orders of methanogens Methanobacteriales, Methanococcales, Methanopyrales, and Methanoplasmatales primarily utilize the hydrogenotrophic methanogenic pathway, with $\mathrm{H}_{2}$ and $\mathrm{CO}_{2}$ as their electron donor and acceptor (Liu and Whitman, 2008; Paul et al., 2012). In contrast the Methanosarcinales and the Methanomicrobiales have wide metabolic substrate ranges. The Methanosarcinales are able to produce methane by dismutation of single carbon compounds, in addition to either acetoclastic or hydrogenotrophic methanogenesis (Kendall and Boone, 2006). The catabolic methyl dismutase process has thus far been exclusively identified in the Methanosarcinales. The Methanomicrobiales can utilize formate and some alcohols in addition to hydrogen and carbon dioxide (Liu and Whitman, 2008). Recently two strains of methanogens have been cultured that have revised the upper limits of archaeal life: Methanopyrus and Methanocaldococcus strains 
Table 1.1 Summary of the barcoded pyrosequencing and clone library percent composition from deep-sea hydrothermal vent deposits for the Archaeoglobales, Thermococcales, methanogens, Nanoarchaeota, and Ignicoccus. AMOR, Arctic Mid-Ocean Ridge; CIR, Central Indian Ridge; JDF, Juan de Fuca Ridge; MAR, MidAtlantic Ridge; ND, none detected; 1 denotes barcoded pyrosequencing studies; 2 denotes clone library studies.

\begin{tabular}{|c|c|c|c|c|c|c|}
\hline & Archaeoglobales & Thermococcales & Methanogens & Ignicoccus & Nanoarchaeota & Reference \\
\hline ELSC (Kilo Moana) $^{1}$ & 5.6 & 7.3 & 2.2 & 1.7 & 14.4 & Flores et al., 2012a \\
\hline ELSC (Tow Cam) ${ }^{1}$ & 2.1 & 6.3 & 2.4 & 0.5 & 1.1 & Flores et al., 2012a \\
\hline ELSC (Tahi Moana) $^{1}$ & 0.8 & 6.8 & 1.1 & 0.5 & 6.6 & Flores et al., 2012a \\
\hline $\operatorname{ELSC}(\mathbf{A B E})^{1}$ & 1.4 & 3 & 1.4 & 0.5 & 0.9 & Flores et al., 2012a \\
\hline ELSC (Tui Malila) $^{1}$ & 0.8 & 9.8 & 0.94 & 1.7 & 1.3 & Flores et al., 2012a \\
\hline ELSC (Mariner) ${ }^{1}$ & 2 & 46.4 & 0.25 & 1.2 & 0.01 & Flores et al., 2012a \\
\hline ELSC (Kilo Moana) $^{2}$ & 80 & 12 & ND & ND & ND & Pagé, 2008 \\
\hline ELSC (Tow Cam 1) & 2 & 8 & 88 & ND & ND & Pagé, 2008 \\
\hline ELSC (Tow Cam 2) ${ }^{2}$ & 20 & 68 & ND & ND & ND & Pagé, 2008 \\
\hline ELSC $\left(\right.$ Mariner) ${ }^{2}$ & 18 & 20 & ND & ND & ND & Pagé, 2008 \\
\hline MAR (Rainbow) ${ }^{1}$ & 11.4 & 20 & 32.1 & 0.1 & 2.5 & Flores et al., 2011 \\
\hline MAR (Lucky Strike) ${ }^{1}$ & 4 & 18 & ND & 1.3 & 1 & Flores et al., 2012a \\
\hline MAR (TAG) $)^{1}$ & 19.1 & 13.4 & ND & 0.4 & 0.09 & Reysenbach, \\
\hline MAR $(\text { Ashadze })^{2}$ & 19 & 6 & 25 & ND & ND & Roussel et al., 2011 \\
\hline MAR (Rainbow) ${ }^{2}$ & 14 & 7 & ND & ND & 2 & Roussel et al., 2011 \\
\hline MAR (Snake Pit) ${ }^{2}$ & 22 & 71 & ND & ND & ND & Reysenbach et al., 2000 \\
\hline MAR (Logatchev) $)^{2}$ & 7 & 11 & 74 & ND & ND & Perner et al., 2007 \\
\hline MAR (Lucky Strike) ${ }^{2}$ & $\mathrm{ND}$ & 100 & ND & ND & ND & Wery et al., 2008 \\
\hline Off Axis (Lost City) ${ }^{2}$ & ND & ND & 75 & ND & ND & Roussel et al., 2011 \\
\hline Off Axis (Lost City) ${ }^{2}$ & ND & ND & 85 & ND & ND & Schrenk et al., 2004 \\
\hline AMOR (Loki Castle) ${ }^{1}$ & 1.8 & 28.4 & 2.8 & ND & ND & Jaeschke et al., 2013 \\
\hline Guaymas $^{1}$ & 2.9 & 15.1 & 25.7 & 0.07 & 1.9 & Reysenbach, \\
\hline Guaymas $^{2}$ & 3 & 24 & 46 & ND & ND & Page et al., 2008 \\
\hline Guaymas $^{2}$ & 5 & 4 & 19 & 23 & ND & Teske et al., 2002 \\
\hline JDF (Dead Dog) ${ }^{1}$ & 35 & 4 & ND & ND & ND & Olins et al., 2013 \\
\hline JDF $(\text { SulX) })^{2}$ & 100 & ND & ND & ND & ND & Pagé, 2008 \\
\hline JDF $(\operatorname{DanX})^{2}$ & 96 & ND & ND & ND & ND & Pagé, 2008 \\
\hline JDF $(\mathbf{S M X})^{2}$ & 8 & 18 & ND & ND & ND & Pagé, 2008 \\
\hline JDF (Mothra) ${ }^{2}$ & 3 & 16 & 9 & ND & ND & Schrenk et al., 2003 \\
\hline $\operatorname{EPR}(13 N)^{2}$ & 21 & 88 & 30 & ND & ND & Nercessian et al., 2003 \\
\hline $\operatorname{EPR}(9 \mathrm{~N})^{2}$ & 24 & 21 & 3 & ND & ND & Kormas et al., 2006 \\
\hline EPR $(\text { Proto })^{2}$ & ND & 7 & ND & 83 & ND & McCliment et al., 2006 \\
\hline $\mathbf{E P R}^{2}$ & ND & 56 & ND & ND & ND & McCliment et al., 2006 \\
\hline CIR (Edmond) $)^{2}$ & ND & 7 & ND & ND & $\mathrm{ND}$ & Hoek et al., 2003 \\
\hline CIR (Kairei) $^{2}$ & ND & 25 & 75 & ND & ND & Takai et al., 2004 \\
\hline Okinawa $^{2}$ & 6 & 18 & 12 & ND & ND & Nunoura \& Takai, 2009 \\
\hline Izu-Bonin Arc ${ }^{2}$ & 7 & 12 & 11 & ND & ND & Higashi et al., 2004 \\
\hline $\operatorname{Manus} \operatorname{Basin}()^{2}$ & ND & 28 & ND & 22 & ND & Takai et al., 2001 \\
\hline
\end{tabular}


were cultivated at the highest known temperature for growth $\left(122^{\circ} \mathrm{C}\right)$ and for nitrogen fixation $\left(92^{\circ} \mathrm{C}\right)$ respectively (Mehta et al., 2006; Takai et al., 2008).

Archaeoglobus fulgidus was the first isolated sulfate-reducing Archaea, originally found in marine springs off Volcano, Italy (Stetter et al., 1987). The genus currently contains five other species: A. profundus, A. veneficus, A. infectus 'A.

lithotrophicus', and A. sulfaticallidus (Burggraf et al., 1990, Huber et al., 1997; Mori et al., 2008; Steinsbu et al., 2010). They represent a key group in biogeochemical cycling of sulfur as they are able to utilize sulfate, sulfite, or thiosulfate as a terminal electron acceptor (Stetter et al., 1987). Acetate, lactate, and pyruvate are other electron donors that can be utilized by some members of the Archaeoglobus instead of molecular hydrogen. Growth by strict chemolithoautotrophy has only been identified by ' $A$. lithotrophicus' (Hartzell and Reed, 2006).

Within the Archaeoglobales, two other genera Ferroglobus and Geoglobus are autrotrophs and are able to utilize ferric iron (Tor \& Lovley, 2001; Kashefi et al., 2002). The Ferroglobus have wide metabolic diversity as some members are able to utilize hydrogen, ferrous iron or hydrogen sulfide, with either nitrate or thiosulfate as electron acceptors (Hafenbradl et al., 1996). All of the isolated strains from the family Archaeoglobaceae have been identified from environmental samples associated with hydrothermal vents or oil reservoirs (Table 1.1) (Steinsbu et al., 2010).

The Thermococcales are generally anaerobic obligate heterotrophs and are the most frequently identified archaeal group from hydrothermal vents and have also been found at terrestrial hot springs, oil reservoirs, and from deep subsurface environments (Table 1.1) (Ronimus et al., 1997; Reysenbach et al., 2000; Takai et al., 2001; 
Nercessian et al., 2003; Takai et al., 2004; Kormas et al., 2006). The Thermococcales are composed of three genera: Pyrococcus, Thermococcus, and Paleococcus that generally exhibit a heterotrophic fermentative metabolism. The genus Pyrococcus is a hyperthermophilic group whose members have optimal growth that can exceed $100^{\circ} \mathrm{C}$ and have been isolated strictly from hydrothermal vents and thrives in a specific ecological niche (Morikawa et al., 1994). The only known obligate barophilic hyperthermophile, strain Pyrococcus CH1, was cultured from Ashadze vent field on the Mid-Atlantic Ridge (MAR), one of the deepest known hydrothermal vent fields (Zeng et al., 2009). Due to this specific ecological niche, Pyrococcus spp. are found in much smaller proportion of the archaeal community than the genus Thermococcus that has much wider physiological and metabolic capabilities (Table 1.1). Thermococcus spp. have the most cultured representatives within the order and have been isolated from a wide distribution of environments, such as terrestrial hot springs, oil reservoirs, in addition to hydrothermal vents (Lepage et al., 2004; Takai et al., 2004; Nakagawa et al., 2005a). The third genus within the Thermococcales, Paleococcus is rarely detected at hydrothermal vents. To date only three species within Paleococcus have been described: Palaeococcus helgesonii, Palaeococcus ferrophilus, and Paleococcus pacificus (Takai et al., 2000; Amend et al., 2003; Zeng et al., 2013). This group has similar growth conditions to the other two genera and utilizes elemental sulfur or ferrous iron as electron acceptors (Takai et al., 2000).

There are several endemic archaeal lineages routinely found at hydrothermal vents that are taxonomically identified as DHVEG (Takai and Horikoshi, 1999; Reysenbach et al., 2000; Takai et al., 2001; Hoek et al., 2003; Nercessian et al., 2003; 
Reysenbach et al., 2006; Flores et al., 2012b). Within the DHVEG taxa, the order DHVE2 is represented by the first cultured thermoacidophile, Aciduliprofundum boonei, a peptide fermenter, that was isolated from the Mariner vent field on the Eastern Lau Spreading Center (ELSC) (Reysenbach et al., 2006; Reysenbach and Flores, 2008).

The main groups of Crenarchaeota found at deep-sea hydrothermal vents are the Desulfuroccales, the deep-sea hydrothermal vent crenarchaeotal group (DHVC1), and marine group I (Takai and Horikoshi, 1999; Takai et al., 2006a). The genera Pyrodictium and Pyrolobus are two of the main groups identified members within the Desulfurococcales. The Pyrodicium are characterized by their ability to either reduce elemental sulfur coupled with molecular hydrogen or organics, and the Pyrolobus conducts chemolithoautotrophic hydrogen oxidation with either nitrate, sulfate or oxygen reduction (Reysenbach et al., 2002).

Controversially placed as a monotypic kingdom, the phylum Nanoarchaeota is represented by a single cultured isolate of the species, Nanoarchaeum equitans that was isolated from the Kolbeinsey Ridge, a hydrothermal system located north of Iceland (Huber et al., 2002). N. equitans is a small archaeum (400nm) that grows in strict anaerobic conditions between 75 and $98^{\circ} \mathrm{C}$ (Huber et al., 2002; Brochier et al., 2005). This species is the only known archaeal-archaeal obligate parasite/symbiont and forms a direct connection to the surface of the anaerobic chemolithoautotrophic sulfur-reducing Crenarchaeota, Ignicoccus hospitalis (Huber et al., 2002; Comolli et al., 2009). N. equitans has no known energetic metabolism and thus relies exclusively on metabolites acquired from I. hospitalis (Huber et al., 2002). 


\section{Metabolic Diversity of Major Archaeal Groups}

Of the Archaea, methanogens, Archaeoglobales, and the Thermococcales often represent the major archaeal lineages at hydrothermal vents (Takai et al., 2006a; Nakagawa \& Takai, 2008; Roussel et al., 2011; Flores et al., 2012a). These three thermophilic groups have diverse energetic metabolisms that utilize various electron acceptors and donors along with carbon acquisition strategies (Nealson et al., 2005). This metabolic heterogeneity is implicated in influencing the spatiotemporal distributional pattern of these archaeal lineages in relation to the polymetallic sulfide vent development (Reysenbach et al., 2000; McCliment et al., 2006).

\section{Methanogens}

Chemolithoautotrophic methanogens have been shown to be the first colonizers of some hydrothermal vent deposit structures (Reysenbach et al., 2000; Page et al., 2008). Hydrogenotrophic methanogenesis is the main process of methane formation in high temperature environments, due to its thermodynamic advantage over the fermentation pathway (Table 1.2) (Dhillon et al., 2005; Amend et al., 2011). Under anoxic reducing conditions it is also more energetically advantageous to grow autotrophically due to less of an energetic requirement for the production of biomolecules compared to heterotrophic growth (McCollum and Amend, 2005).

Functional genes surveys of the methyl coenzyme reductase $\alpha$-subunit ( $m c r A$ ) gene that is a vital for methanogenesis have been used to link methanogenesis to specific environments, rather than inferred metabolic capabilities derived from 16S rRNA gene analyses. Functional $m c r A$ gene qPCR analyses have found methanogen $m c r A$ genes in 
relatively large abundances at hydrothermal vent fields with vent fluid enriched in hydrogen, while there were no detected $m c r A$ genes in the relatively low hydrogen, oxic hydrothermal vent fields (Flores et al., 2011). The dearth of methanogens was attributed to low hydrogen concentration and relatively oxidizing conditions, as other hydrogen oxidizers advantageously out-competed the methanogens for hydrogen (Flores et al., 2011).

Phylogenetic analyses of $m c r A$ genes have also revealed phylotypes of Methanococcales at Ashadze, Rainbow, and Guaymas Basin, Methanopyrales phylotypes at $13^{\circ} \mathrm{N}$ and Rainbow, and Methanosarcinales phylotypes at Ashadze, Rainbow, and Guaymas Basin (Nercessian et al., 2005; Dhillon et al., 2005; Roussel et al., 2011). These findings are consistent with thermodynamic geochemical models that indicate that methanogens can only be quantitatively dominant in environments where $\mathrm{CO}_{2}$ is the only terminal electron acceptor, because methanogenesis is less energetically advantageous compared to other terminal electron acceptors such as sulfate, Fe(III), Mn(IV), and nitrate (McCollom, 2007). The thermodynamic specificity of hydrogenotrophic methanogenesis limits the ecological niches that thermophilic methanogens can exploit at deep-sea hydrothermal vents (Ver Eecke et al., 2012; McCollom, 2007).

\section{Archaeoglobales}

As chimneys cool and the bacterial diversity increases there is a greater availability of complex organics that can be utilized as alternate electron donors in place of hydrogen. At the seawater hydrothermal fluid interface, as the hydrothermal fluid 
mixes with the sulfate rich seawater the high temperature environment becomes ideal for mixotrophic sulfate reduction (McCollom, 2007). The concentration of sulfate in seawater is around 300 times greater than oxygen, even at low seawater to hydrothermal fluid mixing ratios hydrogenotrophic sulfate reduction becomes a thermodynamically favorable reaction over other reactions with various terminal electron acceptors (McCollom, 2007). However, dissolved iron is exceedingly low in seawater and as a result the chemical energy availability for the other two genera within the Archaeoglobales, Ferroglobus and Geoglobus is constrained (McCollom, 2007).

Due to the thermodynamic advantage of the Archaeoglobus' sulfate-reducing metabolism, Archaeoglobus is often found to be a prevalent archaeal phylotype at hydrothermal vents, based on vent deposit diversity analyses (Table 1.2). Functional gene qPCR surveys of the dissimilatory sulfate reductase $\beta$-subunits $(d s r B)$ gene that is found in both bacteria and Archaea that is a vital for sulfate or sulfite reduction have revealed widespread distribution across hydrothermal vent fields with dramatically different geochemistry (Flores et al., 2011). In addition, sequence analyses of $d s r B$ genes have revealed Archaeoglobaceae specific phylotypes at Kairei on the Central Indian Ocean (CIR), and at $13^{\circ} \mathrm{N}$ on the East Pacific Rise (EPR) (Nakagawa et al., 2004; Nercessian et al., 2005).

\section{Thermococcales}

As chimneys become more mature, microbial diversity increases as microhabitats become available and the accumulation of complex organics allows for proliferation of heterotrophic microorganisms with more diverse metabolisms, such as 
the Thermococcales (Reysenbach et al., 2000). The Thermococcales utilize complex organics such as peptides, oligosaccharides, pyruvate, and amino acids coupled with hydrogen fermentation or elemental sulfur reduction (Zillig et al., 1983; Fiala and Stetter, 1986; Takai et al., 2000; Amend \& Shock, 2001). In addition, a minority of Thermococcales are also able to oxidize carbon monoxide with hydrogen production, or couple acetate with Fe (III) (Summit \& Baross, 2001; Sokolova et al., 2004).

Due to the metabolic diversity of the Thermococcales with regards to the fermentable substrates, the Thermococcales have an advantage over many other metabolisms in productive environments (Huber et al., 2006). Thermococcales often dominate archaeal clone libraries in more mature, lower temperature hydrothermal vent deposits, and conversely constitute a much smaller proportion at high temperature nascent vents that are dominated by hyperthermophilic chemolithoautotrophic Archaea (McCliment et al., 2006). Temporal studies of in-situ growth chambers have also demonstrated shifts in archaeal community abundances over time from chemolithotrophic archaeal lineages to the chemoorganotrophic Thermococcales (Reysenbach et al., 2000).

\section{Nanoarchaeota}

In contrast to the relatively well studied archaeal groups of the methanogens, Archaeoglobales, and the Thermococcales, little is known about the ecological interactions of the enigmatic lineages of Nanoarchaeota and Ignicoccus. One study found the Nanoarchaeota and Ignicoccus were a predominant archaeal lineage identified from newly formed chimneys at the $9^{\circ} \mathrm{N}$ vent field on the EPR (Table 1.1) (McCliment 
et al., 2006). This same study identified phylogenetically distinct Nanoarchaeota sequences from mature vent samples that did not co-occur with Ignicoccus sequences, suggesting that the secondarily colonizing Nanoarchaeota represent a separate nonIgnicoccus hosted lineage. The high hydrogen and relatively low $\mathrm{pH}$ of the newly formed chimney environments could be favorable growth requirements of the Nanoarchaeota and Ignicoccus and allow them to be pioneering lineages of chimney structures.

\section{Current Metadata}

Until recently the influence of large scale geologic and subsurface geochemical processes on the vent colonizing archaeal communities remained relatively understudied. Two seminal studies by Flores et al. (2011 \& 2012a) used barcoded pyrosequencing to contrast the archaeal community composition of sulfide deposits between hydrothermal vent fields with different host rocks. In the first of the two studies the archaeal community structure was analyzed between the Rainbow and Lucky Strike hydrothermal vent fields located on the MAR that are ultramafic and mafic hosted respectively. The largest contrast between the two vent fields was that at the ultramafic hosted Rainbow vent field, methanogens constituted a large proportion of the archaeal community, while there were no detected methanogens at the basalt/mafic hosted Lucky Strike vent field (Fig 1.1). At Lucky Strike the dearth of methanogens was attributed to low hydrogen concentration and relatively oxidizing conditions as other hydrogen oxidizers such as the Archaeoglobus advantageously out-competed the methanogens for hydrogen. The Archaeoglobus however was found in relatively small proportion at both 
a)

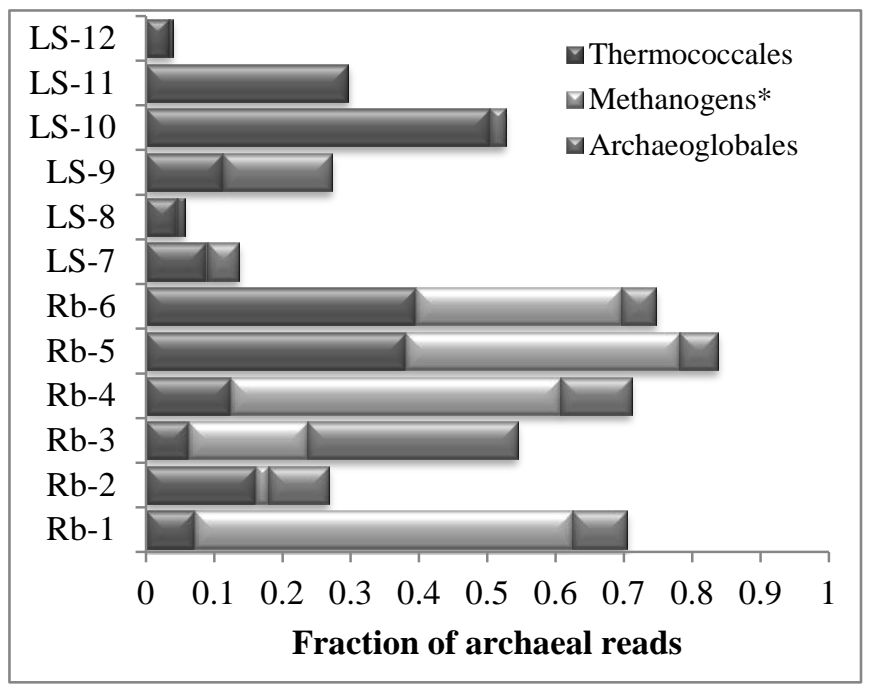

b)

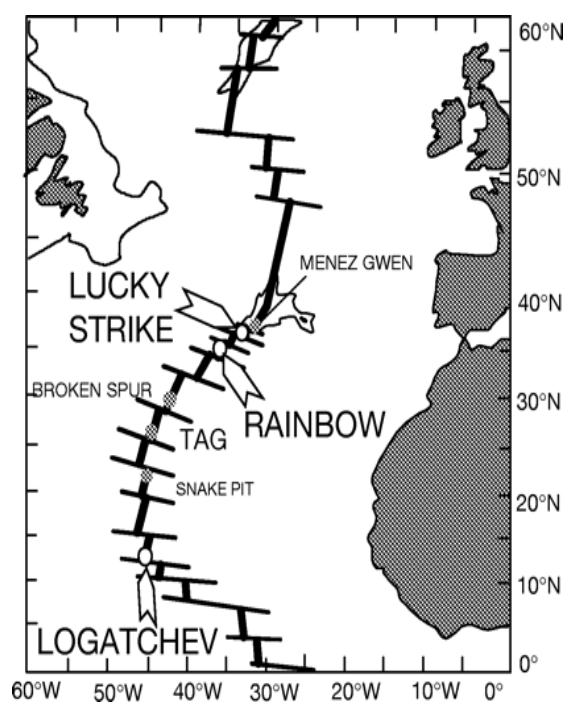

Figure 1.1. a) Fraction of barcoded pyrosequencing 16S rRNA gene reads for the Thermococcales, Methanogens, and Archaeoglobales at Lucky Strike and Rainbow vent fields along the Mid-Atlantic Ridge. Modified from Flores et al., 2011. Rb, Rainbow; LS, Lucky Strike . b) Map of the location of the hydrothermal vent fields Lucky Strike and Rainbow along the Mid-Atlantic Ridge. Modified from Rouxel, 
Rainbow and Lucky Strike compared to the methanogens even though thermodynamically they should out-compete the methanogens for hydrogen. The Thermococcales constituted a relatively large proportion of the archaeal community across both vent fields and appeared to not be structured based on the divergent geochemistry of the two sites.

The understudied lineage of the Nanoarchaeota was identified in all six sequenced samples from Rainbow, but in relatively low proportions (Fig 1.2). In contrast, at Lucky Strike Nanoarchaeota sequences were only detected at two of the six samples. Ignicoccus, the genus of the only confirmed marine Nanoarchaeota host, were only detected from two samples at Lucky Strike. Overall it was found that the Nanoarchaeota were identified at more sites, and in a greater proportion of the archaeal community at ultramafic hosted Rainbow than at the basalt/mafic hosted Lucky Strike, and the inverse can be stated about Ignicoccus which was solely found at Lucky Strike.

In contrast to the more geologically uniform MOR system, Flores et al. (2012a) contrasted the microbial community at six geologically diverse vent fields along the Eastern Lau Spreading Center (ELSC). The ELSC is a back arc basin in the western Pacific that has a generalized geochemical gradient of end member fluid that systematically decreases from north-south in temperature, $\mathrm{pH}$, and metabolically important compounds such as hydrogen and hydrogen-sulfide (Charlou et al., 2002). Of the archaeal community the Thermococcales were detected at all the vent fields, but particularly dominated the archaeal community at the southernmost vent field Mariner constituting, up to $75 \%$ of the community (Fig 1.3). This high proportion of Thermococcales could be associated with the high concentration of single carbon 
a)

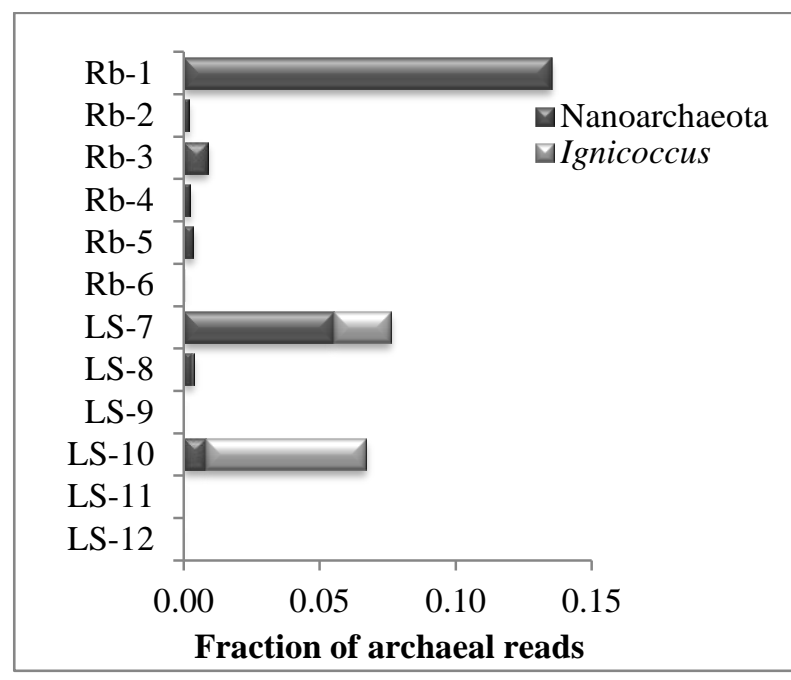

b)

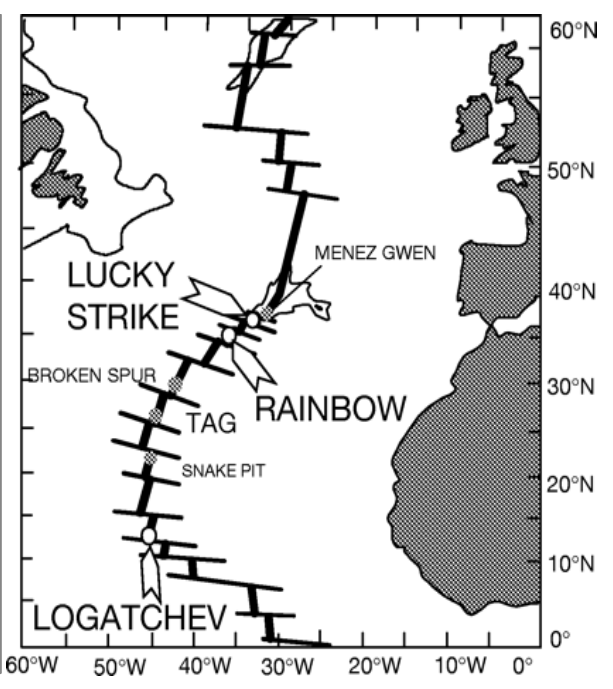

Figure 1.2. a) Fraction of barcoded pyrosequencing 16S rRNA gene reads for the Nanoarchaeota and Ignicoccus at Lucky Strike and Rainbow vent fields along the Mid-Atlantic Ridge. Modified from Flores et al., 2011. Rb, Rainbow; LS, Lucky Strike . b) Map of the location of the hydrothermal vent fields Lucky Strike and Rainbow along the Mid-Atlantic Ridge. Modified from Rouxel , 2004. 
compounds as $\mathrm{CO}_{2}$ concentrations are up to five times higher than the other vent fields and some Thermococcales species are able to oxidize $\mathrm{CO}$ to $\mathrm{CO}_{2}$ (Lee et al., 2008; Zivanovic et al., 2009; Vannier et al., 2011). Methanogens and Archaeoglobus were found in low abundance at all the vent fields along the ELSC, especially at Mariner where the methanogens were almost undetected. Nanoarchaeota OTUs were detected from 27 of the 34 samples, with the highest proportions concentrated in the northernmost basalt-hosted hydrothermal vent field of Kilo Moana and Tahi Moana (Fig 1.4). Ignicoccus was found in relatively low concentrations across all vent fields on the ELSC with only one sample constituting greater than $5 \%$ of the archaeal community. In contrast to the archaeal community between the two vent fields on the MAR that segregated based on vent host rock, the ELSC had similar community structure between the basalt and andesite hosted vent fields, except for the southernmost andesite hosted vent field of Mariner.

These seminal studies were able to identify a direct coupling of the archaeal community structure to large scale geologic processes of plate tectonic interactions and vent host rock. However, some of the interesting lineage specific findings from these studies need to be verified using non-barcoded pyrosequencing molecular analyses.

\section{Scope of Thesis}

In this study I will utilize real-time qPCR with lineage specific primers to examine the quantitative shifts in the community abundance of the major archaeal lineages at globally distributed and geochemically distinct hydrothermal vents. In Chapter 2, I report the further development and modification of real time qPCR 
a)

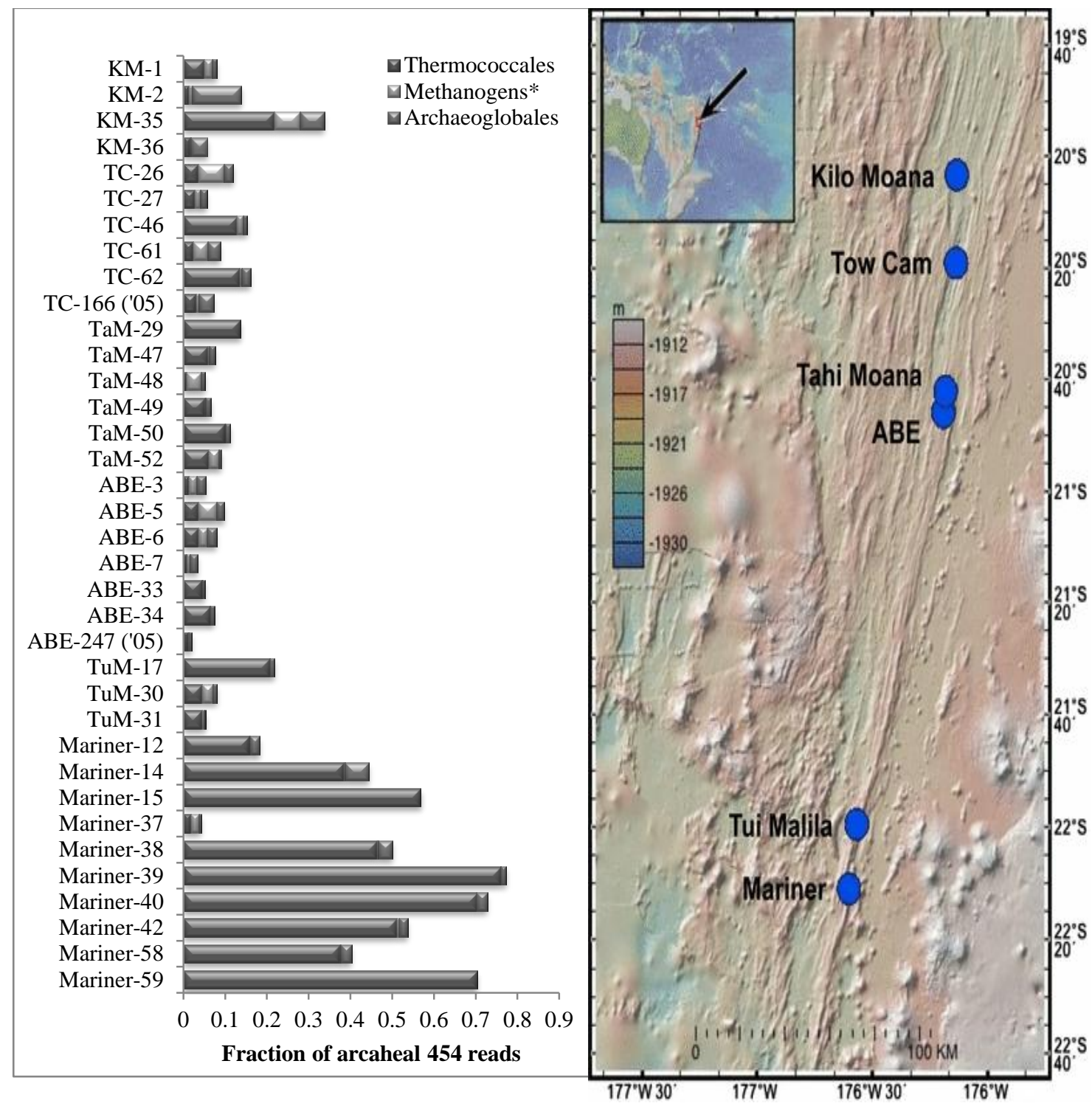

Figure 1.3. a) Fraction of barcoded pyrosequencing 16S rRNA gene reads for the Thermococcales, methanogens, and Archaeoglobales at vent fields along the Eastern Lau Spreading Center. Modified from Flores et al., 2012a. KM, Kilo Moana; TC, Tow Cam; TaM, Tahi b) Map of the Eastern Lau Spreading Center vent fields. Modified from Flores et al. (2012a) \& Ferrini et al. (2008) using the GeoMapApp (http://www.geomapapp.org/). 
a)

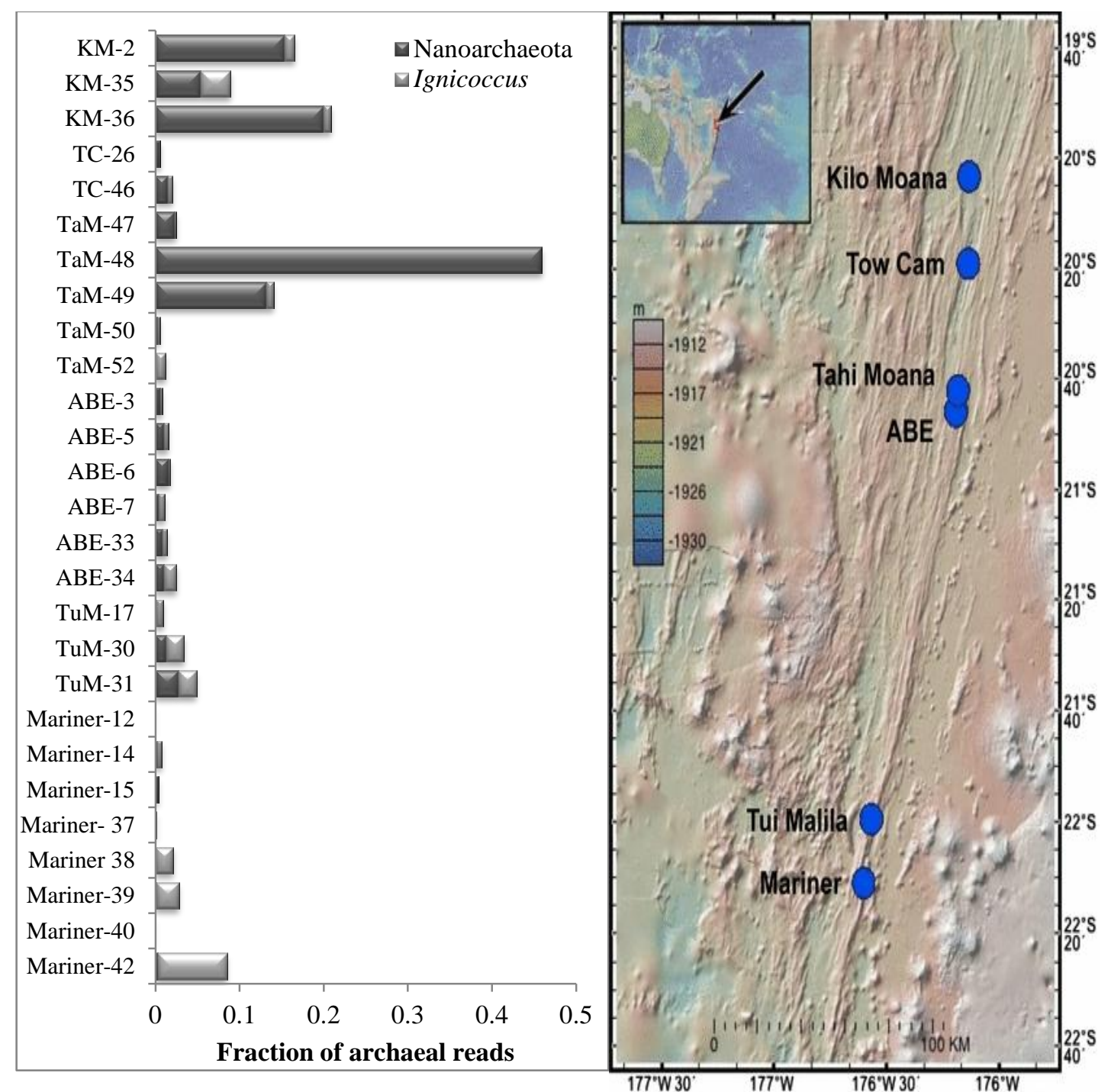

Figure 1.4. a) Fraction of barcoded pyrosequencing 16S rRNA gene reads for the Nanoarchaeota and Ignicoccus at vent fields along the Eastern Lau Spreading Center. Modified from Flores et al., 2012a. KM, Kilo Moana; TC, Tow Cam; TaM, Tahi b) Map of the Eastern Lau Spreading Center vent fields. Modified from Flores et al. (2012a) \& Ferrini et al. (2008) using the GeoMapApp (http://www.geomapapp.org/). 
primers for the Thermococcales and Archaeoglobus, and the lineages of the Ignicoccus, and marine Nanoarchaeota. For Chapter 3, I characterize the archaeal community abundance of the lineages of the Thermococcales, Archaeoglobus, methanogens, Nanoarchaeota and Ignicoccus from polymetallic sulfide deposits from mafic, ultramafic, and andesitic hosted vent fields along the MAR, ELSC, EPR, and the Guaymas Basin. The primary goal of this study is to confirm the archaeal community structural differences between hydrothermal vent fields from the MAR and ELSC along with interesting lineage specific observations of the Thermococcales, Nanoarchaeota, and Ignicoccus based on barcoded sequencing from Flores et al. (2011 \& 2012a). In addition, this study will build upon the previous studies by contrasting the archaeal community abundances of two vent fields in the eastern Pacific (EPR and Guaymas) that are fast-spreading basalt and basalt-sedimented hydrothermal vent fields. This study will also analyze the influence of more logalized geologic processes by contrasting the archaeal community between chimney and flange deposit structures. 
CHAPTER 2: qPCR Primer Design for Hydrothermal Vent Colonizing Archaeal Lineages

Abstract

In the last decade, technological advances in high throughput sequencing have enhanced our ability to analyze complex microbial ecosystems, such as those found at deep-sea hydrothermal vents. However the universal primers utilized in these analyses often result in asymmetric amplification across taxa. Real-time quantitative PCR (qPCR) allows for the quantification of target DNA based on a standard curve from known quantities of target DNA. qPCR assays with taxon specific primers avoid problems associated with sequencing and amplification biases by universal primers by directly assessing the original gDNA rather than amplified PCR product. However, primer sets and cycling conditions developed in earlier studies often are not optimized for qPCR, or do not target newly discovered organisms. In this study I report the development of novel qPCR primers that target several important archaeal groups that inhabit hydrothermal vent deposits: the order Thermococcales, genera Archaeoglobus and Ignicoccus, and finally, members from the purported phylum Nanoarchaeota. Primer specificity was validated by mock archaeal community analyses, melt curve analyses, and traditional Sanger sequencing of environmental samples. 


\section{Introduction}

The domain Archaea is the most recently characterized, and the least understood of all the domains of life (Woese et al., 1990). One of the reasons Archaea remains understudied is because many groups tend to inhabit extreme environments that are difficult to sample. High temperature environments such as hydrothermal vents are seemingly inhospitable, yet harbor some of the most biologically productive areas on earth. In deep-sea hydrothermal vent ecosystems, the interface where seawater and hot hydrothermal fluid meet houses a diverse microbiological community. Archaea are a major component of this biological community and can be up to $50 \%$ of the total microbial assemblage (Harmesen et al., 1997; Nercessian et al., 2003). The global distribution and ephemeral nature of hydrothermal vents have enabled the immense evolutionary diversification of thermophilic Archaea (Lasa, 1993).

At the seawater-hydrothermal fluid interface geochemical gradients create numerous microhabitats comprised of distinct energy sources that can be exploited by various groups of Archaea. The Archaea that exploit the micro-niches possess a variety of physiological capabilities; from chemolithoautrophs to chemoorganotrophs and aerobes to anerobes, and can also survive a range in $\mathrm{pH}$ and temperature. Three archaeal groups that represent this physiologic diversity, and are also major vent-colonizing Archaea are the order Thermococcales, genus Archaeoglobus, and methanogens (Huber and Holden, 2008). In contrast to these well-studied archaeal groups, little is known about the ecological interactions of the Nanoarchaeota and Ignicoccus at hydrothermal vents.

There are still major gaps in our understanding of archaeal community 
composition at deep-sea hydrothermal vents that are in part driven by inconsistencies and biases of molecular approaches used to quantify phylogenetic and metabolic diversity (Suzuki et al., 1997; Buchan et al., 2005).

Microbial ecologists have historically utilized 16S rRNA gene cloning to explore species composition of complex microbial communities. However, 16S rRNA gene clone libraries are not consistent in comparison to natural microbial communities, and often exclude key lineages due to kinetic binding differences across all taxa (Suzuki et al., 1997; Buchan et al., 2005). Cloning and sequencing is an inefficient process and reproducibility of the species composition is particularly problematic and may require more than 10,000 reactions in particularly diverse samples (Narang and Dunbar, 2004). The burgeoning technology of Next Generation barcoded pyrosequencing overcomes the clone library limitation of sequencing depth by amplifying and sequencing up to tens of thousands of short $16 \mathrm{~S}$ rRNA gene reads from a single sample.

Although next generation sequencing has the potential to revolutionize the study of microbial ecosystems, there are a few biases associated with this technology that may result in non-representative datasets. Microbial community diversity analyses of short rRNA gene reads are prone to errors with regards to the methodological and computational steps taken and reduce the ability to get a more accurate representation of the microbial community (Polz and Cavanaugh, 1998; Hong et al., 2009; Engelbrektson et al., 2010; Huse et al., 2010; Haas et al., 2011). The read abundance of barcoded pyrosequencing can also be non-representative due to several systematic biases related to the extraction procedure, amplification, and sequencing (Amend, et al. 2010). In addition, read abundance of barcoded pyrosequencing cannot infer quantitative 
abundance, but can only measure proportional read abundance of a given taxon to other organisms.

Of the various $16 \mathrm{~S}$ rRNA gene primers that are used for barcoded pyrosequencing, many are characteristically prone to inconsistencies in taxonomic coverage and result in non-symmetric datasets between primers (Shakya et al., 2013). Shakya et al. (2013) found that from mock archaeal communities using the V4 archaeal primers, the Archaeoglobales was dramatically underrepresented with greater than tenfold underestimation of the total expected proportional abundance.

In contrast, real time qPCR allows for the quantification of a specific taxa based on a standard curve from known quantities of target DNA (Livak, 2001). Quantification with qPCR avoids problems associated with sequencing biases and amplification by universal primers by directly assessing the genomic community. However, the accuracy of qPCR assays are dependent upon the specificity of the applied primer sets. In the last 20 years, there has been a dramatic increase in the number of published universal and taxon specific primers (Elwood et al., 1985; DasSarma and Fleischmann, 1995; Reysenbach and Pace, 1995; Watanabe et al., 2001; Kolganova et al., 2002; Baker et al., 2003; Nercessian, et al., 2004). Accompanying this rise in published primers has been an exponential increase in the number of $16 \mathrm{~S}$ rRNA gene sequences deposited into public databases (Benson et al., 2010). Due to the continuous discovery of novel sequences, many previously published primer sets were designed without new sequences and are unable to successfully target newly discovered organisms. Also, primers for qPCR often require much more stringent conditions with regards to GC content, melting temperature, and amplicon size than conventional PCR amplification (Taylor et al., 
2010). As a result previously published primer sets often need to be re-optimized or completely redesigned.

Unlike the Thermococcales and the Archaeoglobus, the methanogens have a well established qPCR primer set that is widely used for methanogen detection (Lueders et al., 2001; Luton et al., 2002). The qPCR primer set targets the $m c r A$ gene that codes for the $\alpha$-subunit of methyl coenzyme M (methyl-CoM) reductase that is necessary for the final step in methanogenesis and has close phylogenetic congruency to 16S rRNA gene methanogen phylogenies (Luton et al., 2002). At the time of publication the $m c r A$ qPCR primers were able to recover all five recognized orders of methanogens (Methanopyrales, Methanobacteriales, Methanococcales, Methanomicrobiales, Methanosarcinales) (Luton et al., 2002). Local alignments also indicate the proposed order of the Methanoplasmatales has 1 base change to the mcrA qPCR primers developed by Luton et al. (2002). However the primers do have several mismatches to one of the most recently documented sister groups of the Methanocellales. The $\mathrm{mcrA}$ primers have several advantages over 16S rRNA gene primers for methanogen detection, as the specificity of the $m c r A$ gene is limited to methanogens and methane oxidizers and the breadth of the primer set across the methanogenic orders may recover more novel sequences, and as a result create a more representative reconstruction of the methanogen community (Luton et al., 2002).

In this study we report the development of qPCR primers that target the Thermococcales, Archaeoglobus, Ignicoccus, along with the marine Nanoarchaeota. These novel primers were designed based on a comprehensive survey of the published databases (February 2012), and unpublished archaeal 16S rRNA genes. The specificity 
of the primers were validated by both mock archaeal community analyses and sequencing of environmental gDNA vent deposit samples.

\section{Materials and Methods}

qPCR Primer Design

qPCR primers were designed for the Archaoeglobus, Thermococcales, Ignicoccus, and marine Nanoarchaeota using 16S rRNA gene sequences obtained from published databases (SILVA and RDP) from February, 2012 and unpublished sequences of the marine and terrestrial Nanoarchaeota to assure maximum specificity, sensitivity, and efficiency. The primers were designed under the following guidelines: primer length no less than $15 \mathrm{bp}$ and no greater than $30(15<\mathrm{x}<30)$, melting temperature $\sim 60^{\circ} \mathrm{C}$, GC content approximately 50\%, amplicon size less than $300 \mathrm{bp}$, and selfcomplimentary and heterodimer strands were avoided (Taylor et al., 2010). Target 16S rRNA gene sequences were aligned in MEGA5 and cross-referenced against the RDP database using the RDP BLAST program (Cole et al., 2007; Tamura et al., 2011).

\section{Conventional PCR}

Conventional PCR with the designed 16S rRNA gene primers using goTaq PCR mix (Promega, Fitchburg, WI) $(50 \mu 1$ reaction) were conducted to determine if the primers resulted in the desired amplicon size. The PCR thermal cycling conditions were as follows: $5 \mathrm{~min}$ at $94^{\circ} \mathrm{C}, 35$ cycles of $30 \mathrm{~s}$ at $94^{\circ} \mathrm{C}, 30 \mathrm{~s}$ at $\sim 60^{\circ} \mathrm{C}$ and $30 \mathrm{~s}$ at $72^{\circ} \mathrm{C}$, and a final extension of $7 \mathrm{~min}$ at $72^{\circ} \mathrm{C}$. The resultant PCR product was visualized by gel 
electrophoresis. The annealing temperature of each of the designed primers were then optimized by running a PCR with an annealing thermal gradient from $55-65^{\circ} \mathrm{C}$ with both target and non-target archaeal gDNA. Specificity of the designed primers were tested by running PCR assays of non-target archaeal gDNA as negative controls (Archaeoglobus lulqidus, Pyrococcus horikoshii, Ignicoccus hospitalis, and Nanoarchaeum equitans). The designed primers were then used on an environmental sample from the East Pacific Rise (3985-2-24) and the resultant PCR products were sequenced for specificity.

\section{Plasmid Standards}

Plasmid standards for qPCR were prepared by amplification of gDNA provided by the Podar Lab (Oak Ridge National Laboratory) from enrichment cultures of $A$. lulqidus, P. horikoshii, I. hospitalis, and $N$. equitans. The sequences were amplified by conventional PCR using universal 16S rRNA gene primers 4F/1492R and Nanoarchaeota published primers $7 \mathrm{mcF} / 1511 \mathrm{mcR}$ (Hohn et al., 2002). The PCR product was cleaned using a QIAquick PCR Purification Kit and inserted into Escherichia coli plasmids following standard TOPO protocols (Qiagen, Venlo, Netherlands; Invitrogen, Carslbad, CA). Clones were grown in TYPGN + kanamycin broth overnight at $37^{\circ} \mathrm{C}$ (Sambrock \& Russell, 2001). Purification of the DNA was completed by alkaline lysis (Sambrock \& Russell, 2001). The purified plasmid DNA was quantified by Quant-iT PicoGreen mini kit and a microplate reader (BioTek, Winooski, Vermont; Carlsbad, CA). DNA was diluted in PCR water to create a standard dilution series from $1 \times 10^{8}$ to $1 \times 10^{0}$ copies/ $\mu 1$ for qPCR to ensure broad dynamic range of potential plasmid concentrations. 


\section{Quantitative PCR}

Genomic DNA from environmental samples was amplified using the primers designed in this study that target the 16S rRNA gene, using the Quantitect SYBR green PCR kit (Qiagen, Inc., Valencia, CA). qPCR was conducted according to manufacturer's protocols with a $0.8 \mu \mathrm{M}$ final primer concentration. The qPCR thermal cycling protocols were run according to Reysenbach et al. (2006). To test for contamination and/or primer dimer, a melt curve of the PCR products from $55-95^{\circ} \mathrm{C}$ was performed after the final extension to verify the peak of the 16S rRNA gene amplicons. If multiple melting peaks occur there is high probability that the primers are non-specific to the target sequence, or that primer dimers formed (Ferriera, 2006). Initial 16S rRNA gene concentrations were determined based on the mean cycle threshold of the duplicate samples using the Opticon Monitor software analyses. Amplification and quantification of the mcrA functional gene was conducted following the methods outlined in Wilson and colleagues (2010).

\section{Results and Discussion}

Primer Sequence Alignment Analysis

\section{$\underline{\text { Thermococcales }}$}

Order-level forward and reverse primers 993F_Thermo and 1063R_Thermo, were designed to target the Thermococcales (Table 2.1). The less specific forward primer (993F_Thermo) had exact oligonuctotide matches to 442 Thermococcales sequences and twenty-one non-target sequences within the Thermoprotei (Table 2.2) (Cole et al., 2009). The 1063R_Thermo primer matches 31 species of Thermococcus, 


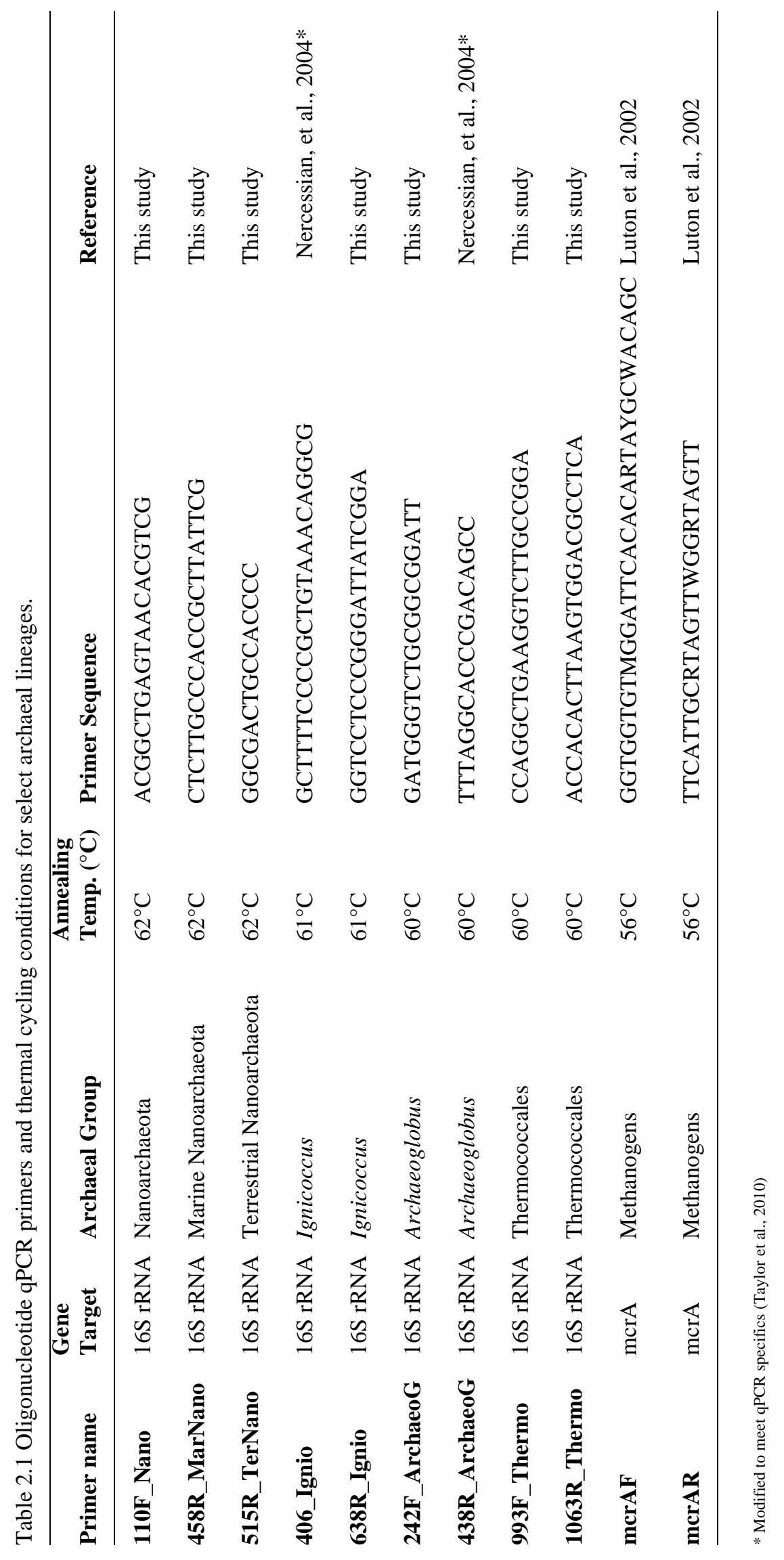


Table 2.2 Oligonucleotide archaeal qPCR primer conditions and taxonomic coverage.

\begin{tabular}{llllll}
\hline Primer Name & GC \% & $\mathbf{T m}^{\circ} \mathbf{C}$ & $\begin{array}{l}\text { Hairpin } \\
\mathbf{T m}^{\circ} \mathbf{C}\end{array}$ & $\begin{array}{l}\text { Target } \\
\text { RDP } \\
\text { Sequences }\end{array}$ & $\begin{array}{l}\text { non-Target } \\
\text { RDP } \\
\text { Sequences }\end{array}$ \\
\hline \hline 110F_Nano & 57.9 & 57.3 & 29.8 & 145 & 5 \\
458R_MarNano & 57.1 & 58.5 & 35.4 & 4 & 0 \\
406_Ignio & 58.3 & 62.9 & 44 & 18 & 6 \\
638R_Ignio & 61.9 & 60.5 & 47.3 & 18 & 262 \\
242F_ArchaeoG & 63.2 & 60.6 & 9.2 & 236 & 590 \\
438R_ArchaeoG & 61.1 & 57.9 & 43.6 & 209 & 0 \\
993F_Thermo & 63.6 & 63.8 & 35.1 & 442 & 21 \\
1063R_Thermo & 52.2 & 60.4 & 57.6 & 450 & 0 \\
\hline
\end{tabular}


seven species of Pyrococcus, and two species of Paleococcus (Table 2.3). The primer sequence contained significant mismatches to closely related Euryarchaeota sequences at the positions 1122, and 1130-1134 (AF297529; AF025822; AF513710).

\section{$\underline{\text { Archaeoglobus }}$}

Genus level forward and reverse primers 242F_ArchaeoG and 438R_ArchaeoG for the Archaeoglobus, were modified from Nercessian et al. (2004) to meet qPCR primer design specifics (Table 2.1). The less specific forward primer (242F_ArchaeoG) matches 589 non-Archaeoglobus sequences including five sequences from Ferroglobus and eighteen from Geoglobus based on the RDP database (Table 2.2) (Table 2.3)(Cole et al., 2009). The more specific reverse primer (438R_ArchaeoG) matches 209 Archaeoglobus sequences from RDP and contains major base changes to the ferric iron reducing Ferroglobus and Geoglobus genera within the Archaeoglobacae at the 444 position (X99565; FJ216404).

\section{$\underline{\text { Nanoarchaeota }}$}

For the proposed Nanoarchaeota phylum, primers that target the marine clade were developed (Table 2.1). The less specific forward primer (110F_Nano) matches 144 published Nanoarchaeota sequences and five bacterial samples based on the RDP database (Table 2.2) (Cole et al., 2009). The specific marine reverse primer (458R_MarNano) matches N. equitans and three published and 24 unpublished marine Nanoarchaeota 16S rRNA sequences (Table 2.2) (Huber et al., 2002; Podar, unpublished). The primer has major mismatches to non-Nanoarchaeota sequences at sites 494, 515, and 516 (AF297529; AF025822; AF513710; X99565; FJ216404; AJ318042; AB010957; AB029339; M35966; Z70250). 
Table 2.3 Cultured representatives targeted by the designed or optimized primers.

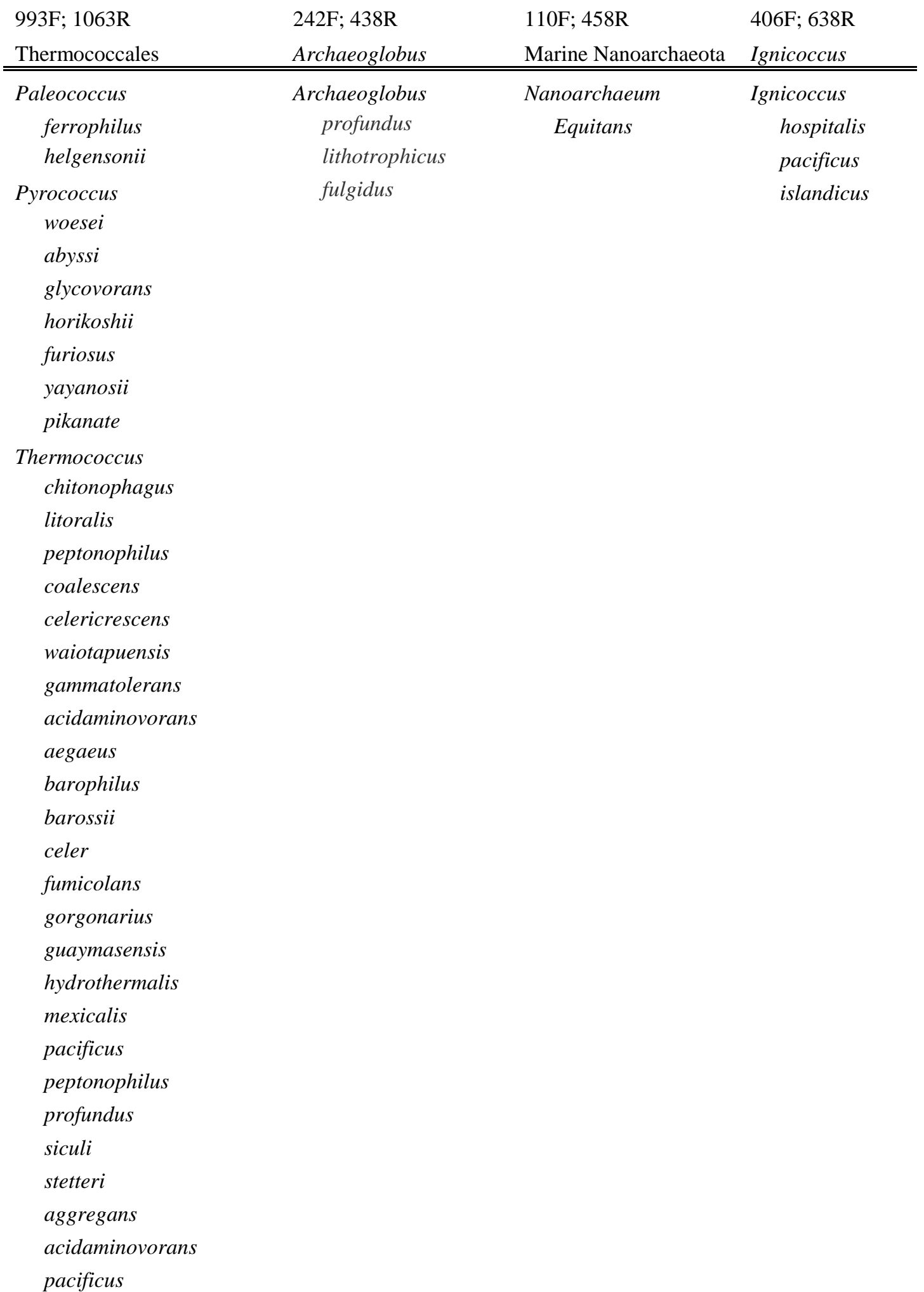


waimanguensis

aegaeus

sibiricus

alcaliphilus

onnurineus

litoralis 


\section{Ignicoccus}

Genus level forward and reverse primers 406F_Ignio and 638R_Ignio for the Ignicoccus were modified from Nercessian et al. (2004) to meet qPCR primer design specifics (Table 2.1). The less specific forward primer (406F_Ignio) matches the three Ignicoccus isolates in addition to $4616 \mathrm{~S}$ rRNA gene Ignicoccus sequences from the RDP database (X99562; AJ271794; CP000816) (Table 2.3) (Cole et al., 2009). The more specific reverse primer (638R_Ignio) matches all three species of Ignicoccus and a total of 18 Ignicoccus sequences and has significant base changes from other Desulfurococcaceae at sites 481 and 486 (AF250331; X99555).

In order to further evaluate the coverage of the designed Ignicoccus primers the reverse primer was aligned to sequences that had a 95\% Max ID to I. hospitalis from the barcoded pyrosequenced samples from the Mid-Atlantic Ridge, Eastern Lau Spreading Center, and Guaymas Basin (Flores et al., 2011; Flores et al., 2012a; Reysenbach, unpublished). The reverse primer aligned with all sequences from Lucky Strike and $81 \%$ of sequences from the ELSC (Fig. 2.1). The primer had mismatches to the samples from Rainbow and Guaymas Basin. However, the samples from Rainbow and Guaymas did not have local alignments that were most similar to Ignicoccus spp. From these two sites the most similar sequences were most closely related to Staphlyothermus hellenicus.

\section{Annealing temperature verification}

The specific annealing temperature of each of the qPCR primer sets was verified by running a conventional PCR with an annealing temperature gradient with target and 


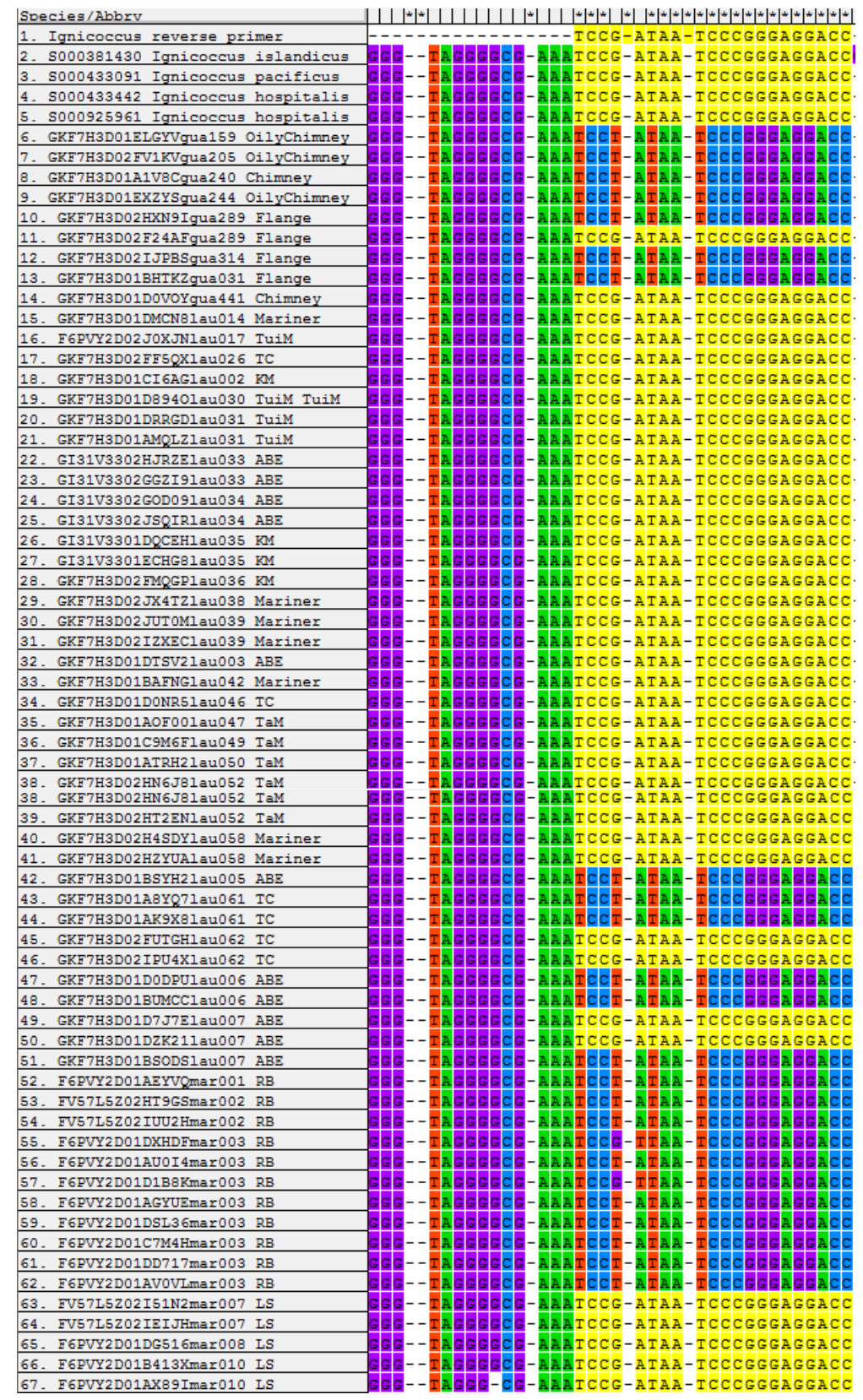

Figure 2.1. Primer alignment of partial Ignicoccus spp.16S rRNA gene sequences from barcoded pyrosequencing from Flores et al., 2011, Flores et al., 2012a, and Reysenbach, unpublished. 
non-target Archaea. The annealing temperature of each primer set was chosen based on the closest temperature to $60^{\circ} \mathrm{C}$ that did not amplify with non-specific gDNA (Table 2.1). The marine and terrestrial Nanoarchaeota sequences had the highest annealing temperature of $62^{\circ} \mathrm{C}$, while the Archaeoglobus and Thermococcales primer sets were found to be $60^{\circ} \mathrm{C}($ Fig $2.2 ; 2.3 ; 2.4 ; 2.5)$.

\section{Primer validation}

Conventional PCR was performed to verify the proper amplicon size for each primer set. Of the qPCR primer sets developed, mock archaeal communities with and without the gDNA target of interest were constructed. For all the primer sets tested there was no amplification of archaeal mock communities without the target DNA (Fig $2.6 ; 2.7 ; 2.8 ; 2.9)$. For the Nanoarchaeota primer sets two less specific forward primers were evaluated $(110 \mathrm{~F}$ and $381 \mathrm{~F})$. The primer set with $381 \mathrm{~F}$ had a non-specific faint amplicon larger than the targeted amplicon size that was not present in the positive control or the $110 \mathrm{~F}$ primer set (Fig 2.9). Due to the non-specific amplification from the $381 \mathrm{~F}$ primer, the $110 \mathrm{~F}$ primer set was further evaluated for qPCR assays, even though the amplicon size is greater than what is recommended for qPCR assays for highest efficiency (Taylor et al., 2010). gDNA mineral sulfide deposit sample from the EPR (sample no. 3985-2-24) was then used to amplify each of the primer pairs using conventional PCR. The resultant PCR products were sequenced, and for all the primer sets returned sequences with the highest MAX ID for sequences within each selected taxa (Table 2.4). All the primer sets had only one single major melt peak between 85 $90^{\circ} \mathrm{C}$, further verifying the specificity of the primer sets (Fig 2.10). Environmental 


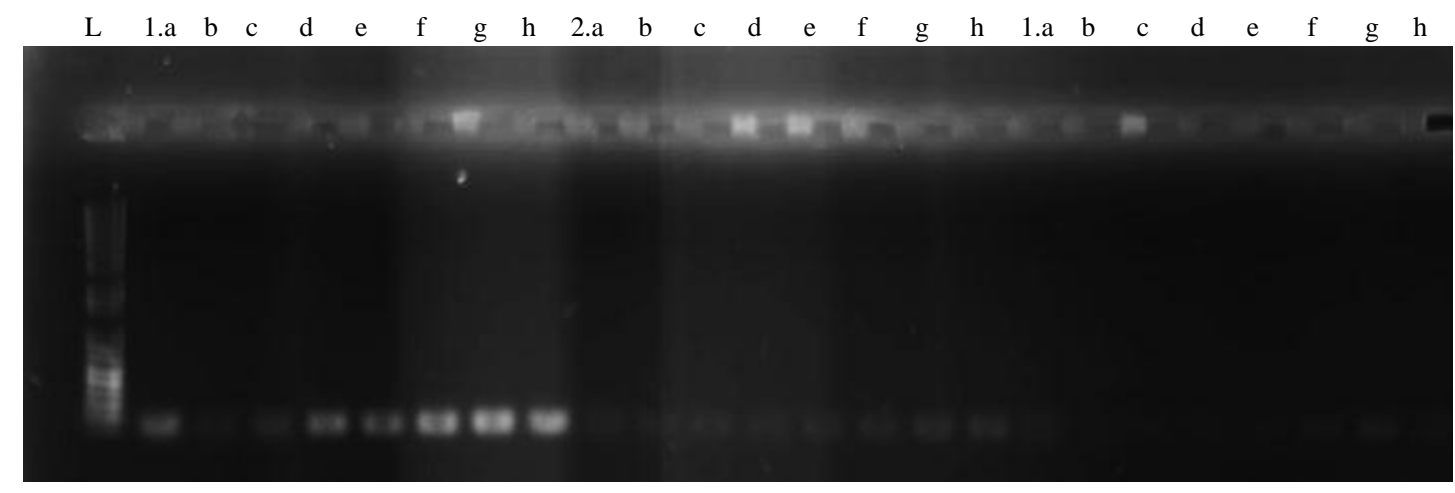

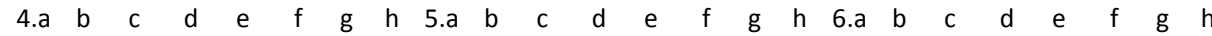

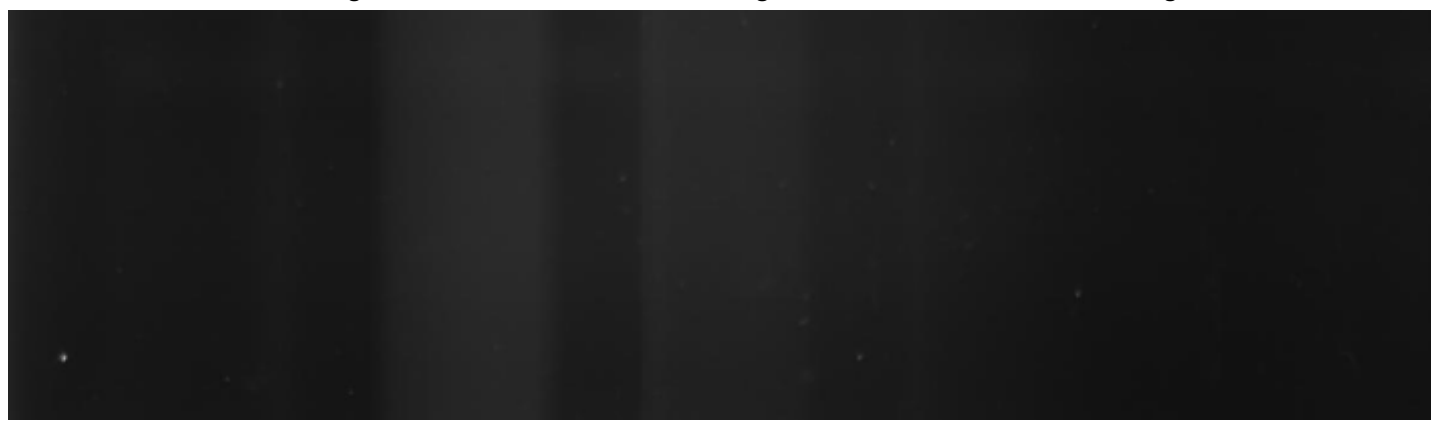

Figure 2.2. Conventional PCR annealing thermal gradient with Thermococcales primers. Sample 1) P. horikoshii 2) A. luliquidus 3) M. jannaschii 4) A. boonei 5) I. hospitalis. 6) no template. Thermal gradient $\left({ }^{\circ} \mathrm{C}\right)$ a) 64 , b) 63.3 , c) 61.8 , d) 59.8 , e) 57.4 , f) 55.3 , g) 53.8 h) 53.0 . 

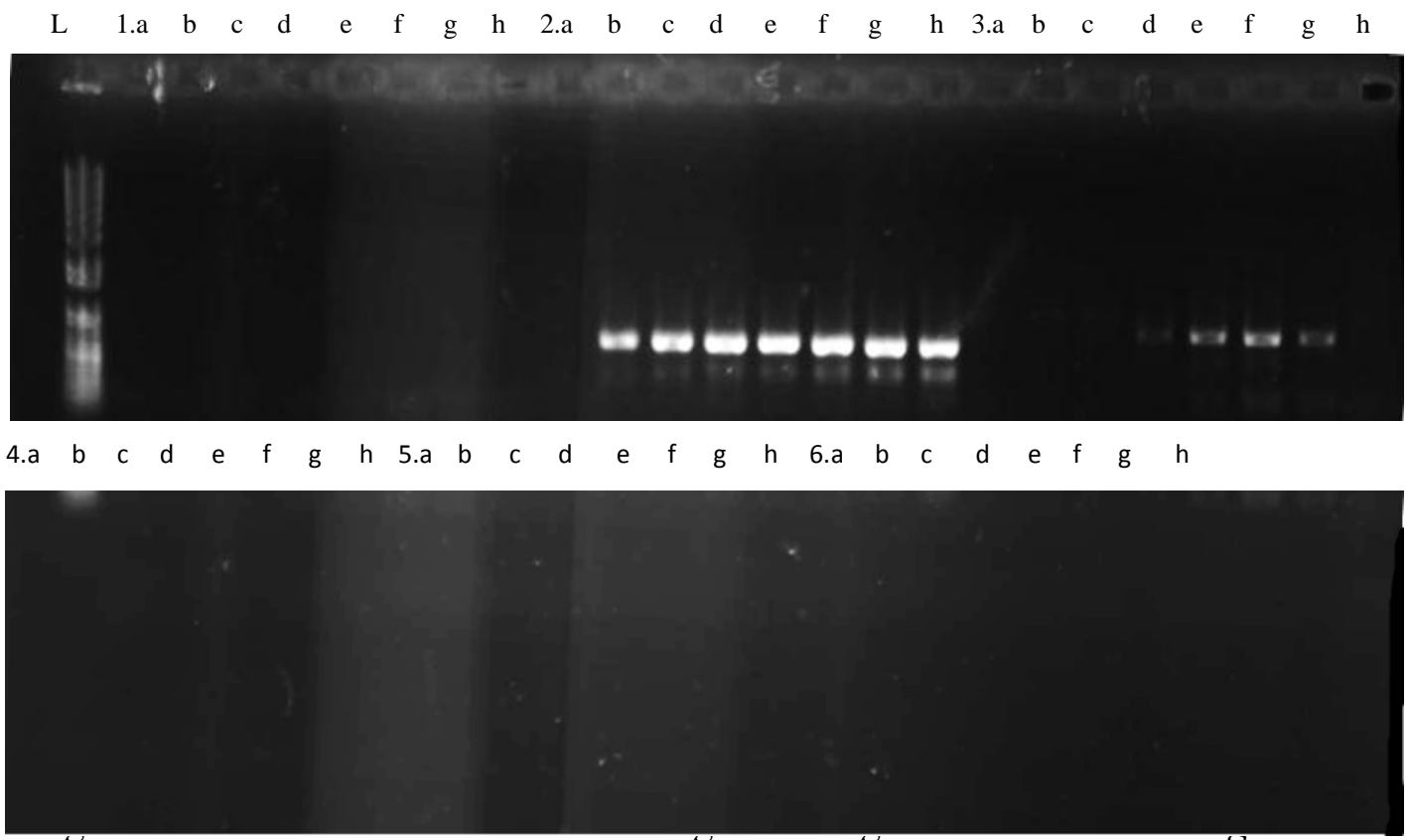

primers. Sample 1) P. horikoshii 2) A. lulqidus 3) M. jannaschii 4) A. boonei 5) I. hospitalis 6) no template. Thermal gradient $\left({ }^{\circ} \mathrm{C}\right)$ a) 64 , b) 63.3 , c) 61.8 , d) 59.8 , e) 57.4 , f) 55.3 , g) 53.8 h) 53.0. 


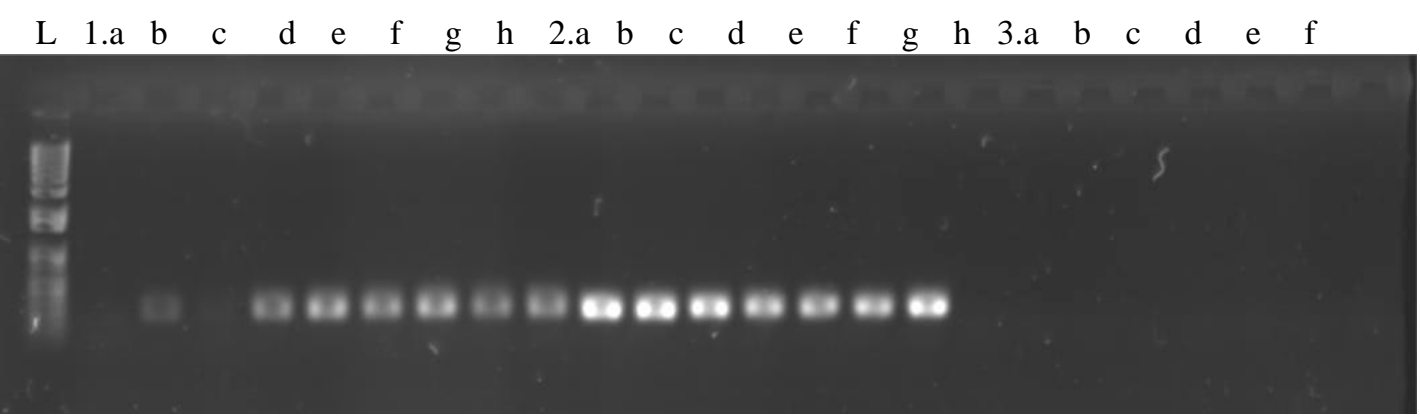

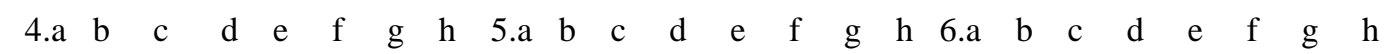

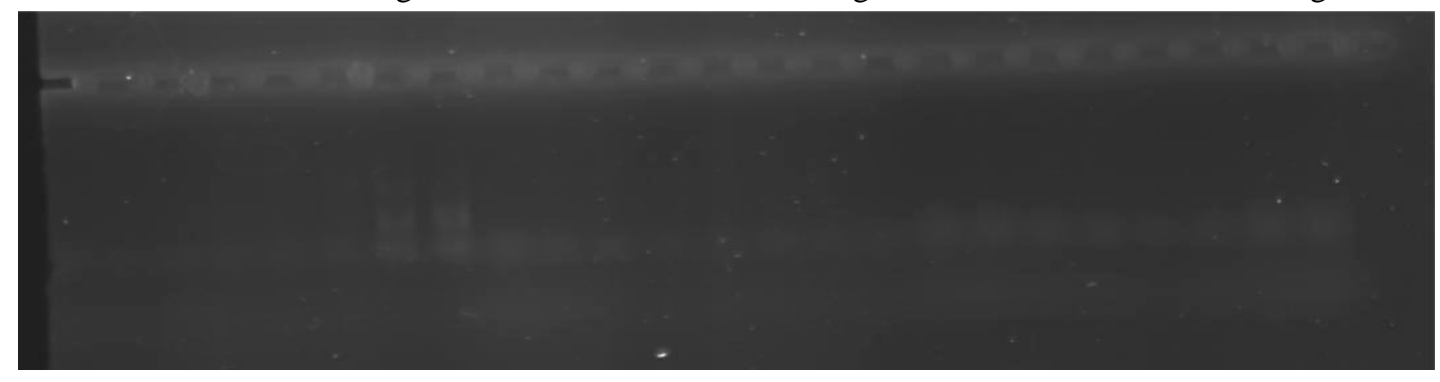

Figure 2.4. Conventional PCR annealing thermal gradient with Ignicoccus primers. Sample 1) I. hospitalis 2) I. hospitalis + N. equitans 3) $2 / 15 / 12$ "Nano" culture 4) P. horikoshii 5) A. boonei. 6) No template. Thermal gradient $\left({ }^{\circ} \mathrm{C}\right)$ a) 64 , b) 63.3, c) 61.8 , d) 59.8 , e) 57.4 , f) 55.3 , g) 53.8 h) 53.0. 

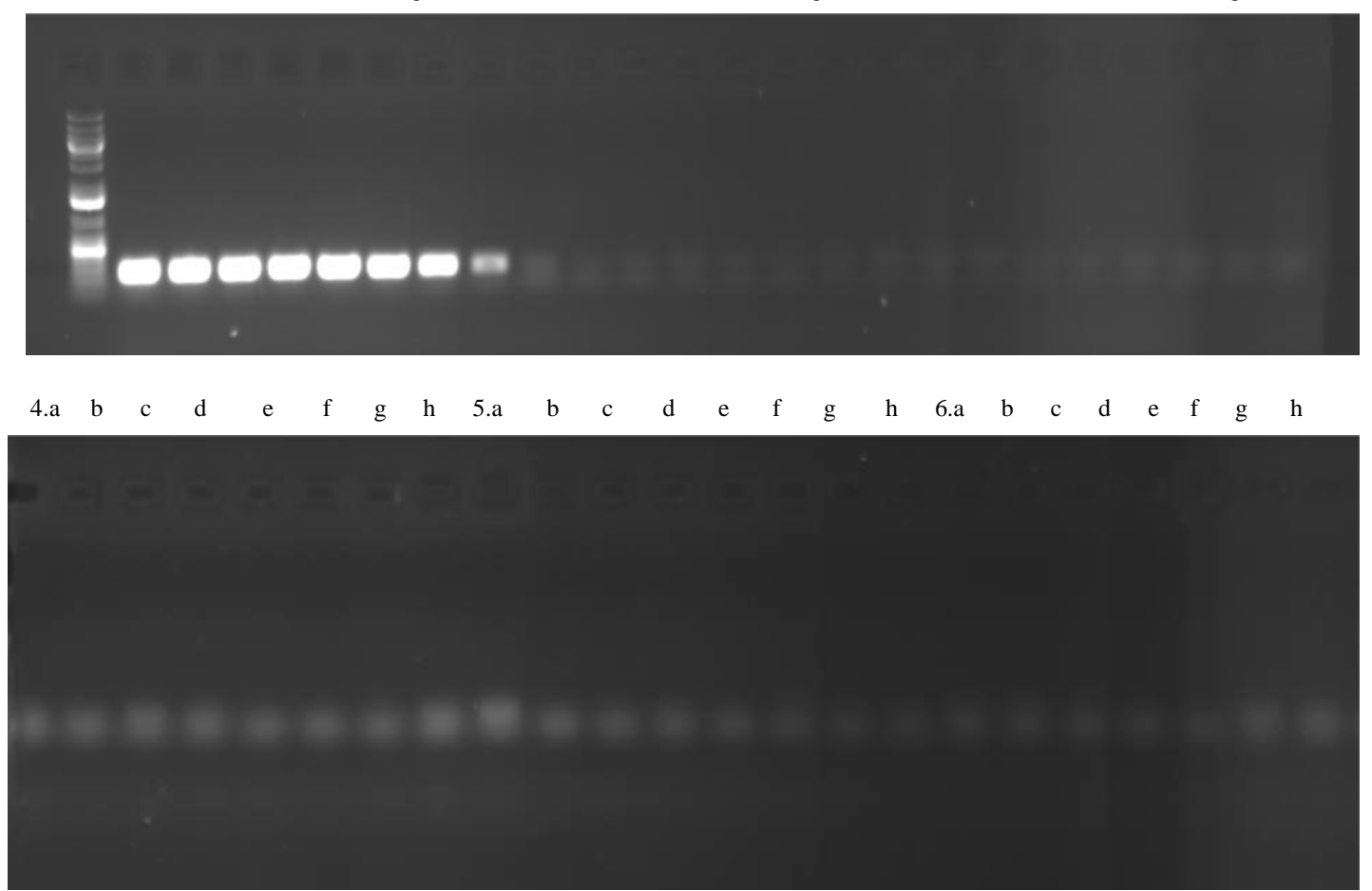

Figure 2.5. Conventional PCR annealing thermal gradient with marine Nanoarchaeota primers. Sample 1) N. equitans 2) P. horikoshii 3) M. jannaschii 4) A. boonei 5) P. aerophilium 6) no template. Thermal gradient $\left({ }^{\circ} \mathrm{C}\right)$ a) 64 , b) 63.3 , c) 61.8 , d) 59.8 , e) 57.4 , f) 55.3 , g) 53.8 h) 53.0. 


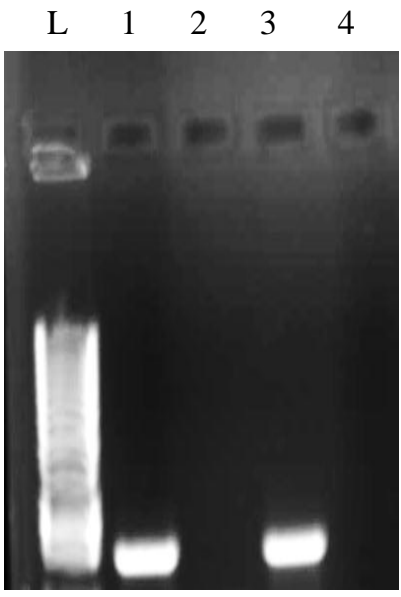

Thermococcales Mock Community

1. Mock w/ Thermococcales (RGD 051)

2. Mock w/o Thermococcales

3. + RGD 051

4. - no template

Figure 2.6. Thermococcales primer mock archaeal community analysis. Mock community: P. aerophilium, A. luliquidus, M. jannasii, I. hospitalis. L, Ladder. 


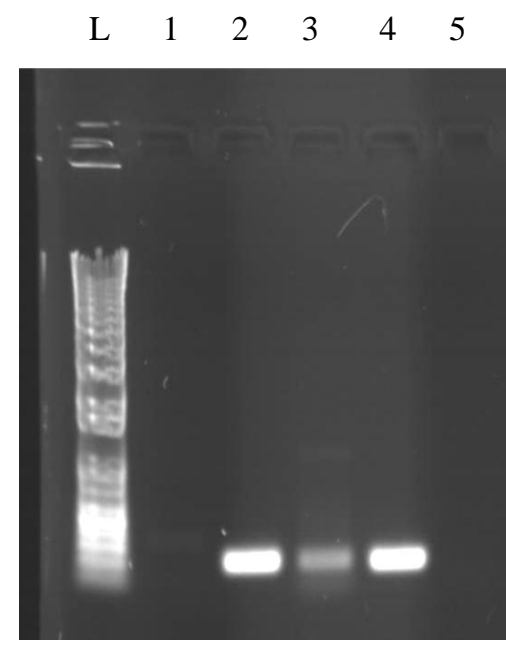

1. Mock w/o Archaeoglobus

2. Mock w/ A. lulqidus

3. 3985-2-24

4. + A. lulqidus

5. - no template

Figure 2.7. Archaeoglobus primer mock archaeal community. Mock community: P. aerophilium, A. lulqidus, M. jannasii, I. hospitalis, P. horikoshi. L, Ladder. 


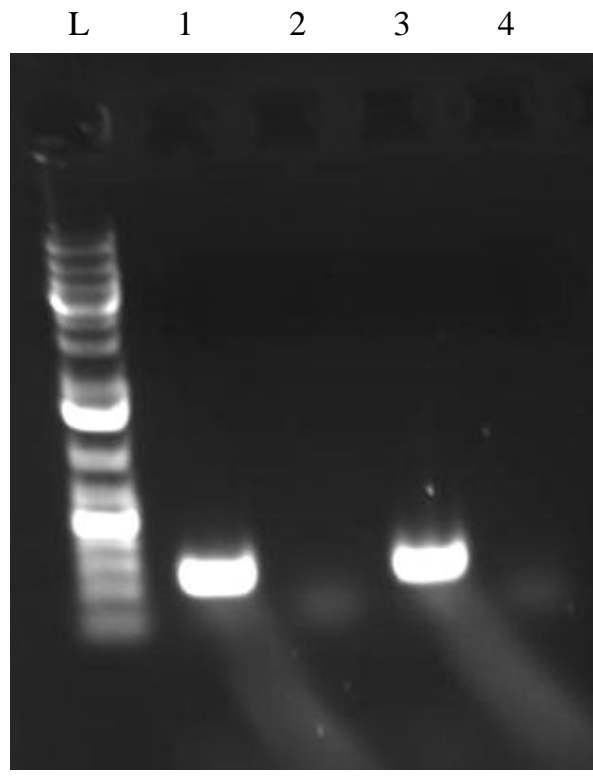

1. Mock w/ I. hospitalis

2. Mock w/o I. hospitalis

3. + I. hospitalis

4. - no template

Figure 2.8. Ignicoccus primer mock archaeal community. Mock community: $P$. aerophilium, A. lulqidus, M. jannasii, A. boonei, P. horikoshi. L, Ladder. 


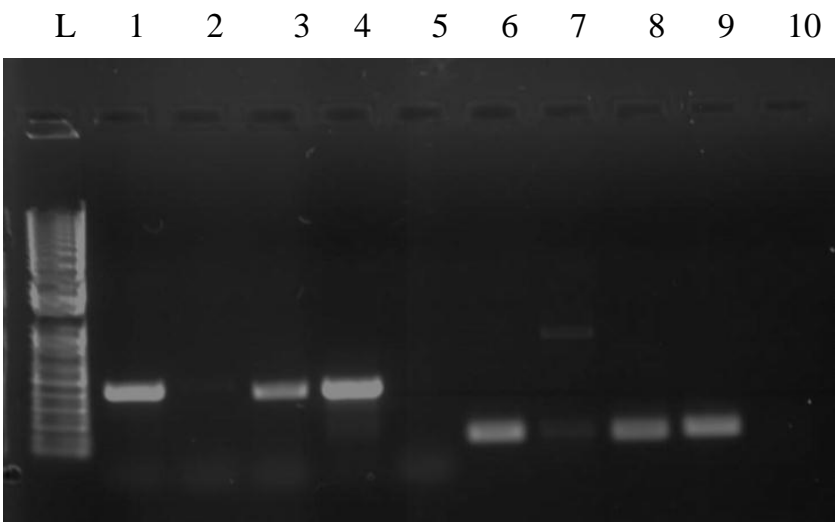

1. Mock w/ nano $110 / 458$

2. Mock w/o nano $110 / 458$

3. 3985-2-24

4. + N. equtians

$5 .-$

6. Mock w/ N. equitans 381/458

7. Mock w/o N. equitans 381/458

8. 3985-2-24

9. + N. equitans

10. - no template

Figure 2.9. Marine Nanoarchaeota primer mock archaeal community analysis of two primer sets 110/458 and 381/458. Mock community: P. aerophilium, A. lulqidus, $M$. jannasii, I. hospitalis, P. horikoshi. L, Ladder. 
Table 2.4. Sanger sequenced PCR products of designed primer sets.

\begin{tabular}{lllll}
\hline Primer Set & Target & Sample & Closest Representative & ID \% \\
\hline \hline 993F; 1063R & Thermococcales & $3985-2-24$ & T. atlanticus & 94.5 \\
242F; 438R & Archaeoglobus spp. & $3985-2-24$ & A. veneficus & 99 \\
406F; 638R & Ignicoccus spp. & $3985-2-24$ & I. pacificus & 99 \\
110F; 458R & Marine Nanoarchaeota & $3985-2-24$ & N. equitans Kin4-M & 95
\end{tabular}



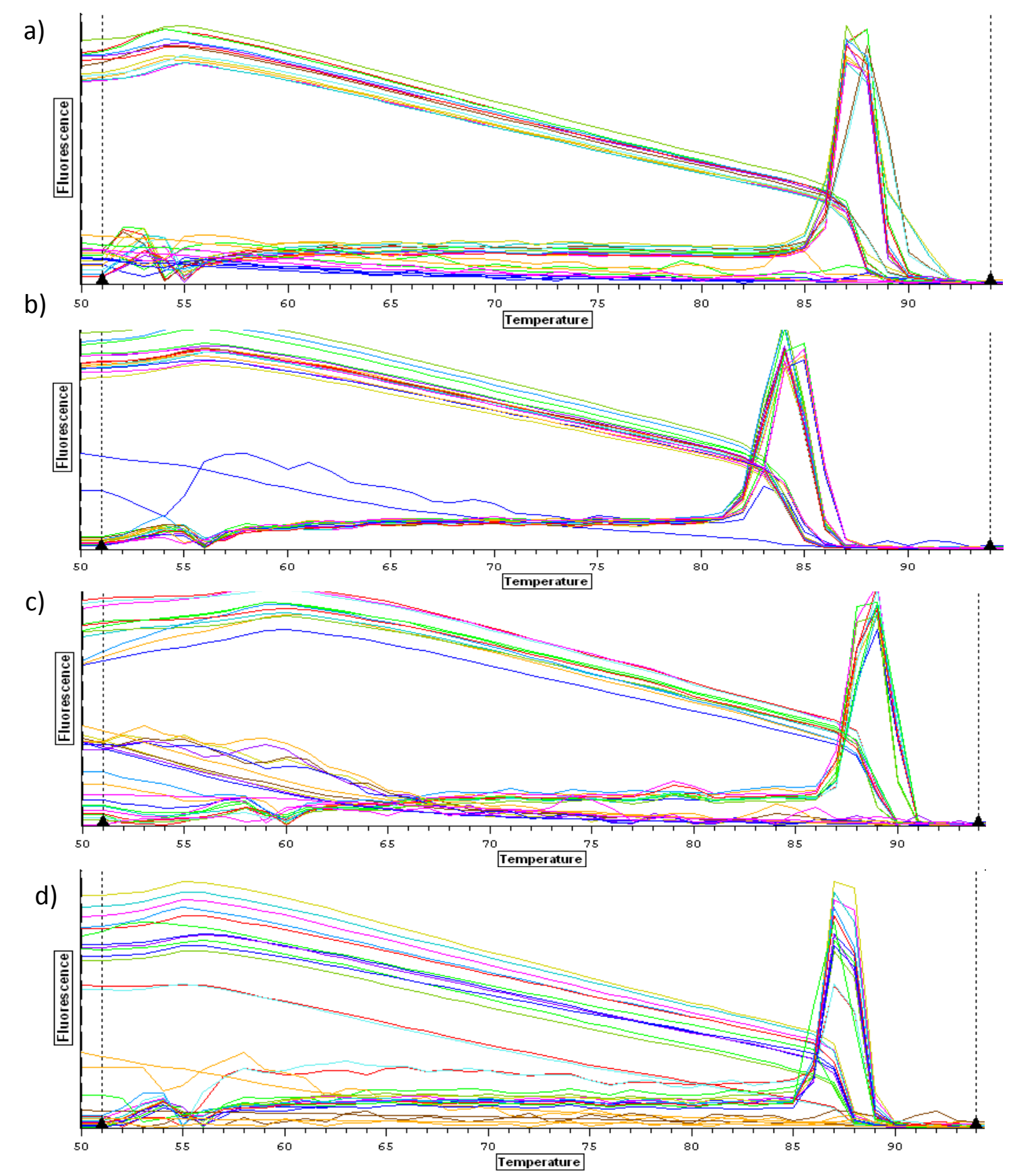

Figure 2.10. Melt curve analysis from environmental samples of the four designed primer sets. a) Thermococcales; b) Archaeoglobus; c) Nanoarchaeota; d) Ignicoccus. 
a)

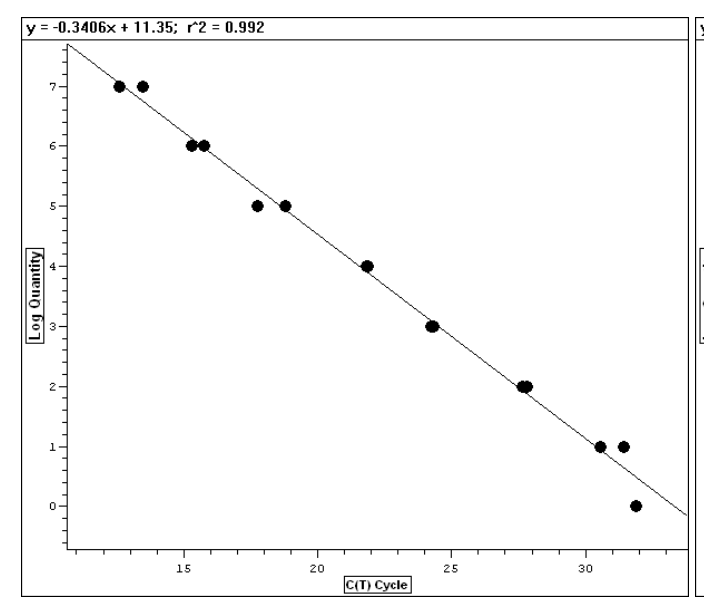

c)

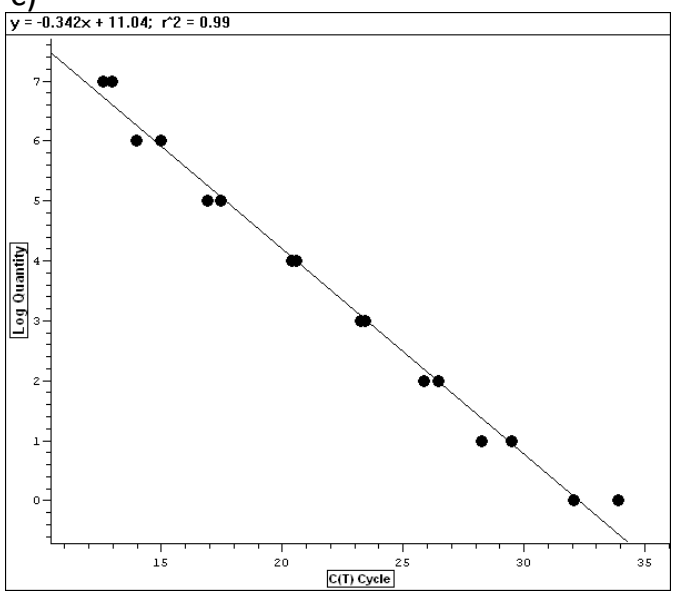

b)

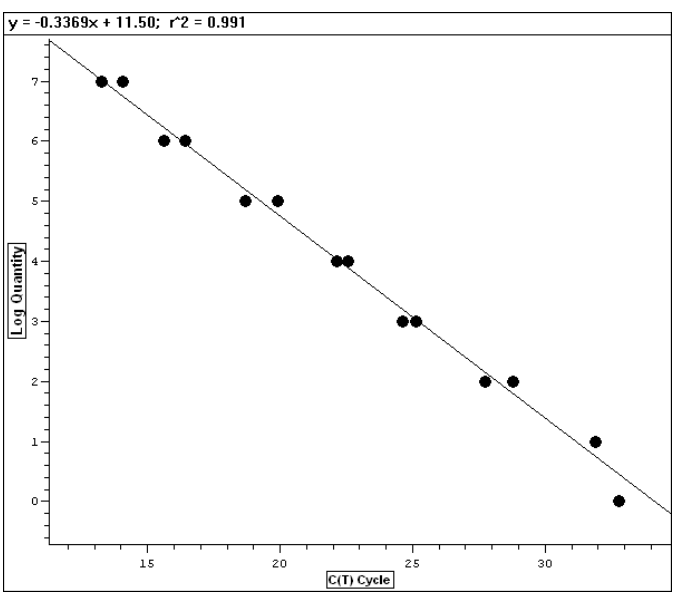

d)

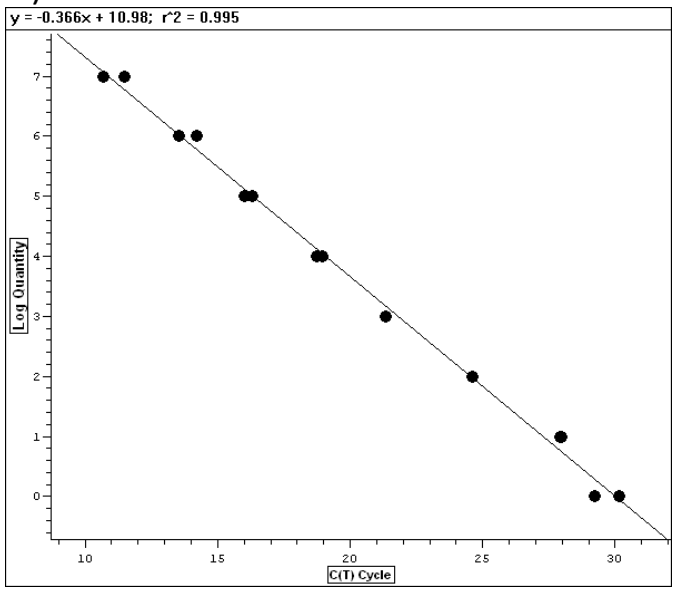

Figure 2.11. Standard curves from of the four designed primer sets. a) Thermococcales; b) Archaeoglobus; c) Nanoarchaeota; d) Ignicoccus. 
microbiological quantification using qPCR across multiple taxon-specific primer sets reduces the gross biases associated with universal primers, and can provide a much more accurate representation of the archaeal community structure (Polz and Cavanaugh, 1998; Suzuki and Giovanni, 1996; Wintzingerode et al., 1997 from Baker et al., 2003). Thus, the qPCR specific primers developed in this study that target the major and understudied groups within the archaeal biome of the Thermococcales, Archaeoglobus, Ignicoccus, and Nanoarchaeota can be used to elucidate archaeal community structure of highly diverse thermophilic communities.

\section{Primer Limitations}

There are several biases associated with primer design that may affect the specificity of the probes. The primers reported in this chapter were dependent upon the published 16S rRNA genes from RDP and unpublished sequences (Sogin et al., 2006). Environmental metagenomic analyses continue to uncover novel full length 16S rRNA genes from rare ecosystems that enhance our understanding of the taxonomic breadth of microbial groups, which then allow researchers to develop more specific primers for qPCR assays (Sogin et al., 2006). The coverage rate of each of the primers also varies due to the size of each phylum: the order specific Thermococcales primers have a lower coverage rate across the entire order due to its size ( $>40$ species), compared to the genus specific Ignicoccus primers that have a high coverage rate as only three species are currently characterized.

\section{Conclusions}


Achieving unbiased molecular analyses of environmental samples is of utmost importance when assessing microbial community structure of the major archaeal groups. Universal primers used for $16 \mathrm{~S}$ rRNA clone libraries and high throughput sequencing are inherently biased due to differences in kinetics and binding efficiencies across many different taxa, in addition to methodological and computational practices associated with high throughput sequencing (Polz and Cavanaugh, 1998; Brunk and Eis, 1998; Reysenbach and Pace, 1995; Suzuki and Giovanni, 1996). As a result, some molecular analyses are not representative of the true microbial community structure. 
CHAPTER 3: Abundance and Distribution of Major and Understudied Archaeal Lineages at Globally Distributed Deep-Sea Hydrothermal Vents

\begin{abstract}
Archaea that colonize deep-sea hydrothermal vent polymetallic sulfide deposits are phylogenetically and physiologically diverse. However, due to technological and sample limitations, the global archaeal inter-vent field patterns and the patterns between diverse sulfide deposit formations are still poorly understood. Of the archaeal lineages, the methanogens, Thermococcales and the Archaeoglobus often represent the dominant groups, while little is known about the ecological relationships of the much less abundant Nanoarchaeota and Ignicoccus spp. To investigate the global patterns of abundance and distribution of these archaeal groups, I used lineage specific and methanogen $m c r A$ functional gene primers for qPCR analysis to compare the archaeal community abundance from 54 samples across ten globally distributed and geochemically distinct vent fields. The archaeal community assemblage varied dramatically from hydrothermal vents with different vent host rocks along the MidAtlantic Ridge and Eastern Lau Spreading Center. In contrast, two vent fields in the East Pacific, $9^{\circ} \mathrm{N}$ on the EPR and Guaymas Basin that are basalt and basalt-sediment hosted respectively were found to have similar community composition. The differences in community composition between the vent fields may be attributed to the metabolically available energy, as the hydrogen oxidizing archaeal groups were found in higher proportion in the ultramafic and fast spreading basalt vent fields that are more enriched in hydrogen. The lineage specific analyses of the Nanoarchaeota and
\end{abstract}


Ignicoccus spp. were found to have an inconsistent proportional relationship to one another. Nanoarchaeota were found in a higher proportion of the archaeal community at the ultramafic and fast spreading vent fields, and Ignicoccus was most prevalent at the ultra-slow spreading basalt and andesite hosted vent fields. Over the entire dataset there was also a proportional shift between the chimney and flange samples, with chemolithotrophic methanogens and Archaeoglobus more dominant on average in chimney samples compared to heterotrophic Thermococcales in the flange samples. The results from this study demonstrate that the archaeal population patterns are in part influenced by geochemical and geologic processes on a global scale, in addition to the more local influence of vent deposit structure. 


\section{Introduction}

Actively venting deep-sea hydrothermal vents are complex and dynamic ecosystems and represent one of the most physiochemically diverse ecosystems on Earth. These environments are characterized by steep physical and chemical gradients that can have temperature extremes in excess of $350^{\circ} \mathrm{C}$ over a $3 \mathrm{~cm}$ span (Takai et al., 2006). The chemical disequilibria between the vent fluid and the oxygenated seawater support a highly diverse and productive microbial ecosystem based around primary production by chemolithoautotrophic microorganisms that gain energy from geochemically derived compounds such as: $\mathrm{H}_{2}, \mathrm{CH}_{4}, \mathrm{H}_{2} \mathrm{~S}$, and $\mathrm{CO}_{2}(\mathrm{Rau}$ and Hedges, 1979; Rau, 1981; Jannasch and Mottl, 1985; Sarrazin and Juniper, 1999; Page et al., 2008).

The geochemical composition of metabolically important compounds in end member hydrothermal fluid can be highly variable between vent fields, and is substantially influenced by the host rock composition (mafic, ultramafic, and andesite) (Von Damm, 1995). Based on geochemical modeling, the dramatic variation in end member hydrogen concentrations, driven by host rock differences, are one of the key factors that influence the microbial diversity by driving available microbial processes (McCollom, 2007). As the primary source of energy at hydrothermal vents is the reduced vent fluid, the oxidation state of the hydrothermal fluid is a principle controller of the energetic requirements for vent colonizing microorganisms (McCollum and Shock, 1997).

Previous archaeal community structural analyses by Flores et al. (2011 \& 2012a) based on barcoded pyrosequencing of chimney deposit samples found that across 
multiple taxonomic levels some vent colonizing Archaea had a direct relationship to end member geochemistry along the Mid-Atlantic Ridge (MAR) and the Eastern Lau Spreading Center (ELSC). In particular, the proportion of methanogens, Archaeoglobus spp., and Thermococcales were found to vary dramatically from geochemically divergent vent fields. The local end member geochemical differences between vent fields that had a direct influence on these archaeal lineages were primarily attributed to differences in host vent rock and other largescale tectonic interactions (Charlou et al., 2011; Flores et al., 2011; Flores et al., 2012a). In addition, the understudied lineage of the Nanoarchaoeta, a monotypic lineage represented solely by the species, Nanoarchaeum equitans, was found to have an inconsistent proportional relationship, across vent fields with different host rocks to the genus of its only known marine host, Ignicoccus.

Besides host rock the accumulation of organic sediment at a minority of hydrothermal vent fields is also a fundamental factor that governs the end member fluid chemistry. The fluid-sediment interaction accelerates sulfide precipitation through diagenetic processes and thermocatalytic decomposition of organic sediment (Edmond et al., 1985). As a result the fluid composition has decreased concentration of metals, $\mathrm{CH}_{4}$, and is much more alkaline from the addition of ammonium (Edmond et al., 1985).

The type of sulfide deposit structure may also influence the availability of metabolically important chemicals as the deposit type can often alter the magnitude and direction of the vent fluid flow and mixing regime (Tivey et al., 2007). Chimneys are the main type of vent deposit structure that rise vertically and primarily exhaust fluid near the apex of the deposit (Tivey et al., 2007). However, some deposits contain 
overhanging flanges, further from the venting source that alter the mixing style of hydrothermal vent fluid by trapping pools of acidic fluid beneath them without mixing with the surrounding seawater (Tivey et al., 2007). As a result of the differences in vent fluid mixing styles and heterogeneity of end-member hydrothermal vent fluid across vent fields, the microbiological diversity and community structure is expected to be constrained (McCollom and Shock, 1997; McCollom, 2007).

Quantitative-PCR (qPCR) was used to verify and to expand onto the findings of Flores et al. (2011 \& 2012a) by using lineage specific primers that target the $16 \mathrm{~S}$ rRNA and the $m c r A$ functional genes of five major archaeal hyperthermophile groups (methanogens, Archaeoglobus, Thermococcales, Nanoarchaeota, and Ignicoccus). This study sought to accomplish this by assessing the global patterns of distribution, abundance, and biodiversity at ten geochemically diverse hydrothermal vent fields and distinct deposit structures from the: East Pacific Rise (EPR) $\left(9^{\circ} 039^{\prime} \mathrm{N}, 109^{\circ} 31^{\prime} \mathrm{W}\right)$, Eastern Lau Spreading Center (ELSC) $\left(176^{\circ} 11.5^{\prime} \mathrm{W}, 20^{\circ} 45.8^{\prime} \mathrm{S}\right)$, Guaymas Basin $\left(27^{\circ}\right.$ $\left.0^{\prime} \mathrm{N} 111^{\circ} 24^{\prime} \mathrm{W}\right)$, along with the Rainbow $\left(36^{\circ} 13^{\prime} \mathrm{N}, 33^{\circ} 54.1^{\prime} \mathrm{W}\right)$ and Lucky Strike $\left(37^{\circ} 17^{\prime} \mathrm{N}, 32^{\circ} 16.3^{\prime} \mathrm{W}\right)$ vent fields on the Mid-Atlantic Ridge (MAR). The overarching goal was to quantify the archaeal community compositional shifts on a global scale across multiple tectonic ridge axes, and on a local scale between chimney and flange deposit structures.

\section{Materials and Methods}

Sample Collection 
Samples were collected and processed by Gilbert Flores from hydrothermal vent sulfur-mineral deposits over the past decade from the EPR $\left(9^{\circ} 039^{\prime} \mathrm{N}, 109^{\circ} 31^{\prime} \mathrm{W}\right)$, $\operatorname{ELSC}\left(176^{\circ} 11.5^{\prime} \mathrm{W}, 20^{\circ} 45.8^{\prime} \mathrm{S}\right), \operatorname{MAR}\left(36^{\circ} 13^{\prime} \mathrm{N}, 33^{\circ} 54.1^{\prime} \mathrm{W}\right)$, and Guaymas Basin $\left(27^{\circ} 0^{\prime}\right.$ $\mathrm{N} 111^{\circ} 24^{\prime} \mathrm{W}$ ) using the manned and unmanned submersibles Alvin and Jason, respectively. Samples were processed and stored anaerobically as previously described (Gotz et al., 2002; Moussard et al., 2004; Reysenbach et al., 2006).

\section{Site Description}

\section{Eastern Lau Spreading Center}

The ELSC is a $397 \mathrm{~km}$ ridge segment located at a convergent plate boundary that contains six vent fields from north to south: Kilo Moana, Tow Cam, Tahi Moana, ABE, Tui Malila, and Mariner (Ferrini et al., 2008; Mottl et al., 2011). The ELSC is a backarc basin that formed due to subduction of the Pacific plate beneath the Australian plate that in effect created a more geologically diverse ridge system than a typical MOR system (Martinez et al., 2007). The three northernmost vent fields; Kilo Moana, Tow Cam, and Tahi Moana have a relatively fast spreading rate $(4-10 \mathrm{~cm} / \mathrm{yr})$ and are all hosted by basalt substrate (Table 3.1) (Tivey, 2007; Ferrini et al., 2008). ABE and Tui Malila are basalt-andesite hosted hydrothermal vents located $10 \mathrm{~km}$ and $150 \mathrm{~km}$ respectively south of Tahi Moana along the ELSC (Ferrini et al., 2008). Mariner which is the southernmost vent field is basalt-andesite hosted, but is more influenced by the subducting Pacific plate than the other basalt-andesite hosted vent fields (Mottl et al., 2011). In general the hydrothermal fluid of each vent field is influenced on a northsouth continuum based on: plate subduction influence, spreading rate, and host rock. In 


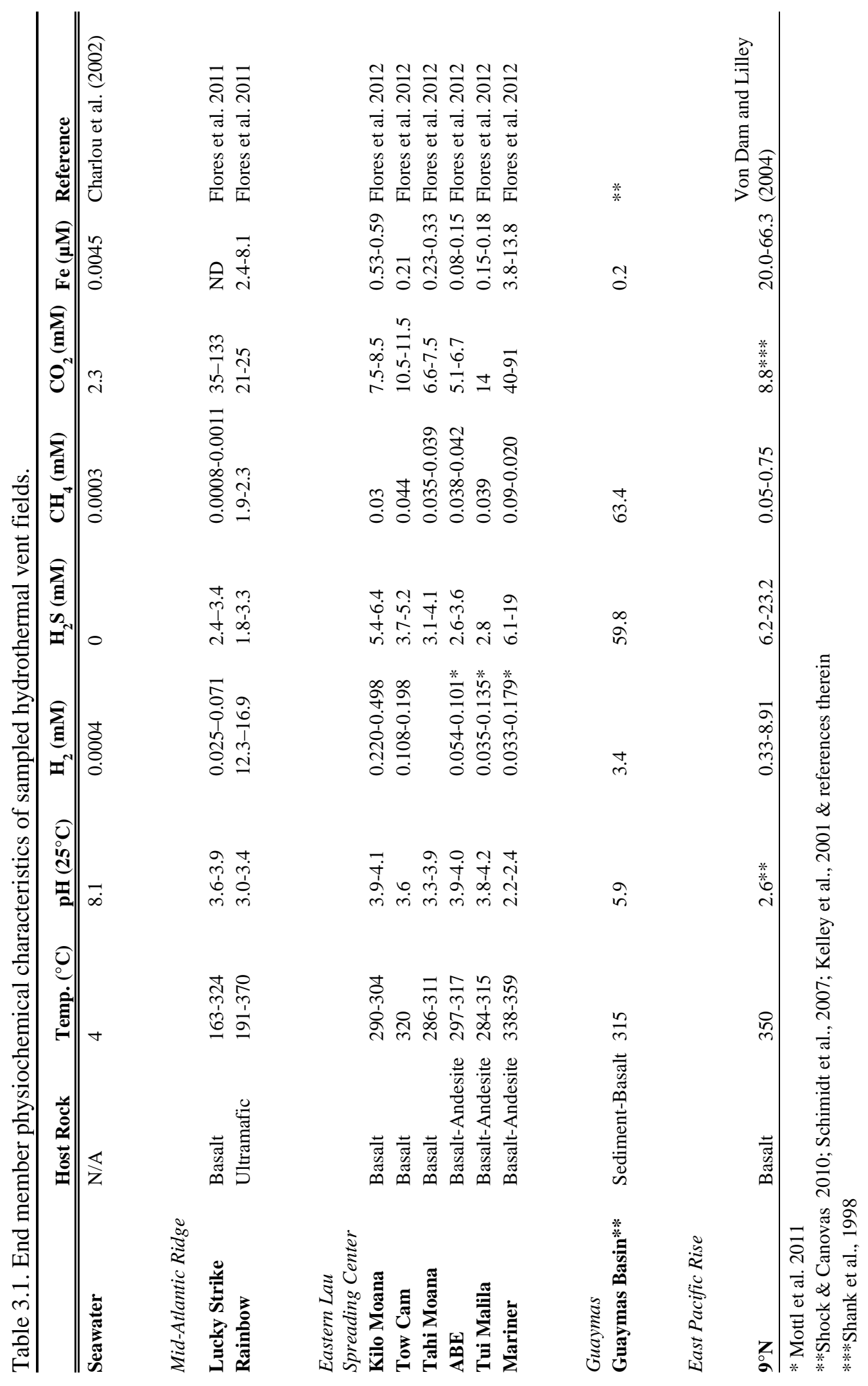


general there is north to south decrease in $\mathrm{H}_{2} \mathrm{~S}, \mathrm{H}_{2}(\mathrm{aq})$, Fe, and temperature, coupled with an increase in $\mathrm{pH}$ at the various vent fields (Mottl et al., 2011). The influence of the subducting Pacific plate increases to the south, while the four most northern vent fields (Kilo Moana, Tow Cam, ABE and Tui Malila) have similar hydrothermal fluid to a typical MOR. Mariner has a higher concentration of $\mathrm{H}_{2} \mathrm{~S}, \mathrm{CO}_{2}, \mathrm{Fe}$, transition metals, lower $\mathrm{pH}$, and higher temperatures than any of the other vent fields (Mottl et al., 2011). The unique hydrothermal fluid at Mariner can be attributed to active degassing magma chamber that inputs a greater concentration of magmatic volatiles than any other vent field on the ELSC (Mottl et al., 2011).

\section{Mid-Atlantic Ridge}

Rainbow $\left(36^{\circ} 13^{\prime} \mathrm{N}, 33^{\circ} 54.1^{\prime} \mathrm{W}\right)$ and Lucky Strike $\left(37^{\circ} 17^{\prime} \mathrm{N}, 32^{\circ} 16.3^{\prime} \mathrm{W}\right)$ are two hydrothermal vent fields along the MAR at a depth of 2270-2330 and 1600-1750 m respectively (Flores et al., 2011). These two fields are separated by $180 \mathrm{~km}$ and are hosted by geologically distinct host rock systems. Rainbow is hosted by ultramafic rocks and emits relatively hot and acidic hydrothermal fluid (Table 3.1). Due to serpentinization reactions with the ultramafic rocks, the hydrothermal fluid is enriched in in $\mathrm{H}_{2}, \mathrm{CH}_{4}, \mathrm{CO}$, metals, and has lower concentrations of $\mathrm{H}_{2} \mathrm{~S}$, relative to basalt-hosted MOR vent fields (Charlou et al., 2002; Douville et al., 2002, Flores et al., 2011).

The Lucky Strike vent field is a basalt hosted hydrothermal vent field which is relatively oxic, has a low concentration of Fe, manganese $(\mathrm{Mn})$, lithium $(\mathrm{Li})$, zinc $(\mathrm{Zn})$, and is relatively alkaline (3.6-3.9) $\left(25^{\circ} \mathrm{C}\right)$, compared to many basalt hosted MOR systems (Von Damm et al., 1998). In addition there is a dramatic difference in the 
concentration of metabolically important gasses between the two vent fields. Lucky

Strike has hydrothermal fluid that has up to three orders of magnitude less $\mathrm{CO}_{2}$, and $\mathrm{H}_{2}$ than Rainbow (Table 3.1) (Von Damm et al., 1998; Charlou et al., 2002).

\section{Guaymas Basin}

Guaymas Basin $\left(27^{\circ} 0^{\prime} \mathrm{N} 111^{\circ} 24^{\prime} \mathrm{W}\right)$ is a MOR hydrothermal vent field located north of the $21^{\circ} \mathrm{N}$ vent field within the Sea of Cortez (Edmond et al., 1985). From south to north as the tectonic axis enters the Sea of Cortez it changes from sediment starved open-ocean to a continental rift, sediment hosted environment (Von Damm et al., 1985). The Sea of Cortez is very biologically productive with a sedimentation rate of 1 to 2 $\mathrm{mm} / \mathrm{yr}$. Due to the high sedimentation rate there is a $100-500 \mathrm{~m}$ thick organic rich diatomaceous sediment layer (Schrader, et al., 1982; Burggraf et al., 1990). The organic sediment layer alters the chemical composition of the end member hydrothermal fluid considerably compared to a typical bare MOR vent fields. The sediment layer interaction with the hydrothermal fluid accelerates metal precipitation and organic thermocatalysis that in effect alters hydrothermal fluid so that the metal concentration is several orders of magnitude lower, and methane is around two orders of magnitude higher than a typical MOR system (Von Damm, 1990). In addition short chain fatty acids, petroleum, and ammonia are released from the sediment (Edmond et al., 1985).

\section{East Pacific Rise}

The $9^{\circ} \mathrm{N}$ hydrothermal vent field $\left(9^{\circ} 039^{\prime} \mathrm{N}, 109^{\circ} 31^{\prime} \mathrm{W}\right)$ on the EPR is a fast spreading MOR system that spreads at a full rate of $11 \mathrm{~cm} / \mathrm{yr}$ and ranges from $2500-2600$ 
$\mathrm{m}$ below the ocean surface (Carbotte and Macdonald, 1992). The $9^{\circ} \mathrm{N}$ hydrothermal vent field is hosted by basalt/mafic rocks. Due to the fast spreading rate eruptions along the EPR axis are relatively frequent, and eruption can often alter the geochemistry of the end member hydrothermal fluid with an increase in $\mathrm{H}_{2}, \mathrm{CH}_{4}$, and $\mathrm{S}^{2-}$ (Lilley et al., 2003; Seewald et al., 2003; Von Damm \& Lilley, 2004). The hydrothermal system at $9^{\circ} \mathrm{N}$ is a dynamic system and experiences geochemical variation and evolution more than ten years post eruption, and has been identified as the most temporally variable system on the global ridge system (Von Damm, 2004).

\section{DNA Extraction}

gDNA from the mineral-sulfide deposits was extracted by Gilbert Flores using Ultra Clean Soil DNA Isolation Kit (MoBio, Carlsbad, CA) according to standard protocol (Reysenbach et al., 2006) (Table 3.2).

$q P C R$

Genomic DNA from environmental samples was amplified using the primers designed in this study that target the 16S rRNA gene, using the Quantitect SYBR green PCR kit (Qiagen, Inc., Valencia, CA). qPCR was conducted according to manufacturer's protocols with a $0.8 \mu \mathrm{M}$ final primer concentration. The qPCR thermal cycling protocols were run according to Reysenbach et al. (2006). To test for contamination and/or primer dimer, a melt curve of the PCR products from $55-95^{\circ} \mathrm{C}$ was performed after the final extension to verify the peak of the $16 \mathrm{~S}$ rRNA gene amplicons. If multiple melting peaks occur there is high probability that the primers are non-specific 
Table 3.2. Hydrothermal vent deposit samples used for qPCR. All samples except for EPR were processed by Flores et al.

MAR, Mid-Atlantic Ridge; GB, Guaymas Basin. * indicates samples also used in pyrosequencing analyses from Flores et al. (2011, 2012a) and Reysenbach unpublished.

\begin{tabular}{|c|c|c|c|c|}
\hline Site & Vent Field & Sample & Year & Deposit Type \\
\hline MAR & Rainbow & RB 165 & 2008 & Chimney \\
\hline MAR & Rainbow & RB 177 & 2008 & Chimney \\
\hline MAR & Rainbow & RB 231 & 2008 & Chimney \\
\hline MAR & Rainbow & RB 241 & 2008 & Chimney \\
\hline MAR & Rainbow & $\mathrm{RB} 3^{*}$ & 2008 & Chimney \\
\hline MAR & Rainbow & $\mathrm{RB} 5 *$ & 2008 & Chimney \\
\hline MAR & Lucky Strike & LS 304 & 2008 & Flange \\
\hline MAR & Lucky Strike & LS 333 & 2008 & Chimney \\
\hline MAR & Lucky Strike & LS 371 & 2008 & Chimney \\
\hline MAR & Lucky Strike & LS 449 & 2008 & Flange \\
\hline MAR & Lucky Strike & LS $8^{*}$ & 2008 & Flange \\
\hline MAR & Lucky Strike & LS $12 *$ & 2008 & Flange \\
\hline Guaymas & GB & Guay09 56 & 2009 & Chimney \\
\hline Guaymas & GB & Guay09 99 & 2009 & Chimney \\
\hline Guaymas & GB & Guay09 159 & 2009 & Chimney \\
\hline Guaymas & GB & Guay09 244 & 2009 & Chimney \\
\hline Guaymas & GB & Guay09 264a & 2009 & Flange \\
\hline Guaymas & GB & Guay09 289* & 2009 & Flange \\
\hline Guaymas & GB & Guay09 302 & 2009 & Flange \\
\hline Guaymas & GB & Guay09 314 & 2009 & Flange \\
\hline Guaymas & GB & Guay09 240* & 2009 & Chimney \\
\hline Guaymas & GB & Guay09 258* & 2009 & Flange \\
\hline Guaymas & GB & Guay09 441* & 2009 & Chimney \\
\hline EPR & $9^{\circ} \mathrm{N}$ & EPR04 23 & 2004 & Flange \\
\hline EPR & $9^{\circ} \mathrm{N}$ & EPR04 29 & 2004 & Flange \\
\hline EPR & $9^{\circ} \mathrm{N}$ & EPR04 1 & 2004 & Chimney \\
\hline EPR & $9^{\circ} \mathrm{N}$ & EPR04 104 & 2004 & Chimney \\
\hline EPR & $9^{\circ} \mathrm{N}$ & EPR04 131 & 2004 & Chimney \\
\hline EPR & $9^{\circ} \mathrm{N}$ & EPR04 207 & 2004 & Chimney \\
\hline EPR & $9^{\circ} \mathrm{N}$ & EPR04 1-D6 & 2004 & Chimney \\
\hline EPR & $9^{\circ} \mathrm{N}$ & EPR04 T2-D6 & 2004 & Chimney \\
\hline ELSC & Kilo Moana & KM 3 & 2009 & Flange \\
\hline ELSC & Kilo Moana & $\mathrm{KM} 2 *$ & 2009 & Chimney \\
\hline ELSC & Tow Cam & TC $1768^{*}$ & 2009 & Chimney \\
\hline
\end{tabular}




\begin{tabular}{lllll} 
ELSC & Tow Cam & TC 26* & 2009 & Chimney \\
ELSC & Tow Cam & TC 62* & 2009 & Chimney \\
ELSC & Tahi Moana & TaM 1381 & 2009 & Flange \\
ELSC & Tahi Moana & TaM 1388 & 2009 & Chimney \\
ELSC & Tahi Moana & TaM 1464 & 2009 & Chimney \\
ELSC & Tahi Moana & TaM 1476 & 2009 & Flange \\
ELSC & ABE & ABE 206 & 2009 & Chimney \\
ELSC & ABE & ABE 3* & 2009 & Chimney \\
ELSC & Tui Malila & TuiM 31 & 2009 & Undetermined \\
ELSC & Tui Malila & TuiM 1123 & 2009 & Flange \\
ELSC & Tui Malila & TuiM 1147 & 2009 & Undetermined \\
ELSC & Tui Malila & TuiM 1556 & 2009 & Flange \\
ELSC & Tui Malila & TuM 30* & 2009 & Flange \\
ELSC & Mariner & Mariner 542 & 2009 & Chimney \\
ELSC & Mariner & Mariner 1493 & 2009 & Flange \\
ELSC & Mariner & Mariner 1704 & 2009 & Flange \\
ELSC & Mariner & Mariner 1718 & 2009 & Chimney \\
ELSC & Mariner & Mariner 14* & 2009 & Flange \\
ELSC & Mariner & Mariner 38* & 2009 & Flange \\
\hline
\end{tabular}


to the target sequence, or that primer dimers formed (Ferriera, 2006). Initial 16S rRNA gene concentrations were determined based on the mean cycle threshold of the duplicate samples using Opticon Monitor software analyses (v. 3.1, Life Science). Amplification and quantification of the mcrA functional gene was conducted following the methods outlined in Wilson et al. (2010).

\section{Statistical Analyses}

The proportion of archaeal taxa genes were transformed by square root and similarity of each sample was assessed through Bray-Curtis analysis. Sample similarity was visualized using a non-metric multidimensional scaling (MDS) plots for samples that are associated with the: MAR, ELSC, and eastern Pacific (EPR and Guaymas Basin). The relationships between the vent fields were tested for significance using ANOSIM (PRIMER v6) (Clarke \& Gorley, 2006).

\section{Nanoarchaeota-Local Similarity Analysis}

In order to identify co-varying archaeal patterns with the understudied Nanoarchaeota, a local similarity analysis (LSA) was conducted (Ruan et al., 2006). The barcoded pyrosequenced hypervariable V4 region of the archaeal 16S rRNA gene from 57 sulfide deposits from the MAR (Flores et al., 2011), Guaymas Basin (Reysenbach, unpublished), and the ELSC (Flores et al., 2012a) were binned to 97\% identity, assigned taxonomic identity from the RDP classifier, and normalized as described in Flores et al., 2011 (Wang et al., 2007). The co-varying relationships between all the OTUs with greater than 100 sequences were analyzed using the (LSA) 
(Ruan et al., 2006). The significant relationships between OTUs were filtered $(\mathrm{P}<0.05)$ and the LSA relationship of the Nanoarchaeota with the highest number of sequences (OTU 804) was visualized using the software Cytoscape (v. 2.8) (Shannon et al., 2003).

\section{Results}

\section{Thermococcales Distribution}

Based on quantification of the Thermococcales-specific qPCR assays, detectable abundances were recovered in all 53 samples. Proportionally the Thermococcales represented the largest mean fraction of the archaeal community at the vent fields of Mariner (24.8\%) and Lucky Strike (25.1\%) followed by EPR (20.5\%) and Guaymas $(13.4 \%)$ (Fig 3.1).

\section{Archaeoglobus Distribution}

Amplification products were detected using Archaeoglobus 16S rRNA gene primers from 48 of the 53 vent deposits $(90.5 \%)$ using lineage specific qPCR primers from chapter 2. The Archaeoglobus represented the largest proportion of the archaeal community at the vent fields Tow Cam (30.9\%), Kilo Moana (29.3\%), and Lucky Strike (18.6\%), and the lowest at three vent fields along the ELSC; Tahi Moana (2.6\%) ABE (2.8\%), and Tui Malila (1.7\%) (Fig 3.1).

\section{Methanogen Distribution}

Amplification products were detected using methanogen specific qPCR assays that target the $m c r A$ gene, putative methanogen sequences were detected in 34 of the 53 


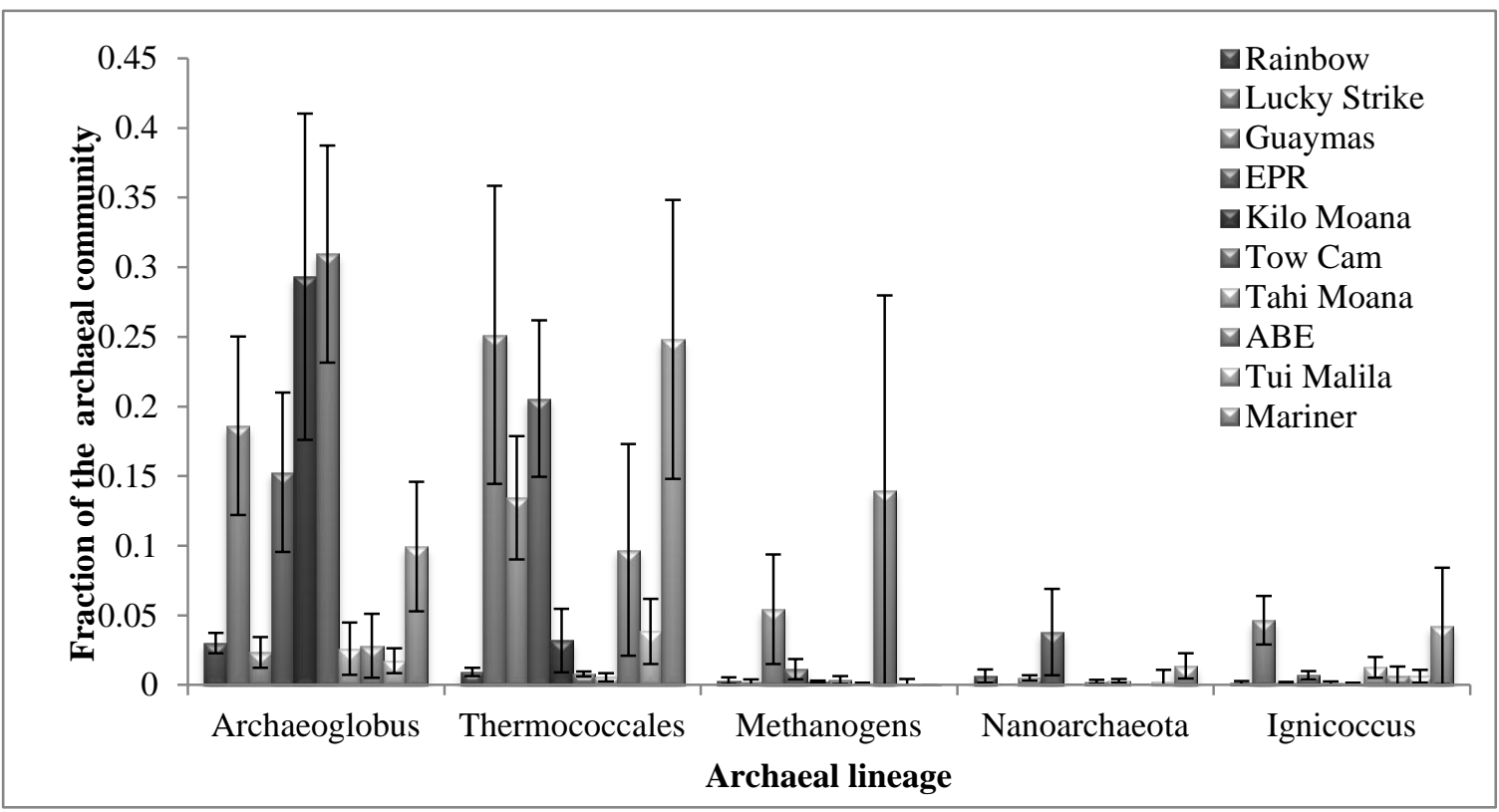

Figure. 3.1. Relative proportion of select archaeal taxa to total archaeal abundance from deposit samples of globally distributed hydrothermal vents. Error bars indicate \pm 1 standard error of the mean (SEM). 
vent deposits samples (64.1\%). All of the samples from Lucky Strike were below the detection limit (BDL). The mean proportional abundance of methanogens was greatest at Tow Cam (13.9\%), followed by Guaymas (5.4\%) and EPR (1.1\%) (Fig 3.1). At all other vent fields the methanogens represented $<1 \%$ of the archaeal community.

\section{Nanoarchaeota Distribution}

Amplification products were detected using Nanoarchaeota 16S rRNA gene primers in 31 of the 53 vent deposits (58.4\%). Nanoarchaeota sequences were detected from five of the fifteen ELSC samples. No Nanoarchaeota sequences were detected from the basalt hosted Lucky Strike, ABE, or Kilo Moana vent field. The Nanoarchaeota were found to be in the greatest proportion of the archaeal community from the EPR samples (3.7\%) (Fig 3.1).

\section{Ignicoccus Distribution}

Amplification products were detected using Ignicoccus 16S rRNA gene primers in 34 of 53 vent deposit samples (64\%), with no sequences identified at Tow Cam along the ELSC. The proportion of Ignicoccus was found to be highest at Lucky Strike (4.6\%) and Mariner (4.2\%) and lowest at Rainbow (0.15\%) and Kilo Moana (0.12\%) of the vent fields that had detectable levels of Ignicoccus (Fig 3.1).

\section{Statistical Analyses:}

\section{$\underline{\text { Overall Community Structure }}$}


Based on the one way-ANOSIM (Primer v6) pairwise analyses of the abundance of the archaeal community from all the vent fields, seven out of 15 analyses were found to have statistically significant patterns of archaeal community abundance $(\mathrm{P}<0.05)$ (Table 3.3).

\section{$\underline{\text { Mid-Atlantic Ridge }}$}

Based on a one-way ANOSIM (Primer v6) analysis of the archaeal communities along the MAR, between the ultramafic Rainbow and basalt hosted Lucky Strike, the two vent fields were found to be statistically distinct from one another $(R=0.465$; $\mathrm{P}<0.05$ ) (Fig 3.2). Graphical visualization on MDS plots further supports this observation, as the samples from the basalt and the ultramafic hosted vent fields do not physically overlap (Fig 3.2).

\section{$\underline{\text { Eastern Lau Spreading Center }}$}

Based on a one-way ANOSIM (Primer v6) analysis of the archaeal communities along the ELSC, the northern basalt hosted vent fields were found to be distinct from the southern andesite hosted vent fields $(\mathrm{R}=0.161$; $\mathrm{P}<0.05)$ (Fig 3.2). Graphical visualization on MDS plots further supports this observation, with the exception of a single sample from Tui Malila, as the basalt and the andesite hosted vent fields do not overlap (Fig 3.2).

\section{$\underline{\text { East Pacific }}$}


Table 3.3. Results of an ANOSIM pairwise archaeal community comparison from globally distributed hydrothermal vents using Primer v6. The comparative ANOSIM statistical relatedness of each community is represented by $\mathrm{R}$ value $(1<\mathrm{X}<-1)$ and $\mathrm{P}$ values are indicated in parentheses and significant relationships between the vent fields are indicated by bold $(\mathrm{P}<0.05)$. EPR, East Pacific Rise; ELSC B, Eastern Lau Spreading Center Basalt; ELSC A, Eastern Lau Spreading Center Andesite.

Rainbow Guaymas Basin EPR ELSC B ELSC A

Guaymas Basin $0.312(\mathbf{0 . 0 1 1})$

$\begin{array}{lll}E P R & \mathbf{0 . 5 3 1}(\mathbf{0 . 0 0 1}) & 0.047(0.218)\end{array}$

$\begin{array}{llll}\text { ELSC B } & 0.198(0.041) & 0.319(0.002) & 0.225(0.013)\end{array}$

$\begin{array}{lllll}\text { ELSC A } & 0.049(0.293) & -0.012(0.53) & -0.039(0.618) & \mathbf{0 . 1 6 1}(\mathbf{0 . 0 3 2})\end{array}$

$\begin{array}{llllll}\text { Lucky Strike } & \mathbf{0 . 4 6 5}(\mathbf{0 . 0 0 6}) & 0.219(0.051) & 0.09(0.131) & 0.197(0.077) & 0.064(0.228)\end{array}$ 

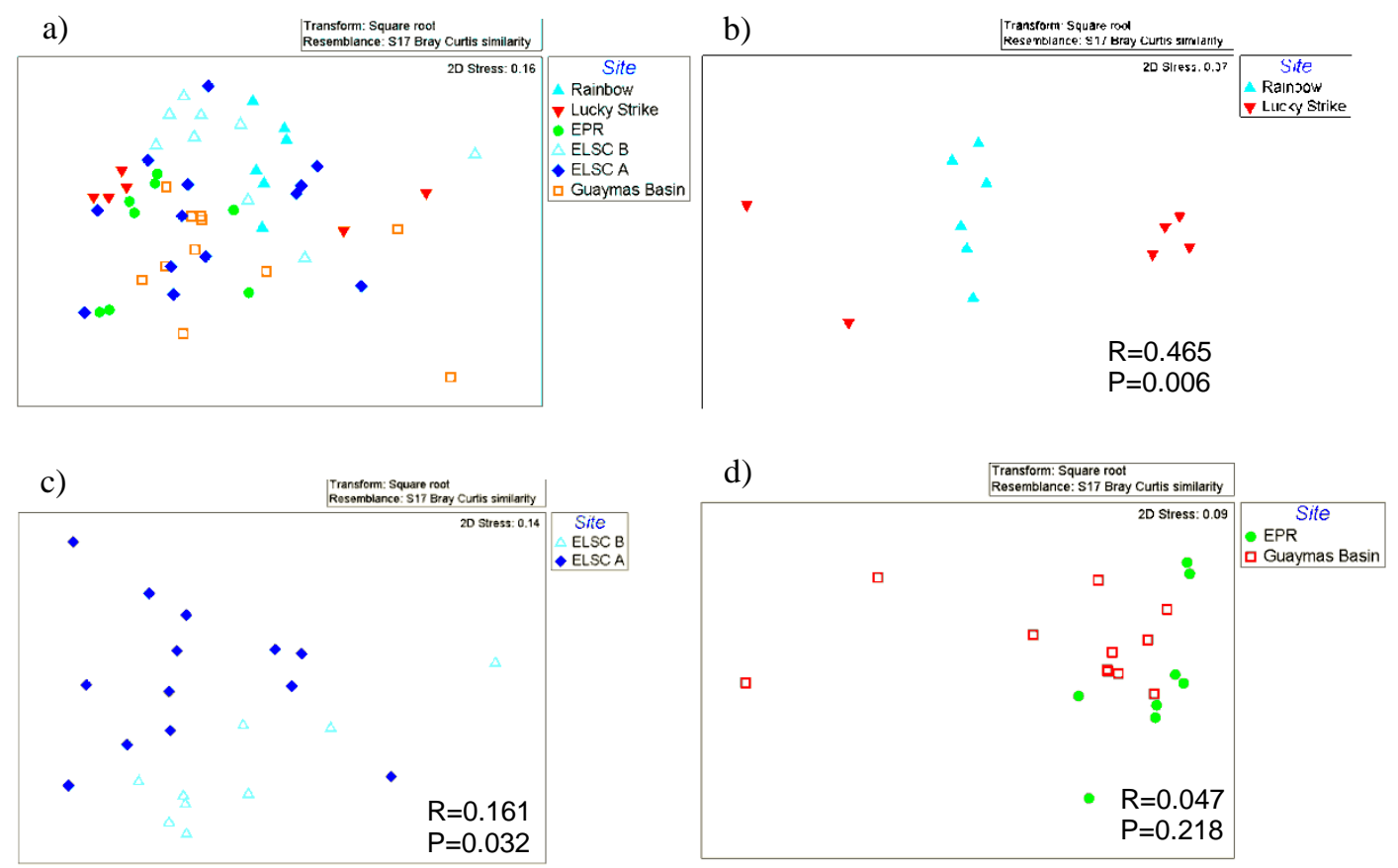

Figure 3.2. MDS using Bray-Curtis similarities of square root transformed archaeal community relatedness of the a) Globally distributed hydrothermal vents b) MAR

c) ELSC d) EPR and Guaymas Basin. Pairwise relatedness (R value) and significance (P value) are displayed based on ANOSIM analyses in the bottom right. EPR, East Pacific Rise; ELSC B, Basalt hosted vent fields on the ELSC; ELSC A, Andesite hosted vent fields on the ELSC. 
Based on a one-way ANOSIM (Primer v6) analysis of the archaeal community between the unsedimented EPR and sediment hosted Guaymas Basin samples, the archaeal community structure was not statistically distinct as determined by ANOSIM (Primer v6) analyses ( $\mathrm{P}>0.05)$ (Table 3.3). MDS plots of the two vent fields also showed physical overlap of the two vent field samples, corroborating the ANOSIM statistical analyses (Fig 3.2)

\section{Nanoarchaeota-Local Similarity Analysis}

LSA was utilized to determine Nanoarchaeota co-occurrence patterns to other archaeal groups using data from previously conducted barcoded pyrosequencing of nine distinct vent fields by Flores et al. (2011, 2012a) and Reysenbach (unpublished). The most prevalent Nanoarchaeota OTU (no. 804) had 3999 reads from 57 tested samples and was identified in $24.6 \%$ of the vent deposit samples (Table 3.4). Fifteen OTUs were positively correlated to this Nanoarchaeota OTU, and 10 of 15 were from the kingdom Euryarchaeota (Fig 3.3). Of the non-Euryarchaeota OTUs, four were Crenarchaeota and one was Nanoarchaeota. Within the Euryarchaeota three of the four most positively correlated OTUs were from the Archaeoglobaceae, followed by two methanogen, Desulfurococcaceae, and Thermofilum OTUs. Five OTUs could only be taxonomically identified up to the Euryarchaeota. Of the OTUs that negatively co-occur with the Nanoarchaeota all are from the Euryarchaeota, with two from the Thermococcaceae and Euryarchaeota respectively, and a single OTU from Archaeoglobi and the "DHVE2".

\section{Flange versus Chimney}


Table 3.4. Co-occurrence results of the Local similarity analysis of the Nanoarchaeota OTU from 62 sulfide deposit samples.

$\begin{array}{clll} & \begin{array}{c}\text { Proportion of } \\ \text { deposits with }\end{array} & \text { Local } & \\ \text { Sequences } & \text { OTU occurrence } & \text { Similarity } & \text { Taxonomic ID }\end{array}$

Maximum ID

Nanoarchaeota OTUs

$804 \quad 3999 \quad 0.246 \quad$ Nanoarchaeum $\quad 82 \%$

Positively correlated

OTUs with 804

$\begin{array}{rccclc}455 & 151 & 0.088 & 0.4694 & \text { Archaeoglobaceae } & 89 \% \\ 461 & 3539 & 0.719 & 0.4582 & \text { Archaeoglobus } & 95 \% \\ 1137 & 120 & 0.105 & 0.415 & \text { Euryarchaeota } & 98 \% \\ 1060 & 2538 & 0.667 & 0.4108 & \text { Archaeoglobus } & 100 \% \\ 494 & 3557 & 0.123 & 0.3885 & \text { Methanothermococcus } & 89 \% \\ 638 & 5105 & 0.772 & 0.3532 & \text { Desulfurococcales } & 98 \% \\ 484 & 454 & 0.088 & 0.3496 & \text { Methanococcus } & 99 \% \\ 567 & 210 & 0.035 & 0.3391 & \text { Euryarchaeota } & 74 \% \\ 176 & 288 & 0.088 & 0.3296 & \text { Nanoarchaeum } & 76 \% \\ 32 & 321 & 0.281 & 0.3285 & \text { Thermofilum } & 64 \% \\ 751 & 105 & 0.123 & 0.3227 & \text { Euryarchaeota } & 58 \% \\ 474 & 175 & 0.211 & 0.3077 & \text { Euryarchaeota } & 74 \% \\ 490 & 103 & 0.07 & 0.301 & \text { Euryarchaeota } & 92 \% \\ 871 & 295 & 0.105 & 0.2947 & \text { Thermofilum } & 68 \% \\ 415 & 166 & 0.456 & 0.3053 & \text { Desulfurococcaceae } & 51 \%\end{array}$

Negatively correlated OTUS with 804

\begin{tabular}{|c|c|c|c|c|c|}
\hline 860 & 2293 & 0.509 & -0.3135 & Euryarchaeota & $87 \%$ \\
\hline 1148 & 1389 & 0.667 & -0.3176 & $\begin{array}{l}\text { "DHVE2" } \\
\text { Euryarchaeota }\end{array}$ & $98 \%$ \\
\hline 1248 & 535 & 0.228 & -0.3229 & Euryarchaeota & $65 \%$ \\
\hline 739 & 101 & 0.404 & -0.3459 & Archaeoglobi & $95 \%$ \\
\hline 1038 & 30156 & 1 & -0.3567 & Thermococcus & $100 \%$ \\
\hline 421 & 538 & 0.386 & -0.3596 & Thermococcaceae & $70 \%$ \\
\hline
\end{tabular}




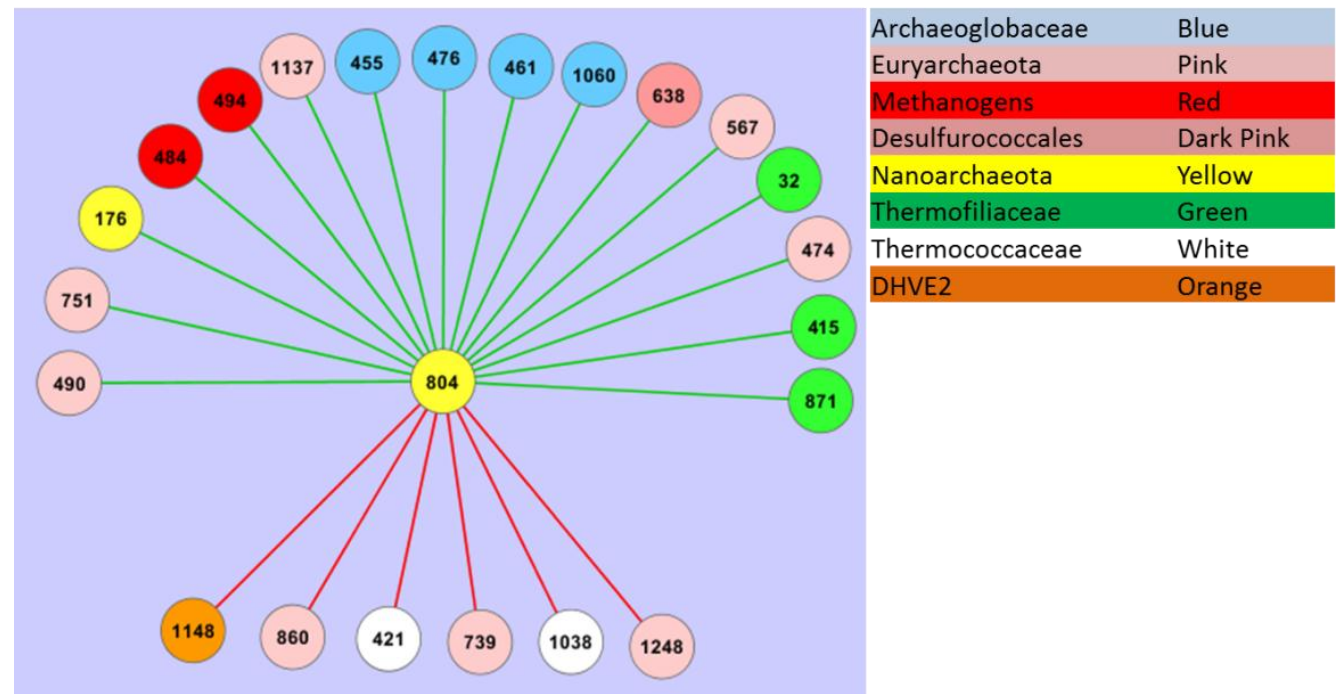

Figure 3.3 Co-occurrence results of the local similarity analysis of the Nanoarchaeota OTU from 62 sulfide deposit samples visualized using Cytoscape. 
The abundance and proportion of the five archaeal groups were tested to determine if there was a significant shift in archaeal community composition between the chimney and flange deposit structures (Fig 3.4). Overall the chemosynthetic groups of the methanogens and Archaeoglobus constituted a larger proportion of the archaeal community from chimney samples than from flange samples. There was an opposing shift associated with the Thermococcales that were found in a higher proportion at flange samples. The Nanoarchaeota and Ignicoccus showed no distinct structuring based on chimney or flange deposit structures.

Based on a one-way ANOSIM (Primer v6) analysis of the archaeal community abundance between flange and chimney structures across the entire dataset the archaeal community structure was found to have statistically significant relationship (Primer v6) $(\mathrm{R}=0.120 ; \mathrm{P}=0.013)$.

\section{Discussion}

\section{Mid-Atlantic Ridge}

Similar to Flores et al. (2011), this study found that the archaeal community composition was statistically distinct between the basalt-hosted Lucky Strike and the ultramafic-hosted Rainbow vent fields (Fig 3.2). Based on qPCR and barcoded pyrosequencing analyses the primary difference in archaeal composition between the two vent fields was the presence of methanogens from Rainbow vent deposit samples and the dearth of methanogens at Lucky Strike (Fig 3.1) (Flores et al., 2011). The prevalence of methanogens at Rainbow was attributed to the high concentration of aqueous hydrogen that is two to three orders of magnitude higher at Rainbow as a result 


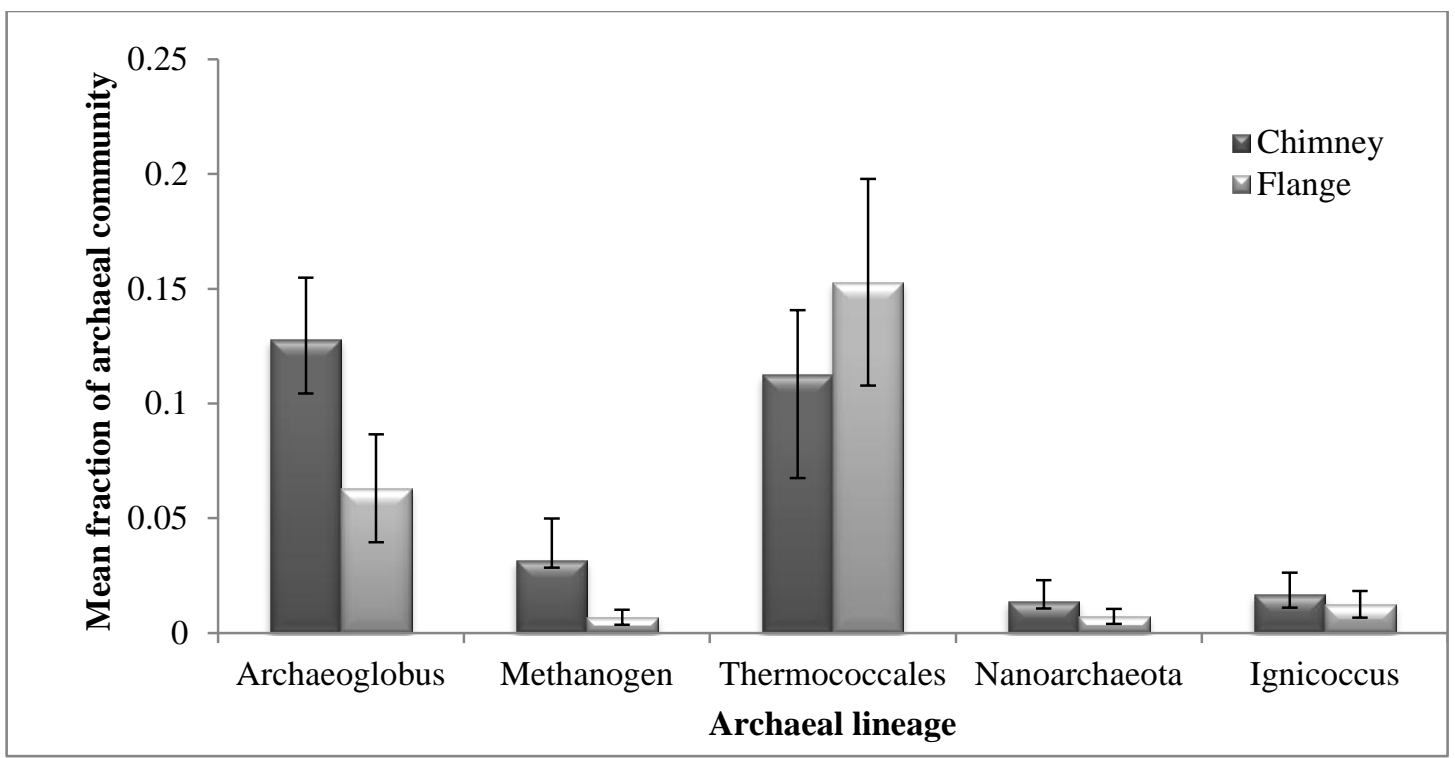

Figure 3.4. Relative proportion of selected archaeal taxa from chimney and flange hydrothermal vent deposits from globally distributed hydrothermal vents, based on qPCR. Error bars indicate \pm 1 standard error of the mean (SEM). 
of serpentinization reactions between the ultramafic rocks and seawater (Charlou et al., 2011; Flores et al., 2011). The dearth of methanogens at Lucky Strike is however most likely driven by the relatively oxidizing conditions as the vent field has experienced prolonged hydrothermal activity due to its slow spreading rate, and as a result the mineral assemblage beneath the vent field has potentially been thoroughly leached and has reached a state of equilibrium with respect to fluid composition (Palmer and Edmond, 1989; Honnorez et al., 1998; Von Damm et al., 1998; Gallant \& Von Damm, 2006). As a result the end member fluid chemistry is likely below the minimum hydrogen threashold for methanogenesis (Flores et al., 2011).

\section{Eastern Lau Spreading Center}

Along the ELSC there is a generalized geochemical gradient of decreasing concentration of metabolically important compounds such as hydrogen, hydrogen sulfide, and methane from the northern vent fields (Kilo Moana, Tahi Moana, and Tow Cam) to the southern (ABE, Tui Malila, and Mariner) driven by changes in host rock due to increasing influence of the subducting Pacific plate. The archaeal community structure mimics the geologic and geochemical shift from north to south as the Archaeoglobus and methanogens are in in a higher proportion in the north while the Thermococcales are in high proportions in the south. In anaerobic environments, methanogens and Archaeoglobus predominantly gain energy through the oxidation of hydrogen with $\mathrm{CO}_{2}$ or sulfur compounds as terminal electron acceptors. Flores et al. (2012a) found that the community differences between vent fields were primarily driven by the proportional abundance of Thermococcales at the southernmost vent field of 
Mariner. The high proportion of Thermococcales at Mariner was also observed from this dataset and potentially could be attributed to the high concentration of single carbon compounds at Mariner, as some species within the Thermococcales are carboxytrophic and are able to oxidize carbon monoxide (Lee et al., 2008; Zivanovic et al., 2009;

Vannier et al., 2011; Flores et al., 2012).

In spite of the geochemical shift from north to south and the transition from basalt to andesite hosted vent rock along the ELSC, Flores et al. (2012a) found that the archaeal community structure was similar across the ELSC, except for Mariner that had a divergent community structure. In contrast, the analyses from this study found that the community composition segregated based on host rock. The three basalt-hosted vent fields (Kilo Moana, Tahi Moana, and Tow Cam) and the three andesite hosted vent fields (ABE, Tui Malila, and Mariner) overall had statistically distinct community structures based on Brays-Curtis similarity analyses and ANOSIM relatedness $(\mathrm{P}<0.05)$. One potential explanation for this discrepancy could be an underestimation of some of the major archaeal lineages from barcoded pyrosequencing, in particular the Archaeoglobus. In the three most northern vent fields from qPCR assays Archaeoglobus was found to be in the highest proportion at two of the three basalt-hosted vent fields (Kilo Moana and Tow Cam). The higher proportion of Archaeoglobus may be a function of the high hydrogen concentration at the basalt-hosted vent fields (Charlou et al., 2012). Flores et al., (2012a) in contrast found that Archaeoglobus only represented a very small minority of the archaeal community, and may be a function of biases with the V4 primers used. The V4 universal primers that were used for barcoded pyrosequencing were found to have greater than tenfold underestimation of the total expected 
proportional abundance for the order Archaeoglobales (Shakya et al., 2013). The low proportion of Archaeoglobus detected from barcoded pyrosequencing may be a contributing factor to the lack of differentiation between the basalt and andesite hosted vent fields along the ELSC.

\section{East Pacific}

Traversing north of the EPR vent fields, along the tectonic ridge system, there is a transitional shift from sediment starved open ocean system to a sediment hosted enclosed vent field within the Sea of Cortez (Von Damm et al., 1985). At Guaymas Basin, due to the highly productive photic zone the sedimentation rate is two orders or magnitude greater than at the EPR vent fields (Von Damm et al., 1985). Due to the influence of the of 100-500 m organic rich diatomaceous sediment layer the end member hydrothermal vent fluid between the EPR and Guaymas Basin are characteristically distinct. The end member fluid at Guaymas Basin has a very low concentration of metals due to precipitation within the sediment, as well as increased methane from thermocatalysis of the organic sediment, and is much more alkaline because of the input of ammonium. As a result, the archaeal community structural differences between the EPR and the Guaymas Basin are a model system for analyzing the geologic influence of sedimentation. Even though there are stark geochemical differences between the unsedimented EPR and sedimented Guaymas Basin, the archaeal community structure of the five tested lineages was not significantly different $(\mathrm{P}>0.05)$ (Fig 3.2). These results suggest that the geochemical differences driven by sedimentation between the 
EPR and Guaymas basin are not a strong structuring force of the major archaeal lineages.

The insignificant difference between these two vent fields could be due to the energetic metabolisms of the assayed archaeal lineages. Methanogens, Archaeoglobus, and Ignicoccus all utilize hydrogen as their primary electron donor, while the Thermococcales are generally heterotrophs that are stimulated by elemental sulfur, and the Nanoarchaeota has no known energetic metabolism. Thus the geochemical differences driven by sedimentation do not significantly impact the metabolically important chemicals for the major archaeal lineages. However, the influence of sedimentation most likely affects the abundance of microorganisms that have methane oxidizing or iron redox energetic metabolisms as there is a substantially higher concentration of methane and a low concentration of metals at Guaymas Basin (Shock and Canovas, 2010).

\section{Hydrogen Cycling}

Methanogens and Archaeoglobus are the two main hydrogen oxidizing archaeal lineages at deep sea hydrothermal vents, most likely because at elevated temperatures hydrogenotrophic methanogenesis and sulfate reduction are thermodynamically the most energetically favorable reactions (McCollom and Shock, 1997; Shock and Holland, 2004). Based on the qPCR assays the methanogen mcrA and Archaeoglobus 16S rRNA gene were found in high abundances at Rainbow, EPR, and Guaymas hydrothermal vent fields (Fig 3.5). However at the remaining hydrothermal vent field samples Archaeoglobus was the predominant hydrogen oxidizing lineage, with only two 


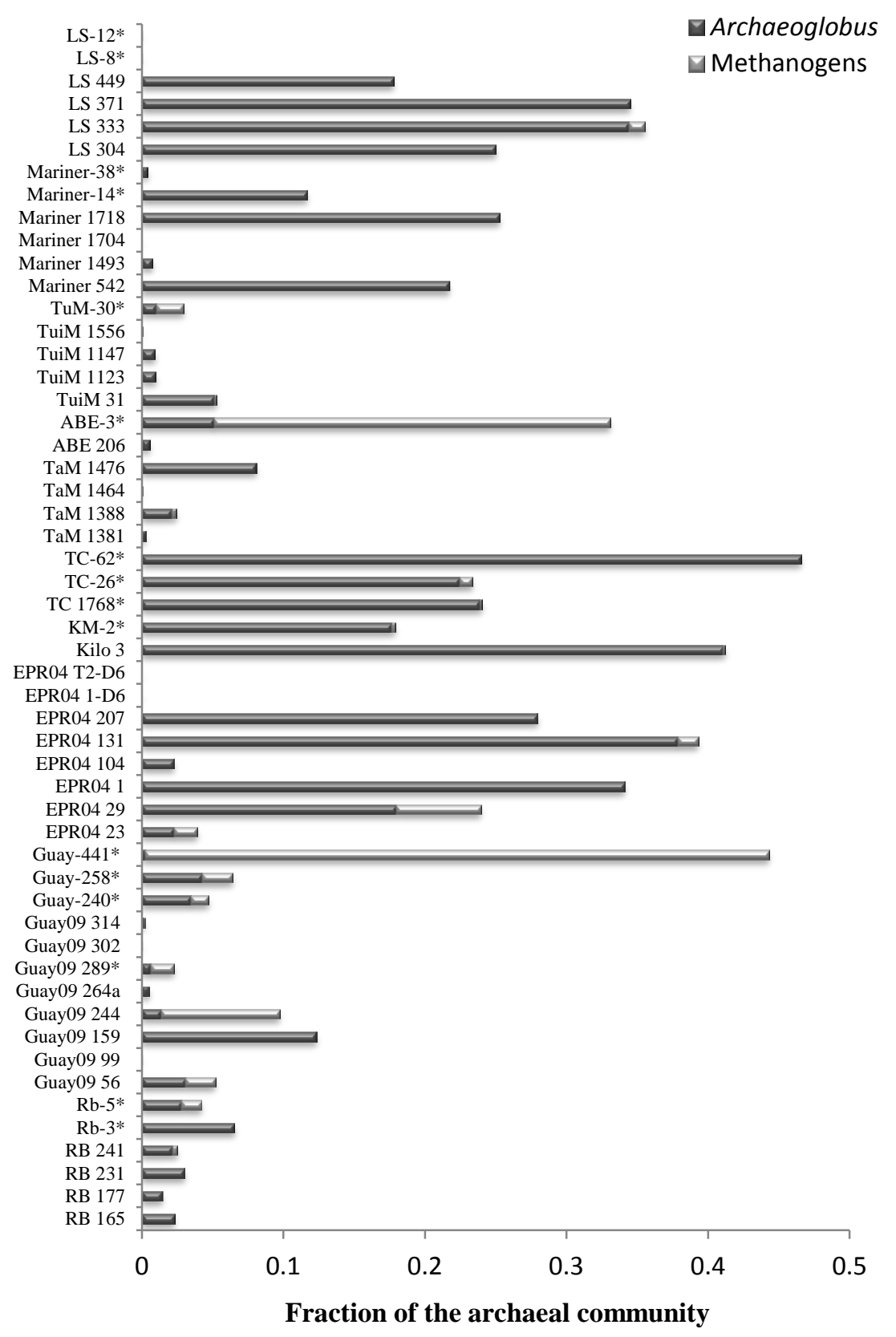

Figure 3.5. Relative proportion of Archaeoglobus and methanogen (mcrA) genes based on qPCR. Vent fields are organized in ascending order with the highest hydrogen end member concentrations at the bottom. 
exceptions (Tum 30 \& ABE 3) (Fig 3.5). The methanogen abundances at the hydrothermal vents were found to be generally proportional to the hydrogen concentration of the end member hydrothermal fluids. This observation is consistent with previous molecular analyses that found that vent fields with high end-member hydrogen concentrations; Iheya North Field, Logatchev, Rainbow, and Kairei all had high proportions of methanogens (Nakagawa et al., 2006; Takai et al., 2008; Takai et al., 2009; Flores et al., 2011). It is also consistent with thermodynamic modeling, as methanogenesis is kinetically constrained in low hydrogen environments compared to other terminal electron acceptors such as sulfate, Fe (III), Mn (IV), and nitrate (McCollom, 2007). In high temperature sulfide deposits sulfate reducers should thermodynamically outcompete methanogens for $\mathrm{H}_{2}$, provided that sulfate is not limiting (McCollom, 2007). The concentration of sulfate in water can be around 300 times greater than oxygen, thus sulfate should not be limiting, even at very low hydrothermal fluid/seawater mixing ratios (McColom, 2007). Thus at low hydrogen concentrations other energetic metabolisms will outcompete the hydrogenotrophic methanogens for hydrogen, such as sulfate reduction by the Archaeoglobus.

Ver Eecke et al., (2012) demonstrated that hydrogen limitation was a key determinant for Methanocaldococcus growth, and that the minimum hydrogen threshold for growth of this methanogen was $17-23 \mu \mathrm{M}$. The Mariner vent field along the ELSC lies below this predicted hydrogen threshold, yet from a single sample from Mariner (Mariner14) we obtained $m c r A$ gene copies. The methanogens detected at Mariner experience temporal and/or spatial variability in hydrogen concentrations, or could have a lower hydrogen threshold than other non-Methanocaldococcus spp., or be part of a 
potential syntrophy with Thermococcales, as some species of Thermococcales are able to oxidize $\mathrm{CO}$ and create $\mathrm{H}_{2}$ as a metabolic end product (Ver Eecke et al., 2012).

\section{Nanoarchaeota/Ignicoccus}

Based on the Nanoarchaeota specific qPCR assays it is evident that the marine Nanoarchaeota are widespread at most deep-sea hydrothermal vents, and particularly in hydrothermal vent chimneys that are ultramafic (Rainbow) or fast spreading basalthosted (EPR and Guaymas) (Fig 3.6). Despite their distribution, the Nanoarchaeota and Ignicoccus represented a minority of the total archaeal community. Over the ten vent field dataset the mean proportional archaeal abundance of both the Nanoarchaeota and Ignicoccus was never greater than $5 \%$ of the archaeal community.

Due to metabolic limitations of $N$. equitans, if I. hospitalis was the sole host in marine environments for all Nanoarchaeota species one would expect the relative proportion of Ignicoccus to Nanoarchaeota to be relatively constant across the vent fields. However, the proportion of Nanoarchaeota to Ignicoccus was not consistent across all ten vent fields as the Nanoarchaeota was found in highest proportions at Rainbow, Guaymas Basin, and the EPR, and the Ignicoccus was observed in the highest proportion from the Lucky Strike, Mariner, and ABE vent samples (Fig 3.6; Fig 3.7). This analysis is consistent with the barcoded pyrosequencing analysis of chimney samples from the MAR and ELSC by Flores et al., (2011; 2012a) that found Nanoarchaeota phylotypes to be in the largest proportion at the Rainbow and Kilo Moana vent fields along the MAR and ELSC respectively. Conversely, these studies found Ignicoccus phylotypes to be in the largest proportion at the Lucky Strike and 


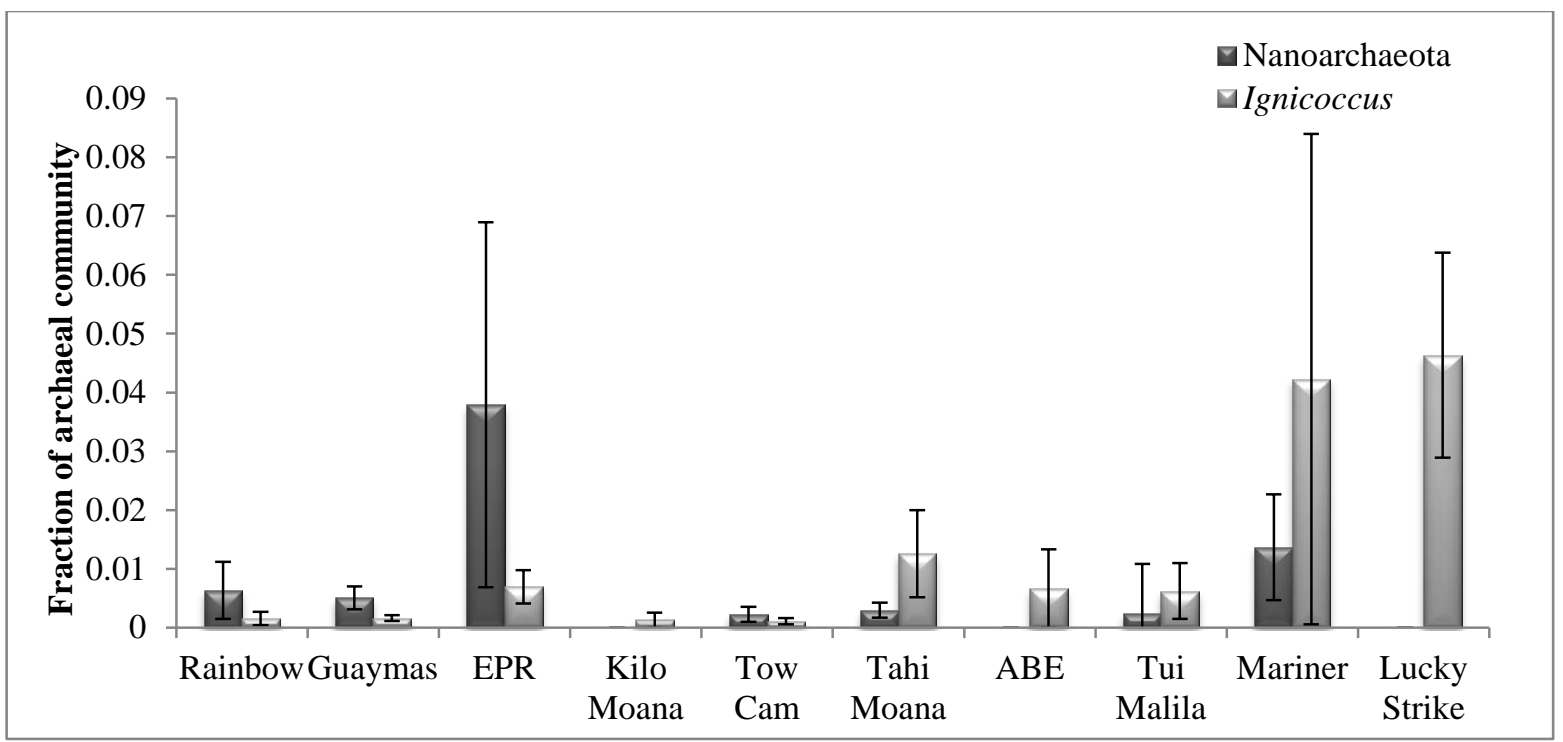

Figure. 3.6. Relative proportion of the Nanoarchaeota and Ignicoccus from deposit samples of globally distributed hydrothermal vents. Error bars indicate \pm 1 standard error of the mean (SEM). 


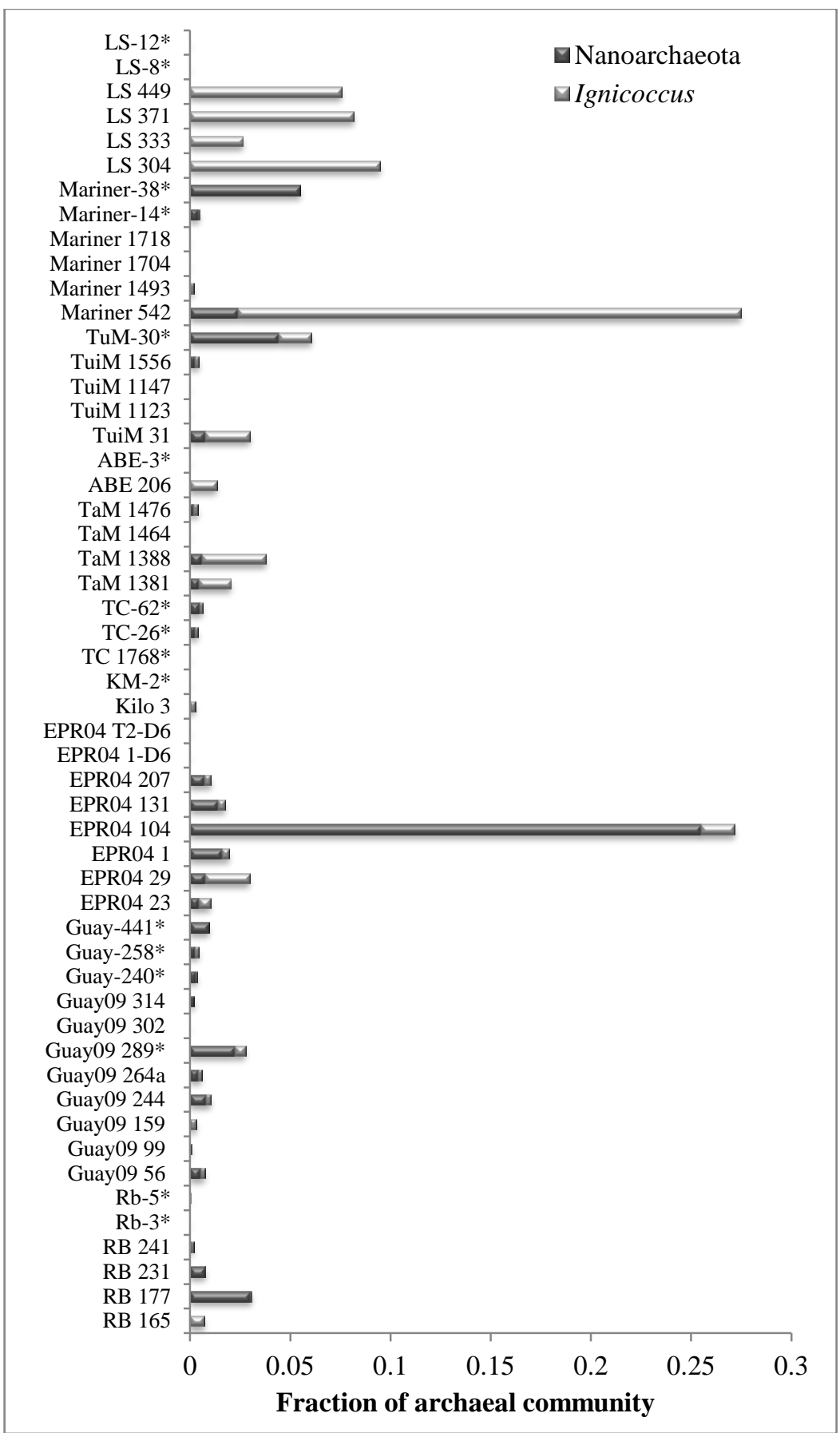

Figure. 3.7. Relative proportion of the Nanoarchaeota and Ignicoccus sequences, based on qPCR. Vent fields are organized in ascending order with the highest hydrogen end member concentration on the bottom. 
Mariner vent fields. However there are a few factors that may affect the observed Nanoarchaeota to Ignicoccus proportion. N. equitans is known to have a variable number of cells attached to I. hospitalis, and due to limitations of primer design, the qPCR assays that targeted the genus Ignicoccus also contain two known species (I. pacificus, and I. islandicus) that have not been shown to be hosts of the N. equitans (Huber et al., 2002). However, the proportion of Nanoarchaeota to the overall archaeal community may not be completely representative as the qPCR universal archaeal primers used in this study does not match all marine Nanoarchaeota sequences. The forward primer in particular only matches two Nanoarchaeota sequences from the RDP database from Rainbow hydrothermal vent samples.

Nanoarchaeota-Local Similarity Analysis

As little is known about the ecological relationship of the Nanoarchaeota in hydrothermal vent deposits, the co-occurring relationship of the most prevalent Nanoarchaeota OTU to other archaeal lineages from previously reported barcoded pyrosequencing data was elucidated through LSA analysis (Flores et al., 2011; Flores et al., 2012a; Reysenbach, unpublished). The positively correlated OTUs that were identified past the kingdom level were generally associated with chemosynthetic energetic metabolisms of either: sulfate reduction, methanogenesis, or sulfur metabolisms (Table 3.4 Fig 3.3). The marine Nanoarchaeota appear to have overlapping ecological niches to Archaeoglobaceae, methanogens, Thermofilaceae, along with two Desulfurococcaceae OTUs. The Desulfurococcaceae is the family of the I. hospitalis, the only known marine Nanoarchaeota host. It is unknown if any of these lineages may 
be previously unidentified Nanoarchaeota hosts or just have overlapping environmental niches. Thus far the only confirmed non-Ignicoccus host is a "Sulfolobus-like" Archaea isolated from the Obsidian Pool at Yellowstone National Park through flow cytometry, and analyzed using single cell genomics (Podar et al., 2013). Of the six OTUs that negatively occur with the Nanoarchaeota, the Thermococcaceae and "DHVE2" can be identified as having generally heterotrophic energetic metabolisms that utilize peptides or carbohydrates. The only identifiable chemosynthetic metabolism is one OTU associated with the Archaeoglobi with either sulfate reduction or iron metabolism.

\section{Flange versus Chimney}

In addition to plate tectonic interactions that influence the structure of the archaeal community at hydrothermal vents, the deposit structure within each hydrothermal vent appears to influence the abundance and distribution of the examined archaeal lineages. The chemosynthetic methanogens and sulfate reducing Archaeoglobus constituted a higher proportion of the archaeal community from the chimney samples than the flange samples (Fig 3.4). This shift in community structure could be associated with the differences in the fluid mixing style. At flanges compared to chimney deposits, the diffuse hydrothermal fluid gets trapped beneath the flanges and is conductively cooled that result in a strongly thermoacidic environment (Tivey et al, 2005). The chemosynthetic lineages may be more influenced by the availability of chemically rich hydrothermal fluid than the heterotrophic Thermococcales.

Previous studies have found that hyperthermophilic chemolithoautotrophic Archaea often inhabit a micro-niche within the innermost section of the chimney closest 
to the vent source, and the bacterial abundance is often highest farther from the venting point and is dominant on the outer crust (Sievert et al., 1999; Sievert et al., 2000). Flange deposits are farther from the venting source and may harbor a more mature microbial community, as there is a buildup of carbon from both bacterial and archaeal chemolithoautotrophs. The heterotrophic groups such as the Thermococcales are then able to utilize the fixed carbon in the form of peptides and carbohydrates (Reysenbach et al., 2000). This shift in predominance of heterotrophic Archaea at flange deposits was also observed from the peptide fermenting thermoacidophile "DHVE2", that was found in much higher concentrations from flange rather than chimney samples (Flores et al., 2012b).

However, there is often substantial heterogeneity even within the same flange deposit. Two Tui Malila samples from opposing sides of the same flange (TuiM 1556 \& 30) were found to have Thermococcales and Nanoarchaeota abundances that were three orders of magnitude higher on the upper portion of the flange than the lower. Due to the extraordinarily steep physical and geochemical gradients at hydrothermal vents, archaeal community structuring may be the most strongly influenced by environmental pressures than in any other microbial biotope.

\section{Conclusion}

Physical and geochemical pressures resulting from complex geologic processes, such as host rock interactions, have long been attributed to driving the available metabolic processes and the microbial diversity at deep sea hydrothermal vents (Tivey $\&$ McDuff, 1990; Tivey et al., 1995; McCollom \& Shock, 1997; Luther et al., 2001; 
McCollom, 2007; Amend and Shock, 2011). Analysis of Archaea from distinct hydrothermal vent systems demonstrated that the community structure is not solely based on host rock, but potentially more complex interaction such as spreading rate and vent deposit structure.

The abundance and distribution of the physiologically diverse major archaeal groups were generally associated with ecological niches within the different hydrothermal vents and the vent deposit structures. Hydrogen oxidizing lineages of the methanogens and Archaeoglobus were found to be generally proportional to the hydrogen concentration of the end member hydrothermal fluids, and more abundant in chimney samples closer to the venting source.

Prior to this study, the abundance and global distributional patterns of the Nanoarchaeota in marine environments was sparse and inconsistently studied across many different molecular techniques. This study showed that the Nanoarchaeota are ubiquitous at most deep-sea hydrothermal vents and generally co-occur with methanogens, Archaeoglobaceae, and Desulfurococcaceae, and have an inconsistent proportional relationship to the genus Ignicoccus. This study and the qPCR primers developed can be used to further investigate this lineage as an initial step for isolation of novel Nanoarchaeota species and potential new hosts through enrichment culture or metagenomic analyses. These analyses and results could also further aid in uncovering the unsettled phylogeny, genetic diversity, and evolutionary history of this archaeal lineage. 


\section{CHAPTER 4: Conclusion}

Archaea that colonize deep-sea hydrothermal vents have been extensively studied through both culture dependent and independent analyses (Takai et al., 2006;

Takai et al., 2011). Culture independent phylogenetic analyses have been used to establish evolutionary relationships, infer physiology and community structure (Moyer, 1998). However, these rRNA based analyses are not without their shortcomings, and are often hampered by biases introduced by the methodological and computational steps taken (Polz and Cavanaugh, 1998; Hong et al., 2009; Engelbrektson et al., 2010; Huse et al., 2010; Haas et al., 2011). Until recently most studies have primarily focused on community structure from mid-ocean ridge systems or have sampled from a single tectonic ridge, to the exclusion of alternative host rock systems. As a result of technological shortcomings and sample limitation the global patterns of the abundance and distribution of major archaeal lineages and the abiotic factors that may influence these patterns are still not well understood. The studies presented in this thesis are intended to better our understanding of the global patterns of archaeal abundance, community structure, and the potential influence of environmental factors.

In Chapter 2 qPCR specific primers were designed or optimized for the major and understudied archaeal lineages of the Archaeoglobus, Thermococcales, marine Nanoarchaeota, and the Ignicoccus. These novel primers were designed based on a comprehensive survey of published databases, and unpublished archaeal 16S rRNA genes. Target $16 \mathrm{~S}$ rRNA gene sequences were used to develop candidate primers by using MEGA5 software and cross-referenced against the RDP database with the RDP 
BLAST program (Cole et al., 2007; Tamura et al., 2011). Each primer was designed using the following guidelines: primer length between $15-30 \mathrm{bp}$, melting temperature approximately $60^{\circ} \mathrm{C}, \mathrm{G}+\mathrm{C}$ content approximately $50 \%$, amplicon size less than $300 \mathrm{bp}$, and limited self-complimentary and heterodimer strands. The specificity of the primers were validated by PCR analyses of both mock archaeal community and environmental gDNA vent deposit samples, and sequencing.

In Chapter 3 I utilized the developed and optimized qPCR specific primers from Chapter 2 along with methanogen mcrA functional gene primers to compare the archaeal community abundance from 54 samples across ten geochemically distinct vent fields. The hydrothermal vent fields tested have a range of host rocks (mafic, ultramafic, and andesite), along with sedimentation and spreading rate. The geologic differences between the sites are predicted to influence the available energetic metabolisms, and thus impact the structure of the microbial community (McCollom, 2007). Based on the qPCR assays of the five archaeal lineages, this study found that the archaeal community assemblage varied dramatically from hydrothermal vents with different vent host rocks along the Mid-Atlantic Ridge and Eastern Lau Spreading Center. In contrast, two vent fields in the East Pacific, $9^{\circ} \mathrm{N}$ on the EPR and Guaymas Basin that are basalt and basaltsediment hosted were found to have similar community composition. These differences in community composition may be driven in part by the availability of chemical energy, as the hydrogen oxidizing lineages of the methanogens and Archaeoglobus were found in higher abundance in the hydrogen enriched vent fields and the heterotrophic Thermococcales constituted a higher proportion of the archaeal community at the less enriched vent fields. In addition, lineage specific analyses of the Nanoarchaeota and the 
genus of its only known marine host, Ignicoccus, were identified to have an inconsistent proportional relationship to each other. Nanoarchaeota phylotypes were found in the highest proportion at the ultramafic or fast spreading basalt hosted vent fields, and the Ignicoccus at the andesite or slow spreading basalt vent fields.

The vent deposit structure was also identified to influence the archaeal distributional patterns. Distinct archaeal communities were observed between the chimney and horizontal flange structures. The chimney samples were found to have a higher proportion of chemosynthetic methanogens and Archaeoglobus, and inversely the flange structures were found to have higher proportions of the heterotrophic Thermococcales. This archaeal proportional shift could be driven by energetic microniches within the vent deposit. The chemolithotrophic lineages may be in higher proportion at the chimney structures as they readily colonize the area closest to the venting source and the heterotrophic Thermococcales dominate in more mature structures with potentially higher concentrations of fixed carbon further from the fluid source.

\section{Future Directions}

Nearly four decades have passed since the discovery of the first deep-sea hydrothermal vent at the Galapagos Rift; yet hydrothermal vent ecosystems continue to be one of least understood biotopes on Earth. This project helped to expand on the understanding of this ecosystem by analyzing the global patterns of archaeal abundance and distribution at geologically diverse hydrothermal vents. The research presented here 
has helped to elucidate how the abundance of select archaeal lineages are potentially affected by: 1) host rock, 2) sedimentation, and 3) and vent deposits structure.

To build on this project there are several future research opportunities and questions to address. Similar sampling and molecular analyses could be employed to investigate hydrothermal vent fields that have not been thoroughly studied, such as Edmond and Kairei on the Central Indian Ridge, in addition to vent fields in the Red Sea that are geologically similar to the sediment-hosted Guaymas basin. In addition the qPCR primers developed from Chapter 2 can be used for targeted enrichments or single cell genomics of the Nanoarchaeota that may aid in uncovering the unsettled phylogeny, genetic diversity, and evolutionary history of this unique archaeal lineage.

As this project only focused on five groups of Archaea it is also vital to expand our understanding of the phylogenetic and metabolic diversity at hydrothermal vents, particularly of uncultured microorganisms. This can be accomplished by utilizing metagenomic analyses of archaeal communities across geochemically distinct vent fields and deposit structures, to further assess putative metabolic capabilities and link function to phylogeny. 


\section{REFERENCE}

Alt, J.C. (1995) Subseafloor processes in mid-ocean ridge hydrothermal systems. Pp. 85-114 in Seafloor Hydrothermal Systems: Physical, Chemical, Biological, and Geological Interactions. Humphris, S.E., Zierenberg, R.A., Mullineaux, L.S., and Thomson, R.E. eds, American Geophysical Union, pp. 85-114.

Amend, J.P., Roger, K.L., Shock, E.L., Gurrieri, S., and Inguaggiato, S. (2003)

Energetics of chemolithoautotrophy in the hydrothermal system of Vulcano Island, southern Italy. Geobiol 1: 37-58.

Amend, A.S., Seifert, K.A., and Burns T.D. (2010) Quantifying microbial communities with 454 pyrosequencing: does read abundance count? Mol Ecol 2: 113-118.

Amend, J. P., McCollom, T. M., Hentscher, M., and Bach, W. (2011) Catabolic and anabolic energy for chemolithoautotrophs in deep-sea hydrothermal systems hosted in different rock types. Geochimica et Cosmochimica Acta, 75: 57365748.

Baker, G.C., Smith, J.J., and Cowan, D.A. (2003). Review and re-analysis of domainspecific 16S primers. Journal of Microbiological Methods 55: 541-555.

Baross, J.A., and Deming, J.W. (1983) Growth of black smoker bacteria at temperatures of at least $250{ }^{\circ} \mathrm{C}$. Nature 303: 423.

Baross, J.A., M.D. Lilley, and L.I., Gordon (1982) Is the $\mathrm{CH}_{4}, \mathrm{H}_{2}$ and $\mathrm{CO}$ venting from submarine hydrothermal systems produced by thermophilic bacteria? Nature 298: $366-368$.

Benson, D.A., Karsch-Mizrachi, I., Lipman, D.J., Sotell, J. and Wheller, D.L. (2005) GenBank. Nucleic Acids Res 33: D34-D38 
Benson, D.A., Karsch-Mizarchi, I., Lipman, D.J., Ostell, J., and Sayers, E.W. (2010) GenBank Nucleic Acids Res 38: D46-D51.

Bertoldo, C., and Antranikian, G. (2006) The order Thermococcales. Prokaryotes. 3: 6981.

Bischoff, J.L., and W.E., Seyfried Jr. (1978) Hydrothermal chemistry of seawater from $25^{\circ}$ to $350^{\circ} \mathrm{C}$. Am J Sci 278:838-860.

Bonin, A.S., and Boone, D.R. (2006) The order methanobacteriales. Prokaryotes 3: 231243

Brochier, C., Gribaldo, S., Zivanovic, Y., Confalonieri, F., and Forterre, P. (2005) Nanoarchaea: representatives of a novel archaeal phylum or a fast-evolving euryarchaeal lineage related to Thermococcales? Genome Biol 6: R42.

Buchan, A., Gonzalez J.M., and Moran, M.A. (2005) Overview of the marine roseobacter lineage. Appl Environ Microbiol 71: 5665-5677.

Burggraf, S., Jannasch, H.W., Nicolaus, B., and Stetter, K.O. (1990) Archaeoglobus profundus, sp. nov., represents a new species within the sulfate-reducing archaebacteria. Syst Appl Microbiol 13: 24-28.

Butterfield, D.A., and Massoth, G.J. (1994) Geochemistry of north Cleft segment vent fluids: temporal changes in chlorinity and their possible relation to recent volcanism. J. Geophys. 99: 4951-4968.

Campbell, B.J., Engel, A.S., Porter, M.L., and Takai, K. (2006) The versatile Epsilonproteobacteria: key players in sulphidic habitats. Nature 4: 458-468. 
Carbotte, S.M., and MacDonald, K.C. (1992) East Pacific Rise $8^{\circ}-10^{\circ} 300 N$ : evolution of ridge segments and discontinuities from SeaMARC II and three-dimensional magnetic studies. J Geohys Res 97: 6959-6982.

Casanueva, A., Galada, N., Baker, G.C., Grant, W.D., Heaphy, S., Jones, B., Yanhe, M., Ventosa, A. Blamey, J., and Cowan D.A. (2008) Nanoarchaeal 16S rRNA gene sequences are widely dispersed in hyperthermophilic and mesophilic halophilic environments. Extremophiles : life under extreme conditions 12: 651-6.

Charlou, J.L., Donval, J.P., Fouquet, Y., Jean-Baptiste, P., and Holm, N. (2002) Geochemistry of high $\mathrm{H}_{2}$ and $\mathrm{CH}_{4}$ vent fluids issuing from ultramafic rocks at the Rainbow hydrothermal field (36²'N, MAR). Chem Geol 191: 345-359.

Clarke, K., and Gorley, R. (2006) PRIMER v6. User manual/ tutorial Plymouth routine in mulitvariate ecological research Plymouth Marine Laboratory

Cole, J. R., Wang, Q., Cardenas, E., Fish, J., Chai, B., Farris, R. J., Kulam-SyedMohideen, A.S., McGarrell D.M., Marsh, T., Garrity, G.M., and Tiedje, J.M. (2009) The Ribosomal Database Project: improved alignments and new tools for rRNA analysis. Nucleic acids research, 37(Database issue), D141-5.

Comolli, L.R., Baker, B.J., Downing, K.H., Siegerist, C.E., and Banfield, J.F. (2009) Three-dimensional analysis of the structure and ecology of a novel, ultrasmall archaeon. ISME J 3:159-167.

Crépeau, V., Cambon Bonavita, M.-A., Lesongeur, F., Randrianalivelo, H., Sarradin, P.M., Sarrazin, J., and Godfroy, A. (2011) Diversity and function in microbial mats from the Lucky Strike hydrothermal vent field. FEMS Microbiol Ecol 76: 52440. 
DasSarma, S., and Fleischmann, E.F., (1995) Archaea: A Laboratory ManualHalophiles. Cold Spring Harbour Laboratory Press, New York, pp. 269-272.

Dhillon, A., Lever, M., Lloyd, K.G., Albert, D.B., Sogin, M.L., and Teske, A. (2005) Methanogen diversity evidenced by molecular characterization of methyl coenzyme M Reductase A (mcrA) genes in hydrothermal sediments of the Guaymas Basin. Appl Environ Microbiol 71: 4592-4601.

Douville, E., Charlou, J.L., Oelkers, E.H., Bienvenu, P., Colon, C.F.J., Donval, J.P., Fouquet, Y., Prieur, D., and Appriu, P. (2002) The rainbow vent fluids (36 degrees $\left.14^{\prime} \mathrm{N}, \mathrm{MAR}\right)$ : the influence of ultramafic rocks and phase separation on trace metal content in Mid-Atlantic Ridge hydrothermal fluids. Chem Geol 184: $37-48$.

Edmond, J.M., Measures, C.I., Grant, B., and Sciences, P. (1985) Chemistry of submarine hydrothermal solutions at Guaymas Basin , Gulf of California. Geochimica et Cosmochimica Acta 49: 2221-2237.

Elkins, J. G., Podar, M., Graham, D. E., Makarova, K. S., Wolf, Y., Randau, L., Hedlund, B. P., Brochier-Armanet, C., Kunin, V., Anderson, I., Lapidus, A., Goltsman, E., Barry, K., Koonin, E.V., Hugenholtz, P., Kyrpides, N., Wanner, G., Richardson, P., Keller, and M., Stetter, K.O. (2008) A korarchaeal genome reveals insights into the evolution of the Archaea. Proc Natl Acad Sci USA 105: $8102-7$.

Elwood, H.J., Olsen, G.J., and Sogin, M.L. (1985) The small-subunit ribosomal RNA gene sequences from the hypotrichous ciliates Oxytricha nova and Stylonychia pustulata. Mol. Biol. Evol. 2, 399 
Engelbrektson A., Kunin V., Wrighton K., Zvenigorodsky, N., Chen, F. Ochman, H., and Hugenholtz P (2010) Experimental factors affecting PCR-based estimates of microbial species richness and evenness. ISME J 4: 642-647.

Ferrini, V.L., Tivey, M.K., Carbotte, S.M., Martinez, F., and Roman, C. (2008) Variable morphologic expression of volcanic, tectonic, and hydrothermal processes at six hydrothermal vent fields in the Lau back-arc basin. Geochem Geophy Geosy 9.

Fiala, G. and Stetter, K.O. (1986) Pyrococcus furiosus sp. nov. represents a novel genus of marine heterotrophic archaebacteria growing optimally at 100 1C. Arch Microbiol 145: 56-61.

Flores, G.E., Campbell, J.H., Kirshtein, J.D., Meneghin, J., Podar, M., Steinberg, J.I., Seewald, J.S., Tivey, M.K., Voytek, M.A., Yang, Z.K., and Reysenbach, A.-L. (2011) Microbial community structure of hydrothermal deposits from geochemically different vent fields along the Mid-Atlantic Ridge. Environ Microbiol 13: 2158-71.

Flores, G.E., Shakya, M., Meneghin, J., Yang, Z.K., Seewald, J.S., Geoff Wheat, C., Podar, M., and Reysenbach, A.-L. (2012a) Inter-field variability in the microbial communities of hydrothermal vent deposits from a back-arc basin. Geobiol 10: 333-346.

Flores, G.E., Wagner, I.D., Liu, Y., and Reysenbach, A.-L. (2012b) Distribution, abundance, and diversity patterns of the thermoacidophilic "deep-sea hydrothermal vent euryarchaeota 2". Frontiers in Microbiology, 3: 1-17.

Gamo, T., Okamura, K., Charlou, J.L., Urabe, T., Auzende, J.M., Ishibashi, J., Shitashima, K., and Kodama, Y. (1997) Shipboard scientific party of the Manus- 
Flux Cruise, Acidic and sulfate-rich hydrothermal fluid from the Manus basin, Papua New Guinea. Geology 25: 139-142.

Gamo, T., Chiba, H., Yamanaka, T., Okudaira, T., Hashimoto, J., Tsuchida, S., Ishibashi, J., Kataoka, S., Tsunogai, U., Okamura, K., Sano, Y., and Shinjo R. (2001) Chemical characteristics of newly discovered black smoker fluids and associated hydrothermal plume at the Rodriguez Triple Junction, Central Indian Ridge. Earth Planet. Sci. Lett 193: 371-379.

Götz, D., Banta, A., Beveridge, T.J., Rushdi, A.I., Simoneit, B.R.T., and Reysenbach, AL. (2002) Persephonella marina gen. nov., sp nov and Persephonella guaymasensis sp nov., two novel, thermophilic, hydrogen-oxidizing microaerophiles from deep-sea hydrothermal vents. Int J Syst Evol Micr 52: $1349-1359$.

Haas, B.J., Gevers, D., Earl, A.M., Feldgarden, M., Ward, D.V., Giannoukos, G., Ciulla D, Tabbaa, D., Highland, S.K., Sodergren, E., Methe, B., DeSantis, T.Z., Petrosino, J.F., Knight, R. and Birren, B.W. (2011) Chimeric 16S rRNA sequence formation and detection in Sanger and 454- pyrosequenced PCR amplicons. Genome Res 21: 494- 504.

Hannington, M.D., de Ronde, C.E.J., and Petersen, S. (2005) Sea-floor tectonics and submarine hydrothermal systems. Econ Geol 100: 111-143.

Hartzell, P., and Reed, D. (2006) The genus Archaeoglobus. Prokaryotes. 3: 257-273. Hafenbradl, D., Keller, M., Dirmeier, R., Rachel, R.,Roßnagel, P., Burggraf, S., Huber, H., and Stetter, K.O. (1996) Ferroglobus placidus gen. nov., sp. nov., a novel 
hyperthermophilic archaeum that oxidizes $\mathrm{Fe}^{2+}$ at neutral $\mathrm{pH}$ under anoxic conditions. Arch.Microbiol. 166: 308-314.

Harmsen, H.J.M, Prieur, D. and Jeanthon, C. (1997) Distribution of microorganisms in deep-sea hydrothermal vent chimneys investigated by whole-cell hybridization and enrichment culture of thermophilic subpopulations. Appl Environ Microb 63: 2876-2883.

Higashi, Y., Sunamura, M., Kitamura, K., Nakamura, K.-i., Kurusu, Y., Ishibashi, J.-I., Urabe, T., and Maruyama, A. (2004), Microbial diversity in hydrothermal surface to subsurface environments of Suiyo Seamount, Izu-Bonin Arc, using a catheter-type in situ growth chamber. FEMS Microbiol Ecol. 47: 327-336.

Hoek, J., Banta, A., Hubler, F. and Reysenbach, A.-L. (2003) Microbial diversity of a sulphide spire located in the Edmond deep-sea hydrothermal vent field on the Central Indian Ridge. Geobiol 1: 119-127.

Hohn, M.J., Hedlund, B.P., and Huber, H. (2002) Detection of 16S rDNA sequences representing the novel phylum "Nanoarchaeota": indication for a wide distribution in high temperature biotopes. Systematic and applied microbiology, 25: $551-4$.

Holden, J.F., Takai, K., Summit, M., Bolton, S., Zyskowski, J. and Baross, J.A. (2001) Diversity among three novel groups of hyperthermophilic deep-sea Thermococcus species from three sites in the northeastern Pacific Ocean. FEMS Microbiol Ecol 36: 51-60. 
Holden, J.F., Breier, J.A., Rogers, K.L., Schulte, M.D., and Toner, B.M. (2012)

Biogeochemical processes at hydrothermal vents: Microbes and minerals, bioenergetics, and carbon fluxes. Oceanography 25 :196-208.

Hong, S., Bunge, J., Leslin, C., Jeon, S., and Epstein, S.S. (2009) Polymerase chain reaction primers miss half of rRNA microbial diversity. ISME J 3: 1365-1373.

Huber, H, Jannasch, H., Rachel, Reinhard, R., Fuchs, T., and Stetter, K.O. (1997) Archaeoglobus veneficus sp. nov., a novel facultative chemolithoautotrophic hyperthermophilic sulfite reducer, isolated from abyssal black smokers. System Appl Microbiol 20: 374-380.

Huber, H., Hohn, M.J., Rachel, R., Fuchs, T., Wimmer, V.C., and Stetter, K.O. (2002) A new phylum of Archaea represented by a nanosized hyperthermophilic symbiont. Nature 417: 63-67.

Huber, J.A., Butterfield, D.A., and Baross, J.A. (2002b) Temporal Changes in Archaeal Diversity and Chemistry in a Mid-Ocean Ridge Subseafloor Habitat Temporal Changes in Archaeal Diversity and Chemistry in a Mid-Ocean Ridge Subseafloor Habitat, 68: doi:10.1128/AEM.68.4.1585.

Huber, J.A., Butterfield, D.A., and Baross, J.A. (2006) Diversity and distribution of subseafloor Thermococcales populations in diffuse hydrothermal vents at an active deep-sea volcano in the northeast Pacific Ocean. J Geophys Res 111. doi:10.1029/2005JG000097

Huber, J.A., and J.F., Holden (2008) Modeling the impact of diffuse vent microorganisms along mid-ocean ridges and flanks. Geophysical Monograph Series 178. 
Huber, J.A., Cantin, H.V., Huse, S.M., Welch, D.B.M., Sogin, M.L., and Butterfield, D.A. (2010) Isolated communities of Epsilonproteobacteria in hydrothermal vent fluids of the Mariana Arc seamounts. FEMS Microbiol Ecol 73: 538-49.

Huse, S.M., Welch, D.M., Morrison, H.G., and Sogin, M.L. (2010) Ironing out the wrinkles in the rare biosphere through improved OTU clustering. Environ Microbiol 12: 1889-1898.

Jannasch, H.W., and Wirsen, C.O. (1979) Chemosynthetic primary production at East Pacific sea floor spreading centers. Bioscience 29: 592-598.

Jannasch, H.W. (1995), Microbial interactions with hydrothermal fluids, in Seafloor Hydrothermal Systems: Physical, Chemical, Biological and Geological Interactions, Geophys. Monogr. Ser., vol. 91, edited by S. E. Humphris et al., pp. 273-296, AGU, Washington, D. C.

Jaeschke, A., Jørgensen, S. L., Bernasconi, S. M., Pedersen, R. B., Thorseth, I. H., and Früh-Green, G. L. (2012) Microbial diversity of Loki's Castle black smokers at the Arctic Mid-Ocean Ridge. Geobiol 10: 548-61.

Jones, W.J., Leigh, J.A., Mayer, F., Woese, C.R., and Wolfe, R.S. (1983) Methanococcus jannaschii sp. nov., an extremely thermophilic methanogen from a submarine hydrothermal vent. Arch Microbiol 136: 254-261.

Juniper, S.K. and Tebo, B.M. (1995) Microbe-metal interactions and mineral deposition at hydrothermal vents. In: The Microbiology of Deep-Sea Hydrothermal Vents (Karl, DM, Ed.), pp. 219-253. CRC Press, Boca Raton, FL. 
Karl, D.M. (1995) Ecology of free-living, hydrothermal vent microbial communities. In: The Microbiology of Deep-Sea Hydrothermal Vents. pp. 35-124. CRC Press, Boca Raton, FL.

Kashefi, K., Tor, J.M., Holmes, D.E., Van Praagh, C.V.G., Reysenbach, A-L., and Lovley, D.R. (2002) Geoglobus ahangari gen. nov., sp. nov., a novel hyperthermophilic archaeon capable of oxidizing organic acids and growing autotrophically on hydrogen with $\mathrm{Fe}(\mathrm{III})$ serving as the sole electron acceptor. Int J Syst Evol Micr 52: 719-728.

Kelley, D.S., and Fruh-Green, G.L. (2001) Volatile lines of descent in submarine plutonic environments: insights from stable isotope and fluid inclusion analyses. Geochimica Cosmochimica Acta 65: 3325-3346.

Kolganova, T.V., Kuznetsov, B.B., and Tourova, T.P., (2002) Designing and testing oligonucleotide primers for amplification and se- quencing of Archaeal 16S rRNA genes. Mikrobiologiya 71: 283-286.

Kormas, K.A., Tivey, M.K., Von Damm, K., and Teske, A. (2006) Bacterial and archaeal phylotypes associated with distinct mineralogical layers of a white smoker spire from a deep-sea hydrothermal vent site ( 9 degrees N, East Pacific Rise). Environ Microbiol 8: 909-20.

Kurr, M., Huber, R., König, H., Jannasch, H.W., Fricke, H., Trincone, A., Kristjansson, J.K., and Stetter K.O. (1991) Methanopyrus kandleri, gen. and sp. nov. represents a novel group of hyperthermophilic methanogens, growing at $110^{\circ} \mathrm{C}$. Arch Microbiol 156: 239- 247. 
Lasa I, and Berenguer J. (1993) Thermophilic enzymes and their biotechnological potential. Microbiologia 9: 77-89.

Lee, H.S.,Kang, S.G.,Bae, S.S., Lim, J.K.,Cho, Y., Kim, Y.J., Jeon, J.H.,Cha, S.S., Kwon, K.K., Kim, H.T. (2008)The completegenome sequence of Thermococcus onnurineus NA1 reveals amixed heterotrophic and carboxydotrophicmetabolism. J Bacteriol 190: 7491-7499.

Lepage, E., Marguet, E., Geslin, C., Matte-Tailliez, O,. Zillig, W., Forterre, P., and Tailliez, P. (2004) Molecular diversity of new Thermococcales isolates from a single area of hydrothermal deep-sea vents as revealed by randomly amplified polymorphic DNA fingerprinting and 16S rRNA gene sequence analysis. Appl. Environ. Microbiol. 70: 1277-1286.

Longnecker, K., and Reysenbach, A-L. (2001) Expansion of the geographic distribution of a novel lineage of e-proteobacteria to a hydrothermal vent site on the Southern East Pacific Rise. FEMS Microbiol Ecol 35: 287-293.

Lilley, M.D., J.E. Lupton and E.A. Olson (2002) Using $\mathrm{CO}_{2}$ and $\mathrm{He}$ in vent fluids to constrain along axis magma dimension at $9^{\circ} \mathrm{N}, \mathrm{EPR}$, Eos Trans. AGU, 83, Fall Meeting Suppl., F1386

Liu, Y., and Whitman, W.B. (2008) Metabolic, phylogenetic, and ecological diversity of the methanogenic archaea. Ann NYAcad Sci 1125: 171-189.

Lueders, T., Chin, K.J., Conrad, R., Friedrich, M. (2001) Molecular analyses of methylcoenzyme $\mathrm{M}$ reductase $\alpha$-subunit $(m c r A)$ genes in rice field soil and enrichment 
cultures reveal the methanogenic phenotype of a novel archaeal lineage. Environ Microbiol 3: 194-204.

Luton, P. E., Wayne, J. M., Sharp, R. J., \& Riley, P. W. (2002) The mcrA gene as an alternative to $16 \mathrm{~S}$ rRNA in the phylogenetic analysis of methanogen populations in landfill. Microbiology (Reading, England) 148: 3521-30.

Lutz, R.A., and Kennish, M.J. (1993) Ecology of deep-sea hydrothermal vent communities: A review. Reviews of geophysics 31: 211-242

Martinez, F., Okino, K., Ohara, Y., Reysenbach, A-L., and Goffredi, S.K. (2007) Backarc Basins. Oceanography 20: 116-127.

McCliment, E.A., Voglesonger, K.M., O’Day, P.A., Dunn, E.E., Holloway, J.R., and Cary, S.C. (2006) Colonization of nascent, deep-sea hydrothermal vents by a novel Archaeal and Nanoarchaeal assemblage. Environ Microbiol 8: 114-25.

McCollom, T.M., and Shock, E.L. (1997) Geochemical constraints on chemolithoautotrophic metabolism by microorganisms in seafloor hydrothermal systems. Geochim. Cosmochim. Acta 61: 4375-4391.

McCollum, T.M., and P.J., Amend (2005) A thermodynamic assessment of energy requirements for biomass synthesis by chemolithoautotrophic micro-organisms in oxic and anoxic environments. Geobiol 3: 135-144.

McCollom, T.M. (2007) Geochemical constraints on sources of metabolic energy for chemolithoautotrophy in ultramafic-hosted deep-sea hydrothermal systems. Astrobiology 7: 933-50. 
Mehta, M.P.,and Baross J.A. (2006) Nitrogen fixation at $92^{\circ} \mathrm{C}$ by a hydrothermal vent archaeon. Science 314:1783-1786.

Mori, K., Maruyama, A., Urabe, T., Suzuki, K., and S., Hanada. (2008) Archaeoglobus infectus sp. nov., a novel thermophilic, chemolithoheterotrophic archaeon isolated from a deep-sea rock collected at Suiyo Seamount, Izu-Bonin Arc, western Pacific Ocean. Int J Syst Evol Micbiol 58: 810-816.

Morikaw, A.M., Izawa, Y., Rashid, N., Hoaki T., and Imanaka T. (1994) Purification and characterization of a thermostable thiol protease from a newly isolated hyperthermophilic Pyrococcus sp. Appl Environ Microbiol 60: 4559-4566.

Mottl, M.J., Seewald J.S., Wheat, C.G., Tivey, M.K., Michael, P.J., Proskurowski, G., McCollom, T.M., Reeves, E., Sharkey, J., You, C.-F., Chan, L.-H., and Pichler, T. (2011) Chemistry of hot springs along the Eastern Lau Spreading Center. Geochimica et Cosmochimica Acta 75: 1013-1038.

Moussard, H., L’Haridon, S., Tindall, B.J., Banta, A., Schumann, P., Stackebrandt, E., Reysenbach, A.L., and Jeanthon, C. (2004). Thermodesulfatator indicus gen. nov., sp. nov., a novel thermophilic chemolithoautotrophic sulfate- reducing bacterium isolated from the Central Indian Ridge. Int J Syst Evol Microbiol 54: $227-233$.

Nakagawa, S., Takai, K., Horikoshi, K., and Sako, Y. (2003) Persephonella hydrogeniphila sp. nov., a novel thermophilic, hydrogen-oxidizing bacterium from a deep-sea hydrothermal vent chimney. Int J Syst Evol Micbiol 53: 863869. 
Nakagawa, T., Nakagawa, S., Inagaki, F.,Takai, K., and Horikoshi, K. (2004)

Phylogenetic diversity of sulfate-reducing prokaryotes in active deep-sea hydrothermal vent chimney structures. FEMS Microbiol Lett 232:145-152.

Nakagawa, S., Takai, K., Inagaki, F., Chiba, H., Ishibashi, J., Kataoka, S., Hirayama, H., Nunoura, T., Horikoshi, K., and Sako, Y. (2005a) Variability in microbial community and venting chemistry in a sediment-hosted backarc hydrothermal system: impacts of subseafloor phase-separation. FEMS Microbiol Ecol 54: 141155.

Nakagawa, S., Takai, K., Inagaki, F., Hirayama, H., Nunoura, T., Horikoshi, K., and Sako, Y. (2005b) Distribution, phylogenetic diversity and physiological characteristics of epsilon- Proteobacteria in a deep-sea hydrothermal field. Environ Microbiol 7: 1619-1632.

Nakagawa, T., Takai, K., Suzuki, Y., Hirayama, H., Konno, U., Tsunogai, U., and Horikoshi, K. (2006) Geomicrobiological exploration and characterization of a novel deep-sea hydrothermal system at the TOTO caldera in the Mariana Volcanic Arc Environ Microbiol 8: 37-49.

Nakagawa, S., Takai, K., Inagaki, F., Chiba, H., Ishibashi, J., Kataoka, S., Hirayama, H., Nunoura, T., Horikoshi, K., and Sako, Y. (2006) Variability in microbial community and venting chemistry in a sediment-hosted backarc hydrothermal system: Impacts of subseafloor phase-separation. FEMS Microbiol Ecol 54: 141155.

Nakagawa, S., and Takai, K. (2008) Deep-sea vent chemoautotrophs: diversity, biochemistry and ecological significance. FEMS Microbiol Ecol 65: 1-14. 
Nealson, K.H., Inagaki, F., and Takai, K. (2005) Hydrogen-driven subsurface lithoautotrophic microbial ecosystems (SLiMEs): do they exist and why should we care? Trends in microbiology 13: 405-10.

Nelson, D.C., Wirsen, C.O., and Jannasch, H.W.(1989) Characterization of large, autotrophic Beggiatoa sp. abundant at hydrothermal vent of Guayamas basin. Appl Environ Microb 55: 2909-2917.

Nercessian, O., Reysenbach, A.-L., Prieur, D., and Jeanthon, C. (2003) Archaeal diversity associated with in situ samplers deployed on hydrothermal vents on the East Pacific Rise (13ํ) N). Environ Microbiol 5: 492-502.

Nercessian, O., Bienvenu, N., Moreira, D., Prieur, D. and Jeanthon, C. (2005) Diversity of functional genes of methanogens, methanotrophs and sulfate reducers in deepsea hydrothermal environments. Environ Microbiol 7: 118-132.

Nunoura, T., and Takai, K. (2009) Comparison of microbial communities associated with phase-separation-induced hydrothermal fluids at the Yonaguni Knoll IV hydrothermal field, the Southern Okinawa Trough. FEMS Microbiol Ecol 67: $351-70$.

Olins, H.C., Rogers, D.R., Frank, K.L., Vidoudez C., and Girguis, P.R. (2013) Assessing the influence of physical, geochemical and biological factors on anaerobic microbial primary productivity within hydrothermal vent chimneys. Geobiol 11: 279-293.

Opatkiewicz, A.D., Butterfield, D.A., and Baross, J.A. (2009) Individual hydrothermal vents at Axial Seamount harbor distinct subseafloor microbial communities. FEMS Microbiol Ecol 70: 413-24. 
Orphan, V.J., Taylor, L.T., Hafenbradl, D., and Delong, E.F. (2000). Culture-dependent and culture-independent characterization of microbial assemblages associated with high-temperature petroleum reservoirs. Appl Environ Microbiol 66: 700711.

Pagé, A., Tivey, M. K., Stakes, D. S., and Reysenbach, A.-L. (2008) Temporal and spatial archaeal colonization of hydrothermal vent deposits. Environ Microbiol 10: $874-884$.

Pagé, A. (2008) Microbial Colonization of Deep-sea Hydrothermal Vent Chimneys. ProQuest

Paul, K., Nonoh, J.O., Mikulski, L., and Brune, A (2012) "Methanoplasmatales," Thermoplasmatales-Related Archaea in Termite Guts and Other Environments, Are the Seventh Order of Methanogens. Appl Environ Microbiol 78: 238245-8253.

Perner, M., Kuever, J., Seifert, R., Pape, T., Koschinsky, A., Schmidt, K., Strauss, H., and Imhoff, J.F. (2007) The influence of ultramafic rocks on microbial communities at the Logatchev hydrothermal field, located $15^{\circ} \mathrm{N}$ on the MidAtlantic Ridge. FEMS Microbiol Ecol 61: 97-109.

Polz, M.F., and Cavanaugh, C.M. (1998) Bias in template-to- product ratios in multitemplate PCR. Appl Environ Microbiol 64: 3724-3730.

Podar, M., Makarova, K. S., Graham, D. E., Wolf, Y. I., Koonin, E. V, \& Reysenbach, A. (2013) Insights into archaeal evolution and symbiosis from the genomes of a Nanoarchaeon and its crenarchaeal host from Yellowstone. Biology Direct 8: 9. 
Reysenbach, A.-L., Pace, N.R., (1995) In: Robb, F.T., Place, A.R. (Eds.), Archaea: A Laboratory Manual-Thermophiles. Cold Spring Harbour Laboratory Press, New York, pp. 101-107.

Reysenbach, A-L., Longnecker, K., and Kirshtein, J. (2000) Novel bacterial and archaeal lineages from an in situ growth chamber deployed at a Mid-Atlantic Ridge hydrothermal vent. Appl Environ Microb 66: 3798-806.

Reysenbach, A-L., and Shock., E. (2002) Merging Genomes with Geochemistry in Hydrothermal Ecosystems. Environ Microbiol 296: 1077-1082.

Reysenbach, A.-L., Liu, Y., Banta, A.B., Beveridge, T.J., Kirshtein, J.D., Schouten, S., Tivey, M.K, Von Damm, K.L., and Voytek, M.A. (2006) A ubiquitous thermoacidophilic archaeon from deep-sea hydrothermal vents. Nature 442: 1-4.

Reysenbach, A-L., and Flores, G.E. (2008) Electron microscopy encounters with unusual thermophiles helps direct genomic analysis of Aciduliprofundum boonei. Geobiol 6: 331-6.

Ronimus, R.S., Reysenbach, A.-L., Musgrave, D.R., and Morgan, H.W. (1997) The phylogenetic position of the Thermococcus isolate AN1 based on 16s rRNA gene sequence analysis: a proposal that AN 1 represents a new species, Tlzernzococcus zilligii sp. nov. Arch Microhiol 168: 245-248.

Roussel, E.G., Konn, C., Charlou, J.-L., Donval, J.-P., Fouquet, Y., Querellou, J., Prieur, D., and Cambon Bonavita, M.-A. (2011) Comparison of microbial communities associated with three Atlantic ultramafic hydrothermal systems. FEMS Microbiol Ecol 77: 647-65. 
Rouxel, O. (2004) Copper Isotope Systematics of the Lucky Strike, Rainbow, and Logatchev Sea-Floor Hydrothermal Fields on the Mid-Atlantic Ridge. Econ Geolg 99: 585-600.

Ruan, Q., Dutta, D., Schwalbach, M.S., Steele, J.A., Fuhrman, J.A., and Sun, F. (2006) Local similarity analysis reveals unique associations among marine bacterioplankton species and environmental factors. Bioinformatics 22: 25322538.

Ruby, E.G., Wirsen, C.O., and Jannasch, H.W. (1981) Chemolithotrophic SulfurOxidizing Bacteria from the Galapagos Rift Hydrothermal Vents. Appl Environ Microbiol 42: 317-324.

Ruby, E.G., and Jannasch, H.W. (1982) Physiological characteristics of Thiomicrospira sp. Strain L-12 isolated from deep-sea hydrothermal vents. J Bacteriol 149: 161165.

Sakai, S., Imachi, H., Hanada, S., Ohashi, A., Harada, H., and Kamagata, Y. (2008) Methanocella paludicola gen. nov., sp. nov., a methane-producing archaeon, the first isolate of the lineage 'Rice Cluster I', and proposal of the new archaeal order Methanocellales ord. nov. Int J Syst Evol Micr 58: 929-936.

Sambrock, J., Russell, D.W., "Molecular Cloning” Cold Spring Harbor Laboratory Press, 2001.

Sarrazin, J., and Juniper, S.K. (1999) Biological characteristics of a hydrothermal edifice mosaic community. Mar Ecol Prog Ser 185: 1-19.

Schmidt, K., Koschinsky, A., Garbe-Schonberg, D., de Carvalho, L.M., and Seifert, R. (2007) Geochemistry of hydrothermal fluids from the ultramafic-hosted 
Logatchev hydrothermal field, $15^{\circ} \mathrm{N}$ on the Mid-Atlantic Ridge: Temporal and spatial investigation. Chem Geol 242: 1-21.

Schrader, H. (1982) Diatom biostratigraphy and laminated diatomaceous sediments from the Gulf of California. p. 973-981. In J R Curray (ed.), Initial reports of the Deep Sea Drilling Project, Leg 64. U.S. Government Printing Office, Washington, D.C.

Schrenk, M.O., Kelley, D.S., Delaney, J.R., Baross, J.A. (2003) Incidence and Diversity of Microorganisms within the Walls of an Active Deep-Sea Sulfide Chimney. Appl Environ Microbiol 69: 3580-3592.

Schrenk, M.O., Kelley, D.S., Bolton, S.A, and Baross, J.A. (2004) Low archaeal diversity linked to subseafloor geochemical processes at the Lost City Hydrothermal Field, Mid-Atlantic Ridge. Environ Microbiol. 6: 1086-95.

Seewald, J., Cruse, A., and Saccocia, P. (2003) Aqueous volatiles in hydrothermal fluids from the Main Endeavour Field, northern Juan de Fuca Ridge: Temporal variability following earthquake activity. Earth Planet Sci Lett 216: 575-590.

Shakya, M., Quince, C., Campbell, J. H., Yang, Z. K., Schadt, C. W., and Podar, M. (2013) Comparative metagenomic and rRNA microbial diversity characterization using archaeal and bacterial synthetic communities. Environ Microbiol. doi:10.1111/1462-2920.12086

Shannon, P., Markiel, A., Ozier, O., Baliga, N. S., Wang, J. T., Ramage, D., Amin, N., Schwikowski, B., and Ideker, T. (2003) Cytoscape: a software environment for integratedmodelsof biomolecular interaction networks. Genome Res 13: $2498-$ 2504. 
Shock, E., and Canovas, P. (2010) The potential for abiotic organic synthesis and biosynthesis at seafloor hydrothermal systems. Geofluids 10: 161-192.

Singh, N., Kendall, M.M., Liu, Y.T., and Boone, D.R. (2005) Isolation and characterization of methylotrophic methano- gens from anoxic marine sediments in Skan Bay, Alaska: description of Methanococcoides alaskense sp nov. \& emended description of Methanosarcina baltica. Int J Syst Evol Microbiol 55: $2531-2538$.

Sokolova, T.G., Jeanthon, C., Kostrikina, N.A., Chernyh, N.A., Lebedinsky, A.V., Stackebrandt, E. and Bonch-Osmolovskaya, E.A. (2004) The first evidence of anaerobic $\mathrm{CO}$ oxidation coupled with $\mathrm{H}_{2}$ production by a hyperthermophilic archaeon isolated from a deep-sea hydrothermal vent. Extremophiles 8: 317-323.

Sogin, M.L., Morrison, H.G., Huber, J.A., Mark Welch, D., Huse, S.M., Neal, P.R., Arrieta, J.M.(2006) Microbial diversity in the deep sea and the underexplored "rare biosphere. P NATL ACAD SCI USA 32: 12115-12120.

Steinsbu, B.O., Thorseth I.H., Nakagawa, S., Inagaki, F., Lever, M.A., Engelen, B., Øvreås, L., and Pedersen, R.B. (2010) Archaeoglobus sulfaticallidus sp. nov., a thermophilic and facultatively lithoautotrophic sulfate-reducer isolated from black rust exposed to hot ridge flank crustal fluids. Int J Syst Evol Micr 60: 27452752.

Stetter, K.O., Lauerer, G., Thomm, M., and Neuner, A. (1987) Isolation of extremely thermophilic sulfate reducers - evidence for a novel branch of archaebacteria. Science 236: $822-824$ 
Suzuki, M.T., Rappe, M.S., Haimberge,r Z.W.,Winfield, H., Adair N, Strobel, J., and Giovannoni, S.J. (1997) Bacterial diversity among small-subunit rRNA gene clones and cellular isolates from the same seawater sample. Appl Environ Microbiol 63: 983-989.

Takai, K., Sugai A., Itoh, T., and Horikoshi, K. (2000) Palaeococcus ferrophilus gen. nov., sp. nov., a barophilic, hyperthermophilic archaeon from a deep-sea hydrothermal vent chimney. Int J Syst Evol Micr 50: 489-500.

Takai, K., Komatsu, T., Inagaki, F., Animalcule, S., \& Sugar, R. (2001) Distribution of Archaea in a black smoker chimney structure. Appl Environ Microbiol 67: $3618-3629$.

Takai, K., Gamo, T., Tsunogai, U., Nakayama, N., Hirayama, H., Nealson, K.H., and Horikoshi, K. (2004) Geochemical and microbiological evidence for a hydrogenbased, hyperthermophilic subsurface lithoautotrophic microbial ecosystem (HyperSLiME) beneath an active deep-sea hydrothermal field. Extremophiles 8: 269-82.

Takai, K., Campbell, B.J., Cary, S.C., Suzuki, M., Oida, H., Nunoura, T., Hirayama, H., Nakagawa, S., Suzuki, Y., Inagaki, F., and Horikoshi, K. (2005) Enzymatic and genetic characterization of carbon and energy metabolisms by deep-sea hydrothermal chemolithoautotrophic isolates of Epsilonproteobacteria. Appl. Environ. Microbiol. 71: 7310-7320.

Takai, K., Nakagawa, S., Reysenbach, A., and Hoek, J. (2006) Microbial Ecology of Mid-Ocean Ridges and Back-Arc Basins. In Back-arc spreading systems: geological, biological, chemical, and physical interactions. Christine, D.M., 
Fisher, C.R., Lee, S.M., and Givens, S. (eds.) American geophysical Union, Washington, DC. P. 185-213.

Takai, K., Nakamura, K., Toki, T., Tsunogai, U., Miyazaki, M., Miyazaki, J., Hirayama, H., Nakagawa, S., Nunoura, T., and Horikoshi, K. (2008) Cell proliferation at $122^{\circ} \mathrm{C}$ and isotopically heavy $\mathrm{CH}_{4}$ production by a hyperthermophilic methanogen under high-pressure cultivation. Proc Natl Acad Sci USA 105: 10949-10954.

Takai, K., and Nakamura, K. (2011) Archaeal diversity and community development in deep-sea hydrothermal vents. Curr Opin Microbiol 14: 282-91.

Teske, A., Hinrichs, K.-U., Edgcomb, V., de Vera Gomez, A., Kysela, D., Sylva, S.P., Sogin, M.L., Jannasch, H.W. (2002) Microbial Diversity of Hydrothermal Sediments in the Guaymas Basin: Evidence for Anaerobic Methanotrophic Communities. Appl Environ Microbiol 68: 1994-2007.

Tivey M.K. (2007) Generation of seafloor hydrothermal vent fluids and associated mineral deposits. Oceanography 20: 50-65

Tor, J. M., Kashefi, K., and Lovley, D.R. (2001) Acetate oxidation coupled to Fe(III) reduction in hyperthermophilic microorganisms. Appl. Environ. Microbiol. 67: $1363-1365$.

Vannier, P., Marteinsson, V.T., Fridjonsson, O.H., Oger, P., Jebbar, M. (2011) Complete genomesequence of the hyperthermophilic piezophilic, heterotrophic and carboxydotrophic archaeon Thermococcus barophilus MP. J Bacteriol 193: $1481-1482$. 
Von Damm, K. L. (1990) Seafloor Hydrothermal Activity: Black Smoker Chemistry and Chimneys. Annu Rev Earth Planet Sci 18: 173-204.

Von Damm, K., Bray, A., Buttermore, L., and Oosting, S. (1998) The geochemical controls on vent fluids from the Lucky Strike vent field, Mid-Atlantic Ridge. Earth Planet Sci Lett 160: 521-536.

Von Damm, K.L., and Lilley, M.D. (2004) Diffuse flow hydrothermal fluids from 950'N East Pacific Rise: Origin, evolution and biogeochemical controls. Pp. 245-268 in Te Subseafloor Biosphere at Mid-Ocean Ridges. W.S.D. Wilcock, E.F. DeLong, D.S. Kelley, J.A. Baross, and S.C. Cary, eds, Geophysical Monograph Series, vol. 144, American Geophysical Union, Washington, DC.

Wang, Q., Garrity, G. M., Tiedje, J. M., and Cole, J. R. (2007) Naive Bayesian classifier for rapid assignment of rRNA sequences into the new bacterial taxonomy. Appl Environ Microbiol 73: 5261-5267.

Watanabe, K., Kodama, Y., and Harayama, S., (2001) Design and evaluation of PCR primers to amplify $16 \mathrm{~S}$ ribosomal DNA fragments used for community fingerprinting. J. Microbiol. Methods 44: 253-262.

Wery, N., Cambon-Bonavita, M.-A., Lesongeur, F., and Barbier, G. (2002) Diversity of anaerobic heterotrophic thermophiles isolated from deep-sea hydrothermal vents of the Mid-Atlantic Ridge. FEMS Microbiol Ecol 41: 105-114.

Whitman, W.B., Boone, D.R., and Koga, Y. (2001) Methanocaldococcaceae. The Archaea and the Deeply Branching and Phototrophic Bacteria. Boone, D.R., Castenholz, R.W., and Garrity, G. (eds). New York: Springer-Verlag, pp. 242246. 
Whitman, W.B., Jeanthon, C. (2006) The order methanobacteriales. Prokaryotes 3: 257273.

Wilson, T., Amirbahman, A., Norton, S., and Voytek, M. (2010) A record of phosphorus dynamics in oligotrophic lake sediment. J Paleolimnol 44: 279-294.

Wirsen, C.O., Tuttle, J.H., and JAnnasch, H.W. (1986) Activities of sulfur-oxidizing bacteria at the $21^{\circ} \mathrm{N}$ East Pacific Rise vent site. Mar Bio 92: 449-456.

Woese, C.R., \& Fox, G.E., (1977) Phylogenetic structure of the prokaryotic domain: the primary kingdoms. P Natl Acad Sci USA 74: 5088-5090.

Woese, C.R., Kandler, O., and Wheelis, M.L. (1990) Towards a natural system of organisms: proposal for the domains Archaea, Bacteria, and Eucarya. Proc Natl Acad Sci USA 87: 4576-4579.

Wolfe R.S. (1996) 1776-1996: alessandro volta's combustible air. ASM News 62: 529534.

Zeng, X., Birrien, J.L., Fouquet, Y., Cherkashov, G., Jebbar, M., Querellou, J., Oger, P., Cambon-Bonavita, M.A., Xiao, X., Prieur, D. (2009) Pyrococcus CH1, an obligate piezophilic hyperthermophile: extending the upper pressure-temperature limits for life. ISME J 3:873-876.

Zeng, X., Zhang, X., Jiang, L., Alain, K., Jebbar, M., Shao, Z. (2013) Palaeococcus pacificus sp. nov., an archaeon from deep-sea hydrothermal sediment. Int J Syst Evol Micr 63: 2155-2159. 
Zillig, W., Holz, I., Janekovic, D., Schafer, W. and Reiter, W.D. (1983) The archaebacterium Thermococcus celer represents, a novel genus within the thermophilic branch of the archaebacteria. Syst Appl Microbiol 4: 88-94.

Zivanovic, Y., Armengaud, J., Lagorce, A., Leplat, C.,Gue, M., Anthouard, V., Forterre, P., Wincker, P., Confaloniere, F. (2009) Genomeanalysis and genome-wide proteomics of Thermococcus gammatolerans, the most radioresistant organism known amongst the Archaea. Genome Biology 10, R70. 